\title{
Generation IV Reactors Integrated Materials Technology Program Plan: Focus on Very High Temperature Reactor Materials
}

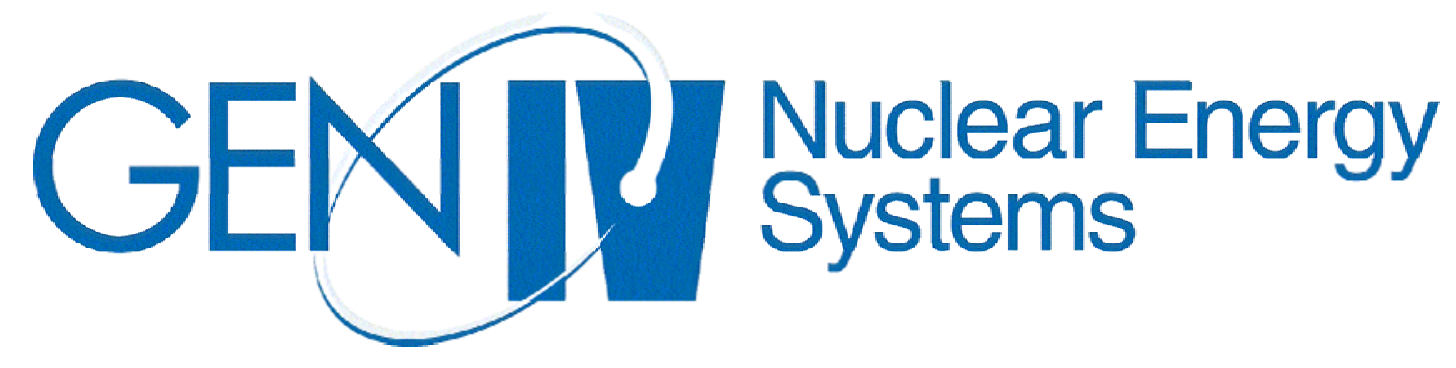

\section{August 2008}

W. R. Corwin, ORNL

T. D. Burchell, ORNL

N. M. Ghoniem, UCLA

Yutai Katoh, ORNL

T. E. McGreevy, Caterpillar

D. Morgan, University

of Wisconsin

R. K. Nanstad, ORNL

\author{
W. Ren, ORNL \\ T. L. Sham \\ L. L. Snead, ORNL \\ R. Soto, INL \\ K. Sridharan, University \\ of Wisconsin
}

G. S. Was, University of Michigan

D. F. Wilson, ORNL

W. E. Windes, INL

J. K. Wright, INL

R. N. Wright, INL

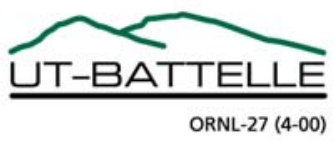




\section{DOCUMENT AVAILABILITY}

Reports produced after January 1, 1996, are generally available free via the U.S. Department of Energy (DOE) Information Bridge.

Web site http://www.osti.gov/bridge

Reports produced before January 1, 1996, may be purchased by members of the public from the following source.

National Technical Information Service
5285 Port Royal Road
Springfield, VA 22161
Telephone 703-605-6000 (1-800-553-6847)
TDD 703-487-4639
Fax 703-605-6900
E-mail info@ntis.gov
Web site http://www.ntis.gov/support/ordernowabout.htm

Reports are available to DOE employees, DOE contractors, Energy Technology Data Exchange (ETDE) representatives, and International Nuclear Information System (INIS) representatives from the following source.

Office of Scientific and Technical Information

P.O. Box 62

Oak Ridge, TN 37831

Telephone 865-576-8401

Fax 865-576-5728

E-mail reports@osti.gov

Web site http://www.osti.gov/contact.html

This report was prepared as an account of work sponsored by an agency of the United States Government. Neither the United States Government nor any agency thereof, nor any of their employees, makes any warranty, express or implied, or assumes any legal liability or responsibility for the accuracy, completeness, or usefulness of any information, apparatus, product, or process disclosed, or represents that its use would not infringe privately owned rights. Reference herein to any specific commercial product, process, or service by trade name, trademark, manufacturer, or otherwise, does not necessarily constitute or imply its endorsement, recommendation, or favoring by the United States Government or any agency thereof. The views and opinions of authors expressed herein do not necessarily state or reflect those of the United States Government or any agency thereof. 


\title{
GENERATION IV REACTORS INTEGRATED MATERIALS TECHNOLOGY PROGRAM PLAN: FOCUS ON VERY HIGH TEMPERATURE REACTOR MATERIALS
}

\author{
W. R. Corwin, ORNL \\ T. D. Burchell, ORNL \\ W. Ren, ORNL \\ G. S. Was, University of Michigan \\ N. M. Ghoniem, UCLA \\ T. L. Sham \\ D. F. Wilson, ORNL \\ Yutai Katoh, ORNL \\ L. L. Snead, ORNL \\ W. E. Windes, INL \\ T. E. McGreevy, Caterpillar \\ R. Soto, INL \\ J. K. Wright, INL \\ D. Morgan, University \\ K. Sridharan, University \\ R. N. Wright, INL \\ of Wisconsin \\ of Wisconsin \\ R. K. Nanstad, ORNL
}

August 31, 2008

\author{
Prepared for \\ Office of Nuclear Science and Technology \\ AF3410000 \\ Prepared by \\ OAK RIDGE NATIONAL LABORATORY \\ Oak Ridge, Tennessee 37831-6285 \\ managed by \\ UT-BATTELLE, LLC \\ for the \\ U.S. DEPARTMENT OF ENERGY \\ under contract DE-AC05-00OR22725
}





\section{CONTENTS}

Page

LIST OF FIGURES.

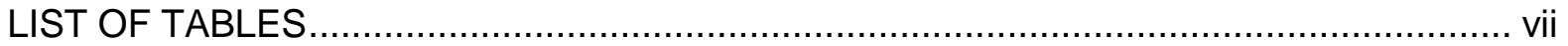

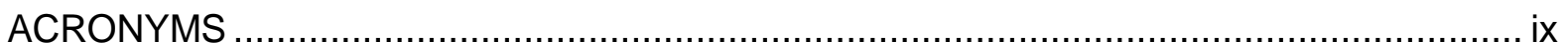

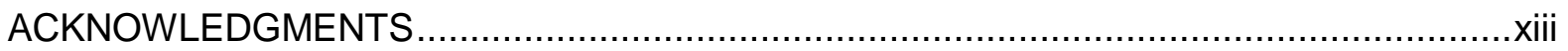

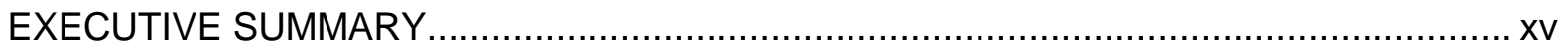

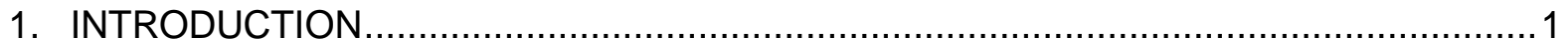

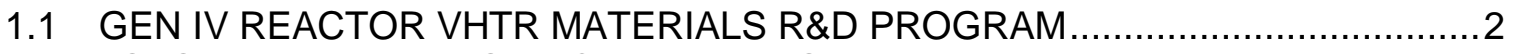

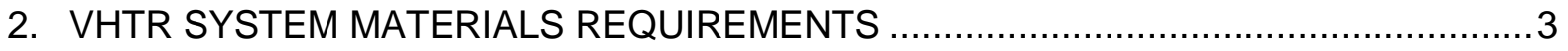

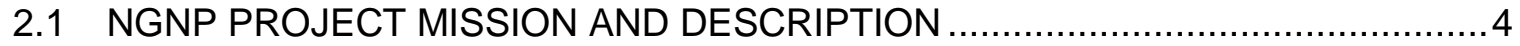

2.1.1 Background and History ................................................................... 4

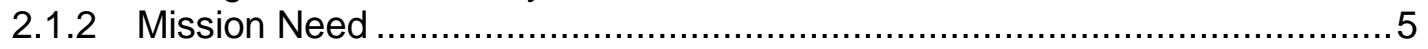

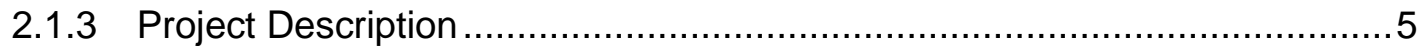

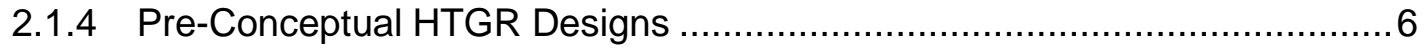

3. NGNP MATERIALS RESEARCH PROGRAMS ….......................................... 19

3.1 GENERAL CONSIDERATIONS FOR NGNP MATERIALS RESEARCH ............19

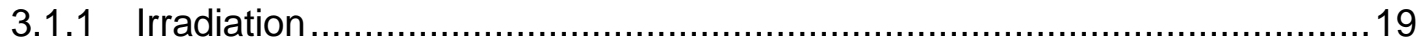

3.1.2 High-Temperature Exposure ........................................................ 20

3.1.3 Helium-Gas-Cooled Reactor Environment ......................................... 20

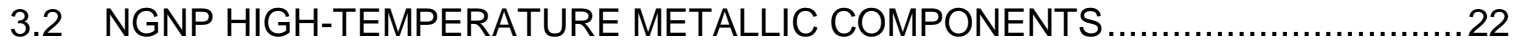

3.2.1 Overall R\&D Planning Assumptions ................................................... 22

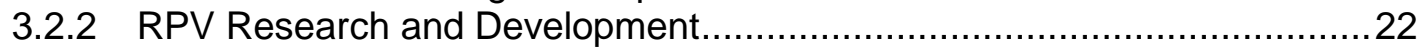

3.2.3 Intermediate Heat Exchanger (IHX) Materials Issues ...............................29

3.3 NGNP HIGH-TEMPERATURE NON-METALLIC COMPONENTS ........................35

3.3.1 Materials Selection and Issues for Reactor Core Graphite, Reflector,

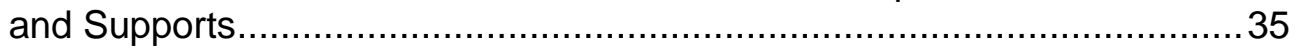

3.3.2 Ceramic Materials Selection and Issues for Thermal Insulation.................42

3.3.3 Reactor Structural Composites Materials Selection and Issues................46

4. OTHER VHTR MATERIALS RESEARCH PROGRAMS .........................................53

4.1 HIGH-TEMPERATURE DESIGN METHODOLOGY AND IMPLEMENTING

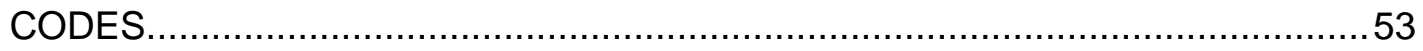

4.1.1 Challenges and Requirements for High-Temperature Structural Design........................................................................................ 53

4.1.2 ASME Code Section III, Subsection NH and Associated Cases ................54

4.1.3 Direct Support of ASME Section III Code for High-Temperature Design Methods .............................................................................. 57

4.2 NUCLEAR ENGINEERING RESEARCH INITIATIVE ................................. 68

4.2.1 Multi-scale Modeling of the Deformation of Advanced Ferritic Steels for Generation IV Nuclear Energy .................................................68

4.2.2 Cladding and Structural Materials for Advanced Nuclear Energy Systems ...................................................................................... 70

4.2.3 Alloys for $1000^{\circ} \mathrm{C}$ Service in the Next Generation Nuclear Plant ...............72

4.2.4 Ab Initio-Based Modeling of Radiation Effects in Multi-Component Alloys .................................................................................. 75

4.2.5 Emissivity of Candidate Materials for VHTR Applications: Role of Oxidation and Surface Modification Treatments ..................................... 77

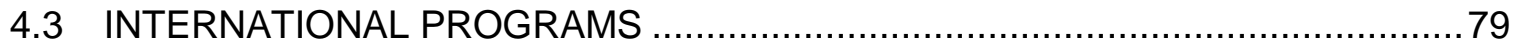

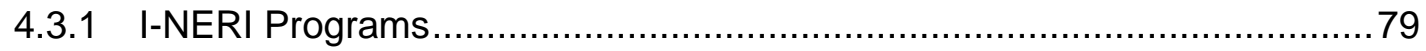


4.3.2 Generation IV International Forum ............................................. 82

4.4 OTHER DOE-NE VHTR MATERIALS RESEARCH PROGRAMS ...................... 85

4.4.1 Nanostructured Materials for High-Temperature Service .......................... 85

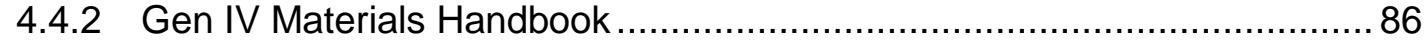

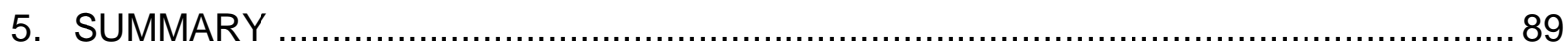

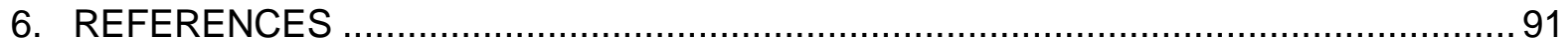




\section{LIST OF FIGURES}

Figure

Page

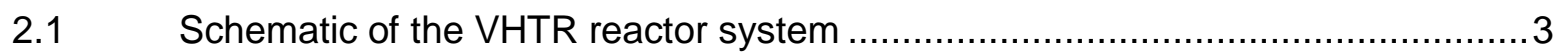

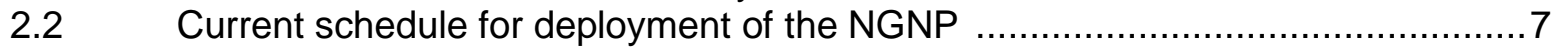

2.3 GT-MHR reactor system cutaway showing the metallic internals structures, core, control rod guide tubes, and cross vessel (labeled as hot duct) ..................

2.4 NGNP configuration as proposed by General Atomics................................. 10

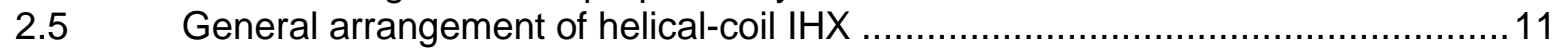

2.6 AREVA control rod design ..................................................................... 12

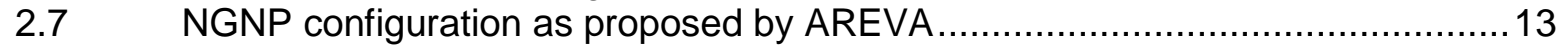

$2.8 \quad$ AREVA vessels arrangement.................................................................. 14

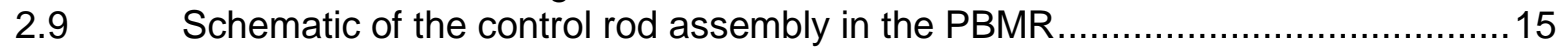

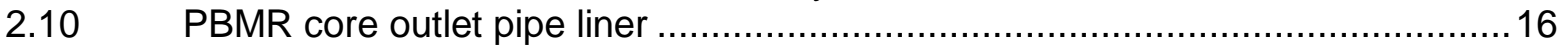

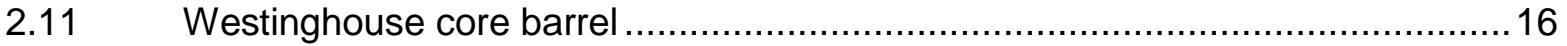

$2.12 \quad$ NGNP configuration as proposed by Westinghouse .................................... 17

$2.13 \quad$ Proposed layout of the reactor unit ........................................................ 17

3.1 Schematic of annular graphite core for HTGR ........................................ 36

3.2 Schematic illustrating the different types of test blanks machined from a billet and the anticipated tests associated with those test coupons ....................38

3.3 Schematic diagram illustrating dose and temperature ranges for AGC and high-temperature vessel (HTV) experiments .................................................. 39

3.4 An optical photomicrograph of the microstructure of grade $\mathrm{H}-451$ graphite revealing the presence of pores, coke filler particles, and cracks ......................41

3.5 Schematic of master schedule for graphite $R \& D$ effort.................................43

3.6 Dose temperature classification for various components discriminating Class 1 and Class 2 composites.

4.1 Plot of the difference between the $\mathrm{CO}$ concentrations at the outlet and inlet for (a) a $\mathrm{CO} / \mathrm{CO}_{2}$ ratio of 7.2 and (b) a $\mathrm{CO} / \mathrm{CO}_{2}$ ratio of 455 at 850,900 , 950 , and $1000^{\circ} \mathrm{C}$

4.2 Weight change for alloy 617 over the temperature range $850-1000^{\circ} \mathrm{C}$ in (a) a $\mathrm{CO} / \mathrm{CO}_{2}$ ratio of 455 and (b) a $\mathrm{CO} / \mathrm{CO}_{2}$ ratio of 7.2 .

4.3 SEM image and corresponding x-ray maps for chromium, aluminum, and oxygen for a sample of 617 exposed to a $\mathrm{CO} / \mathrm{CO}_{2}$ ratio of 455 for $750 \mathrm{~h}$ at $950^{\circ} \mathrm{C}$

4.4 Specific weight gain of J-alloys containing Re during impure-helium exposure at $1000^{\circ} \mathrm{C}$

4.5 Predicted and measured diffusion constants for nickel and dilute chromium in nickel ............................................................................................ 76

4.6 Predicted concentration dependence of tracer diffusion constants under simple interaction model

4.7 Schematic illustration of the high-temperature spectral emissivity measurement system. 



\section{LIST OF TABLES}

Table

Page

2.1 Key operating parameters for the NGNP designs and the Fort St. Vrain

HTGR

2.2 Material selections for elevated temperature components

in the PBMR-DPP

3.1 Composition of helium environments (advanced HTGR) used in past

reactor development programs ....

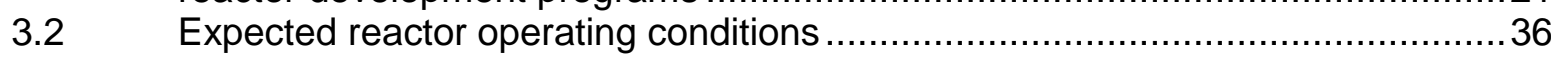

3.3 Candidate nuclear-grade graphite types for NGNP .................................... 37

3.4 Conditions affecting materials selection for reactor internals thermal insulation and potential candidate NGNP materials

3.5 Conditions affecting materials selection for structural composites and potential candidate NGNP materials

3.6 Relative strengths of ceramic composite materials for NGNP applications........49

3.7 HFIR irradiation matrix and status........................................................50

4.1 Current subsection NH materials and maximum allowable times and temperatures......

4.2 Summary of materials and both operating and transient conditions of concern for VHTRs provided by the vendor and owner survey....

4.3 Composition of potential high-temperature nickel alloys from the J-series .........74

$4.4 \quad$ Hopping barriers in nickel-rich Ni-Fe-Cr ...................................................76 



\section{ACRONYMS}

ACRS

$\mathrm{AFCl}$

AGC

AGCNR

ASME

ASTM

AVR

BNCS

BPVC

CPD

CRBR

CRBRP

CRIEPI

CVN

DOE

dpa

DPP

ECCC

EPAct

EPRI

FDL

FEM

F-M

FMI-222

FTIR

GA

GEN IV

GFR

GIF

GMAW

GNEP

GTA

GTAW

GT-MHR

HANARO

HAZ

HFIR

HHT

HTGR

HTR

HTSD

HTTR

HT-UPS

HTV

IHX

IMEF

I-NERI

INL
Advisory Committee on Reactor Safeguards

advanced fuel cycle initiative

ATR Graphite Creep

advanced gas-cooled nuclear reactor

American Society for Mechanical Engineers

American Society for Testing and Materials

Albeitsgemeinshaft Versuchsreakton

Board of Nuclear Codes and Standards

Boiler and Pressure Vessel Code

conceptual and preliminary design

Clinch River Breeder Reactor

Clinch River Breeder Reactor Project

Central Research institute of Power industry in Japan

Charpy-V notch

Department of Energy

displacement per atom

demonstration power plant

European Creek Collaborative Committee

Energy Policy Act

Electric Power Research Institute

final design/licensing

finite element model

ferritic-martensitic

Fiber Materials Inc.

Fourier Transform Infra Red

General Atomics

Generation IV Nuclear Energy Systems

gas-cooled fast reactor

Generation IV International Forum

gas metal arc welding

Global Nuclear Energy Partnership

gas tungsten arc

gas tungsten arc welding

gas turbine-modular high-temperature gas-cooled reactor

High-Flux Advanced Neutron Application Reactor

heat affected zone

High Flux Isotope Reactor

high-temperature helium turbine systems

high-temperature gas-cooled reactor

high-temperature reactor

High-Temperature Structural Design

high-temperature test reactor

high-temperature ultrafine precipitate-strengthened

high-temperature vessel

intermediate heat exchanger

Irradiated Materials Evaluation Facility

International Nuclear Energy Research Initiative

Idaho National Laboratory 


\begin{tabular}{|c|c|}
\hline ISI & in-service inspection \\
\hline JAEA & Japan Atomic Energy Agency \\
\hline KAERI & Korean Atomic Energy Research Institute \\
\hline KMC & Kinetic Monte Carlo \\
\hline KTA & $\begin{array}{l}\text { German Kerntechnischer Ausschuss for which the translated title is, } \\
\text { "Standards of the Nuclear Safety Standards Commission." }\end{array}$ \\
\hline LFR & lead-cooled fast reactor \\
\hline LMR & liquid-metal reactor \\
\hline LRFD & Load and Resistance Factor Design \\
\hline LWR & light water reactor \\
\hline MA & mechanical alloying \\
\hline MD & Molecular Dynamics \\
\hline MDMC & Material Data Management Consortium \\
\hline MI & Materials Intelligence \\
\hline MSR & molten salt reactor \\
\hline $\mathrm{NC}$ & nanoclusters \\
\hline NDE & non-destructive evaluation \\
\hline NERAC & Nuclear Energy Research Advisory Committee \\
\hline NERI & Nuclear Energy Research Initiative \\
\hline NFA & nanostructured ferritic alloy \\
\hline NGNP & Next-Generation Nuclear Plant \\
\hline NIMS & National Material Science in Japan \\
\hline $\mathrm{NPH}$ & nuclear process heat \\
\hline NRC & Nuclear Regulatory Commission \\
\hline ODIN & Online Data \& Information Network \\
\hline ODS & oxide dispersion strengthened \\
\hline PA & project arrangement \\
\hline PBMR & Pebble Bed Modular Reactor \\
\hline PBR & Pebble Bed Reactor \\
\hline PCHE & printed circuit heat exchanger \\
\hline PCS & power conversion system \\
\hline $\mathrm{PCU}$ & power conversion unit \\
\hline PHP & Process Heat Plant \\
\hline PIE & post-irradiation examination \\
\hline PMB & Project Management Board \\
\hline PMR & Prismatic Modular Reactor \\
\hline PNP & prototype nuclear process heat \\
\hline $\mathrm{PP}$ & project plan \\
\hline PWHT & post-weld heat treatment \\
\hline QA & quality assurance \\
\hline RCC-MR & $\begin{array}{l}\text { French Design Code "Design and Construction rules for mechanical } \\
\text { components of FBR nuclear islands and high temperature } \\
\text { applications" }\end{array}$ \\
\hline RCS & Reactivity Control System \\
\hline$R \& D$ & research and development \\
\hline ROK & Republic of Korea \\
\hline ROM & rough order of magnitude \\
\hline $\mathrm{RPV}$ & reactor pressure vessel \\
\hline SA & submerged arc \\
\hline SCWR & supercritical water reactor \\
\hline
\end{tabular}


SFR

SIA

SMA

SMAW

SRF

SSR

THTR

TMT

VHTR sodium-cooled fast reactor

self-interstitial atom

shielded metal arc

shielded metal arc welding

stress reduction factors

simulated stress relief

Thorium Hochtemperature Reaktor

thermo-mechanical treatment

very high temperature reactor 



\section{ACKNOWLEDGMENTS}

The authors gratefully acknowledge the support and guidance provided by Tom O'Conner, Rob Versluis, Sue Lesica, and Trevor Cook of the DOE Office of Nuclear Engineering, Science, and Technology over the past several years as the Gen IV Materials Programs were being implemented and eventually focused on the Very High Temperature Reactor.

The authors also greatly appreciate the valuable comments received from and the time spent by Glenn Romanoski at ORNL in reviewing this report.

Finally, the authors wish to thank Deborah Stevens and Brenda Smith for their help in preparing the report for final publication. 



\section{EXECUTIVE SUMMARY}

Since 2002, the Department of Energy's (DOE's) Generation IV Nuclear Energy Systems (Gen IV) Program has addressed the research and development (R\&D) necessary to support next-generation nuclear energy systems. Such R\&D has been guided by the technology roadmap developed for the Generation IV International Forum. The six most promising systems identified for next-generation nuclear energy are described within this roadmap. Two employ a thermal neutron spectrum with coolants and temperatures that enable hydrogen or electricity production with high efficiency (the Supercritical Water Reactor-SCWR and the Very High Temperature Reactor-VHTR). Three employ a fast neutron spectrum to enable more effective management of actinides through recycling of most components in the discharged fuel (the Gas-cooled Fast Reactor-GFR, the Leadcooled Fast Reactor-LFR, and the Sodium-cooled Fast Reactor-SFR). The Molten Salt Reactor (MSR) employs a circulating liquid fuel mixture that offers considerable flexibility for recycling actinides and may provide an alternative to accelerator-driven systems.

At the inception of DOE's Gen IV program, it was decided to significantly pursue five of the six concepts identified in the Gen IV roadmap to determine which of them was most appropriate to meet the needs of future U.S. nuclear power generation. In particular, evaluation of the highly efficient thermal SCWR and VHTR reactors was initiated primarily for energy production, and evaluation of the three fast reactor concepts, SFR, LFR, and GFR, was begun to assess viability for both energy production and their potential contribution to closing the fuel cycle. Since 2002, assessments have been made about the viability and suitability of these reactor concepts, and by 2008 selections were made for continued development. Within the Gen IV Program itself, only the VHTR class of reactors was selected for continued development. Hence, this document will address the multiple activities under the Gen IV program that contribute to the development of the VHTR.

A few major technologies have been recognized by DOE as necessary to enable the deployment of the next generation of advanced nuclear reactors, including the development and qualification of the structural materials needed to ensure their safe and reliable operation. The focus of this document will be the overall range of DOE's structural materials research activities being conducted to support VHTR development. By far, the largest portion of material's R\&D supporting VHTR development is that being performed directly as part of the Next-Generation Nuclear Plant (NGNP) Project. Supplementary VHTR materials $R \& D$ being performed in the DOE program, including university and international research programs and that being performed under direct contracts with the American Society for Mechanical Engineers (ASME) Boiler and Pressure Vessel Code, will also be described.

Specific areas of high-priority materials research that will be needed to deploy the NGNP and provide a basis for subsequent VHTRs are described, including the following.

Graphite:

- Extensive unirradiated materials characterization and assessment of irradiation effects on properties must be performed to qualify new grades of graphite for nuclear service, including thermo-physical and mechanical properties and their changes, statistical variations from billot-to-billot and lot-to-lot, creep, and especially, irradiation creep.

- Predictive models, as well as codification of the requirements and design methods for graphite core supports, must be developed to provide a basis for licensing.

Ceramics:

- Both fibrous and load-bearing ceramics must be qualified for environmental and radiation service as insulating materials.

Ceramic Composites: 
- Carbon-carbon and SiC-SiC composites must be qualified for specialized usage in selected high-temperature components, such as core stabilizers, control rods, and insulating covers and ducting. This will require development of componentspecific designs and fabrication processes, materials characterization, assessment of environmental and irradiation effects, and establishment of codes and standards for materials testing and design requirements.

Pressure Vessel Steels:

- Qualification of short-term, high-temperature properties of light water reactor steels for anticipated VHTR off-normal conditions must be determined, as well as the effects of aging on tensile, creep, and toughness properties, and on thermal emissivity.

- Large-scale fabrication process for higher temperature alloys, such as $9 \mathrm{Cr}$ $1 \mathrm{MoV}$, including ensuring thick-section and weldment integrity must be developed, as well as improved definitions of creep-fatigue and negligible creep behavior.

High-Temperature Alloys:

- Qualification and codification of materials for the intermediate heat exchanger, such as Alloys 617 or 230 , for long-term very high-temperature creep, creepfatigue, and environmental aging degradation must be done, especially in thin sections for compact designs, for both base metal and weldments.

- Constitutive models and an improved methodology for high-temperature design must be developed. 


\section{INTRODUCTION}

Since 2002, the Department of Energy's (DOE's) Generation IV Nuclear Energy Systems (Gen IV) Program has addressed the research and development (R\&D) necessary to support next-generation nuclear energy systems. Such R\&D has been guided by the technology roadmap developed for the Generation IV International Forum (GIF) over a 2 year period with the participation of over 100 experts from the GIF countries. The roadmap evaluated over 100 future systems proposed by researchers around the world. The effort ended in December 2002 with the roadmap selecting the six most promising Generation IV systems for worldwide development. These are detailed within the Generation IV Technology Roadmap. ${ }^{1}$

The six most promising systems identified for next-generation nuclear energy are described within the roadmap. Two employ a thermal neutron spectrum with coolants and temperatures that enable hydrogen or electricity production with high efficiency (the Supercritical Water Reactor-SCWR and the Very High Temperature Reactor-VHTR). Three employ a fast neutron spectrum to enable more effective management of actinides through recycling of most components in the discharged fuel (the Gas-cooled Fast Reactor-GFR, the Lead-cooled Fast Reactor-LFR, and the Sodium-cooled Fast Reactor-SFR). The Molten Salt Reactor (MSR) employs a circulating liquid fuel mixture that offers considerable flexibility for recycling actinides and may provide an alternative to accelerator-driven systems.

At the inception of DOE's Gen IV program, it was decided to significantly pursue five of the six concepts identified in the Gen IV roadmap to determine which of them was most appropriate to meet the needs of future U.S. nuclear power generation. In particular, evaluation of the highly efficient thermal SCWR and VHTR reactors was initiated primarily for energy production, and evaluation of the three fast reactor concepts, SFR, LFR, and GFR, was begun to assess viability for both energy production and their potential contribution to closing the fuel cycle. Since 2002, assessments have been made about the viability and suitability of these reactor concepts, and by 2008 selections were made for continued development. Within the Gen IV program itself, only the VHTR class of reactors was selected for continued development. The SFR class of reactors was also selected for continued development, but given their potential for helping to close the fuel cycle, SFRs are to be addressed under the Global Nuclear Energy Partnership (GNEP) and Advanced Fuel Cycle Initiative (AFCl) programs. Hence, this document will address the multiple activities under the Gen IV program that contribute to the development of the VHTR.

A few major technologies have been recognized by DOE as necessary to enable the deployment of the next generation of advanced nuclear reactors, including the development and qualification of the structural materials needed to ensure their safe and reliable operation. Therefore the focus of this document will be the overall range of DOE's structural materials activities being conducted to support VHTR development. By far, the largest portion of material's R\&D supporting VHTR development is that being performed directly as part of the Next Generation Nuclear Plant (NGNP) Project. Supplementary VHTR materials $R \& D$ being performed, including university and international research programs and that being performed under direct contracts with the American Society for Mechanical Engineers (ASME) Boiler and Pressure Vessel Code, will also be described. The wide range of structural materials R\&D identified for the broader range of Gen IV reactors systems has been described in several previous reports. ${ }^{1-12}$ 


\subsection{GEN IV REACTOR VHTR MATERIALS R\&D PROGRAM}

A multifaceted R\&D program is being conducted to study, quantify, and, in some cases, develop materials with required properties for the VHTR reactor systems being developed under DOE's Gen IV program. The goal is to ensure that the materials research and development needed to support near- and long-term deployment of VHTR systems comprises a comprehensive and integrated effort to identify and provide the materials data and its interpretation needed for design and construction.

For the range of service conditions expected in VHTR systems, including possible accident scenarios, sufficient data must be developed to demonstrate that the candidate materials meet the following design objectives:

- acceptable dimensional stability including void swelling, thermal creep, irradiation creep, stress relaxation, and irradiation-induced growth;

- acceptable strength, ductility, and toughness;

- acceptable resistance to creep rupture, fatigue cracking, creep-fatigue interactions, and helium embrittlement; and

- acceptable chemical compatibility and corrosion resistance (including stress corrosion cracking and irradiation-assisted stress corrosion cracking) in the presence of coolants and process fluids.

Additionally, it is desirable to develop validated models of microstructure-property relationships to enable predictions of long-term materials behavior to be made with confidence and to develop the high-temperature materials design methodology needed for materials use, codification, and regulatory acceptance.

To make efficient use of program resources, the development of the required databases and methods for their application will incorporate both the extensive results from historic and ongoing programs in the United States and abroad that address related materials needs. These would include, but not be limited to, DOE, Nuclear Regulatory Commission (NRC), and industry programs on liquid-metal-, gas-, and light-water-cooled reactor, fossil-energy, and fusion materials research programs, as well as similar foreign efforts.

The bulk of the overall materials activities for VHTR systems are currently focused on the relatively near-term deployment of a demonstration system identified as the Next Generation Nuclear Plant (NGNP), described in detail in sections that follow. This reactor will limit operating requirements to permit utilization of materials technology that is largely available at the current time, though it will require some extension of the conditions (e.g., lifetime, usage temperature, accumulated neutron dose, environmental exposure, etc.) under which the materials have historically been qualified for nuclear service.

In addition to the materials R\&D that is a part of the NGNP program, there are several other areas of research being performed as part of DOE's overall program to support materials technology needed for both near- and longer-term VHTR systems with higher output temperatures. These include work being performed (1) directly under subcontracts with the ASME Code, (2) within the DOE University Nuclear Energy Research Initiative (NERI) program, (3) on a bilateral basis with specific foreign countries as part of DOE's International Nuclear Energy Research Initiative (I-NERI) program, and (4) under the multilateral GIF Project Arrangement for VHTR Materials, as well as other focused activities supporting advanced VHTR systems. The various activities and the materials R\&D being performed within these areas will be described in the sections that follow. 


\section{VHTR SYSTEM MATERIALS REQUIREMENTS}

Traditionally, the nuclear energy industry in the United States has used light water reactor (LWR) technology for the generation of electricity. This technology is limited to a reactor temperature output of approximately $300^{\circ} \mathrm{C}$. Alternatively, Very High Temperature Gas-Cooled Reactor (VHTR) technology can provide not only electricity but also the hightemperature heat needed for industrial processes and hydrogen production. Such technology can significantly reduce the use of premium fuels for the production of process heat and associated greenhouse gas releases, thus providing a significant competitive advantage for the U.S. industrial markets. Moreover, this technology is inherently safe and proliferation resistant.

The Gen IV roadmap ${ }^{1}$ describes the VHTR reactor systems as

using a thermal neutron spectrum and a once-through uranium cycle. The VHTR system is primarily aimed at relatively faster deployment of a system for high-temperature process heat applications, such as coal gasification and thermochemical hydrogen production, with superior efficiency.

The reference reactor concept has a 600-MWth helium-cooled core based on either the prismatic block fuel of the Gas Turbine-Modular Helium Reactor (GT-MHR) or the pebble fuel of the Pebble Bed Modular Reactor (PBMR). The primary circuit is connected to a steam reformer/steam generator to deliver process heat. The VHTR system has coolant outlet temperatures above $1000^{\circ} \mathrm{C}$.

This system is schematically indicated in Fig. 2.1.

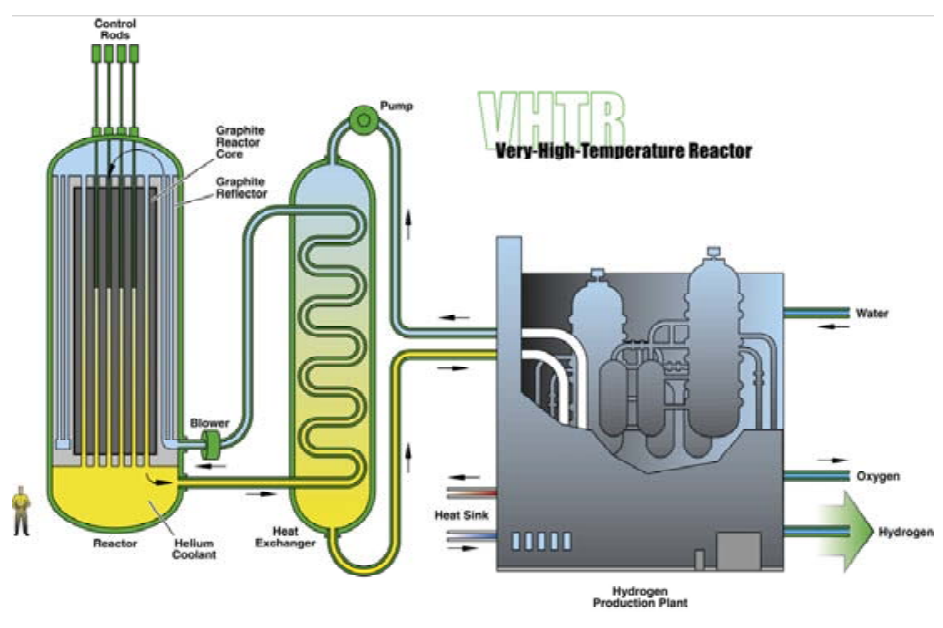

Fig. 2.1. Schematic of the VHTR reactor system.

The U.S. DOE has selected the NGNP project as a demonstration project for the VHTR design that can be deployed by near the end of the next decade. The NGNP reference concept is a helium-cooled, graphite-moderated, thermal neutron spectrum reactor with an outlet temperature in the range of 800 to $950^{\circ} \mathrm{C}$ and a 60-year operating lifetime. The reactor core is envisioned to be either a prismatic graphite block or pebble bed-type core. The plant size, reactor thermal power, and core configuration will be designed to ensure passive decay heat removal without fuel damage or radioactive material releases during 
accidents. The initial fuel cycle will be a once-through use of very high burn-up, low-enriched uranium. The most significant difference in the NGNP compared to a generic VHTR is that the NGNP will limit its outlet temperature to facilitate nearer term deployment than would be possible with an outlet temperature of $1000^{\circ} \mathrm{C}$ or higher.

The basic technology for the NGNP has been established in former high-temperature gas-cooled reactor plants [e.g., DRAGON, Peach Bottom, Albeitsgemeinschaft Versuchsreaktor (AVR), Thorium Hochtemperatur Reaktor (THTR), and Fort St. Vrain]. These reactor designs represent two design categories: the Pebble Bed Reactor (PBR) and the Prismatic Modular Reactor (PMR). Commercial examples of potential NGNP candidates are the Gas Turbine-Modular Helium Reactor (GT-MHR) from General Atomics (GA), the High Temperature Reactor concept (ANTARES) from AREVA, and the Pebble Bed Modular Reactor (PBMR) from PBMR consortium. Furthermore, the Japanese High-Temperature Engineering Test Reactor (HTTR) and Chinese High-Temperature Reactor (HTR) are demonstrating the feasibility of the reactor components and materials needed for NGNP. (The HTTR reached a maximum coolant outlet temperature of $950^{\circ} \mathrm{C}$ in April 2004.) Therefore, the NGNP is focused on building a demonstration plant rather than simply confirming the basic feasibility of the concept.

The operating conditions for the NGNP represent a major departure from existing watercooled reactor technologies. Although a significant assortment of materials and alloys for high-temperature applications are in use in the petrochemical, metals processing, and aerospace industries, only a very limited number of these materials have been tested or qualified for use in nuclear reactor-related systems. Today's high-temperature alloys and associated American Society of Mechanical Engineers (ASME) Codes for reactor applications reach about $800^{\circ} \mathrm{C}$. Some primary system components for the NGNP will require use of materials at temperatures above $800^{\circ} \mathrm{C}$. Such use will require further assessment of existing, well-characterized materials or selection of newer materials for which less data exists. Potential postulated accident conditions with associated temperatures above nominal operational temperatures would dictate the use of composite or ceramic materials within the reactor pressure vessel (RPV). The use of structural ceramics or composites in safety-related reactor components represents a completely new challenge to the nuclear industry.

\subsection{NGNP PROJECT MISSION AND DESCRIPTION}

The NGNP will be a licensed commercial HTGR plant capable of producing energyrelated revenue. The NGNP project will design, construct, and operate an HTGR plant and associated technologies establishing the technological basis for expanded commercial applications and infrastructure for the commercialization of this new generation of advanced nuclear plants.

\subsubsection{Background and History}

In July of 2005, Congress passed the Energy Policy Act of 2005 (EPAct; H.R. 6), which was signed into law by the President in August of 2005. Under Section 641, the Act states that "the Secretary shall establish a project to be known as the "Next Generation Nuclear Plant [NGNP] Project'." It continues, "The Project shall consist of the research, development, design, construction, and operation of a prototype plant, including a nuclear reactor that:

a. Is based on research and development (R\&D) activities supported by the Generation IV Nuclear Energy systems Initiative....

b. Shall be used 
- To generate electricity

- To produce hydrogen

- Or both to generate electricity and to produce hydrogen."

The EPAct 2005 established the expectations for NGNP program execution, including industry participation and cost sharing, international collaboration, NRC licensing, and review by the Nuclear Energy Research Advisory Committee (NERAC).

The DOE has selected the Idaho National Laboratory (INL) as the lead national laboratory for nuclear energy research. Per the terms of the EPAct, Title VI, Subtitle C, Section 662, INL, will lead the development of the NGNP by integrating, conducting, and coordinating all necessary R\&D activities and by organizing project participants.

\subsubsection{Mission Need}

As presented in the National Energy Policy, there is a national strategic need to promote further reliance on safe, clean, economical nuclear energy. In the 2003 State of the Union Address, President George W. Bush launched a new National Hydrogen Fuel Initiative to provide domestically produced clean-burning hydrogen to the transportation sector as an alternative to imported oil. The combination of these two objectives, to promote nuclear energy and to produce clean-burning hydrogen, can be met simultaneously with the development of new advanced reactor and hydrogen generation technology. The DOE mission need is to develop this combined technology that will enable the continued use of secure, domestic nuclear energy and establish a greenhouse-gas-free technology for the production of hydrogen, thereby supporting both the President's agenda for a hydrogen economy and the DOE's strategic goal to promote a diverse supply of energy.

The mission need statement developed for NGNP was approved by the DOE Deputy Secretary on October 18, 2004, officially completing Critical Decision-0.

\subsubsection{Project Description}

The strategic goal of the NGNP project is to broaden the environmental and economic benefits of nuclear energy to the U.S. economy by demonstrating its applicability to market sectors currently satisfying their energy needs from fossil fuels.

The NGNP project will provide the basis for commercialization of a new generation of advanced nuclear plants that utilize high-temperature gas-cooled reactor (HTGR) technology. The project will result in a full-scale prototype that demonstrates the safety and economics of the design, the commercial potential of the HTGR technology, associated industrial applications, and the licensing framework. This nuclear-based technology can provide high-temperature process heat (up to $950^{\circ} \mathrm{C}$ ) that can be used as a substitute for the burning of fossil fuels for a wide range of commercial applications. The substitution of the HTGR for burning fossil fuels conserves these resources for other uses, reduces our dependence on off-shore energy supply, and eliminates the emissions of greenhouse gases attendant to the burning of these fuels.

High-level NGNP project objectives support both the NGNP mission and the DOE vision, as follows:

- Developing and implementing the technologies important to achieving the functional performance and design requirements determined through close collaboration with commercial industry end users

- Demonstrating the basis for commercialization of the nuclear system, the heat transfer and transport system, the hydrogen production process, and the power conversion 
system. An essential part of the prototype operations will be demonstrating that the requisite reliability and capacity factor can be achieved over an extended period of operation

- Establishing the basis for licensing future commercial units of NGNP by the NRC. This will be achieved in major part through licensing the prototype and initiating the process for certification of the nuclear system design

- Fostering rebuilding of the U.S. nuclear industrial infrastructure and contributing to making the U.S. industry self-sufficient for our nuclear energy production needs

The scope of the NGNP project is as follows:

- To secure sufficient support from government and commercial entities, ensuring the viability of the NGNP project

- To execute and complete all project deliverables, including conceptual design, preliminary and final design, construction, and startup and acceptance testing for the NGNP facility

- To complete and integrate specifically assigned technology development and system confirmatory and verification tasks

- To obtain NRC licensing as required for a commercial demonstration reactor prototype

- To provide project management and integration that will coordinate and combine the efforts of the many and varied project partners, subcontractors, and stakeholders

The scope of the operational program will be further defined as the project progresses and will be covered in future NGNP operational program plans.

The current schedule for overall deployment of the NGNP, including major activities, in provided in Fig. 2.2.

\subsubsection{Pre-Conceptual HTGR Designs}

In FY 2007, preconceptual design work was initiated by the NGNP project at INL. This section summarizes the current HTGR preconceptual designs that are described in detail in the NGNP Pre-Conceptual Design Report. ${ }^{13-16}$ This work was completed by three contractor teams with extensive experience in HTGR technology, nuclear power applications, and hydrogen production. Each contractor developed a recommended design for NGNP and a commercial version of the HTGR. Research and development, data needs, and future studies required to achieve operation of the NGNP were identified as part of the work. In addition, a number of special studies were requested from all three or two of the three teams. The special studies include a reactor-type trade study, ${ }^{17}$ pre-conceptual heat transfer and transport studies, ${ }^{18}$ a primary and secondary cycle trade study, ${ }^{19}$ and a power conversion system trade study. ${ }^{20}$ The three designs developed are as follows:

- $\quad$ The GT-MHR concept: team led by General Atomics team with Washington Group International; Rolls-Royce (United Kingdom); Toshiba Corporation and Fuji Electric Systems (Japan); Korean Atomic Energy Research Institute and Doosan Heavy Industries and Construction (Korea); and OKB Mechanical Design (Russia).

- The ANTARES concept: team led by AREVA NP, Inc., with Burns \& Roe, Washington Group International; BWXT; Dominion Engineering; Air Products; Hamilton-SundstrandRocketdyne; Mitsubishi Heavy Industries (MHI); NovaTech; and Entergy. 


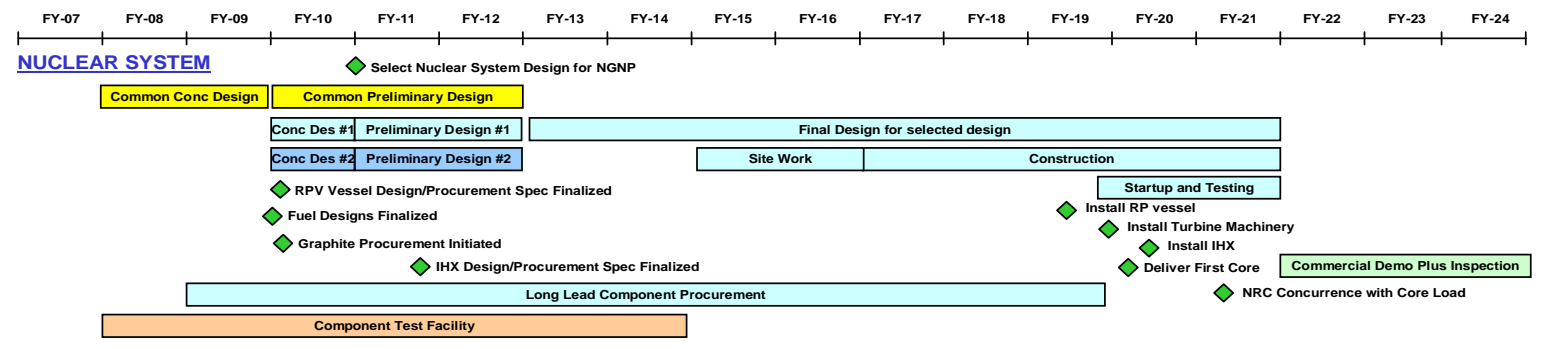

LICENSING AND REGULATORY

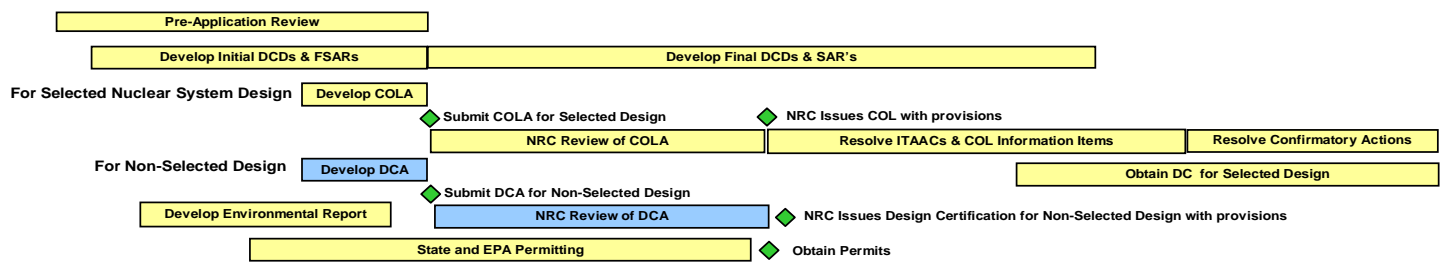

RESEARCH AND DEVELOPMENT MILESTONES

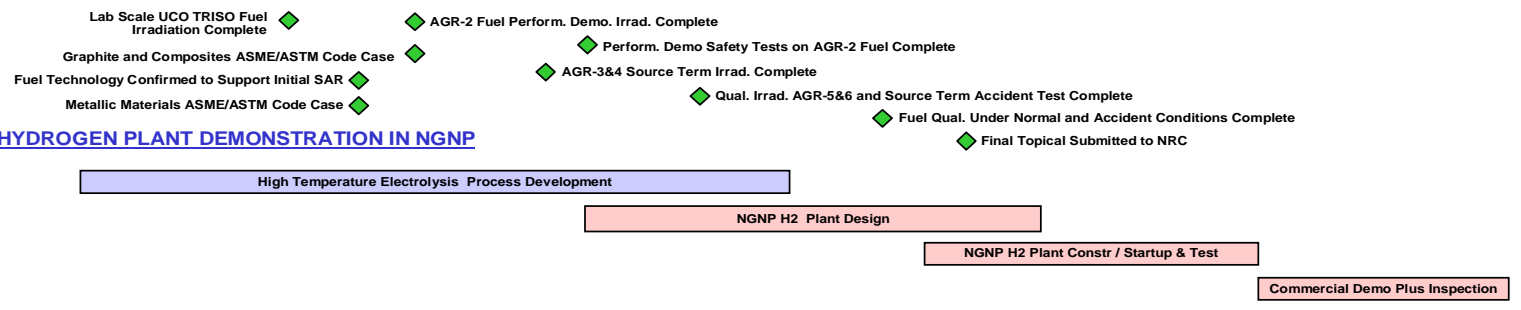

Fig. 2.2. Current schedule for deployment of the NGNP.

- The PBMR concept: team led by Westinghouse Electric Company, LLC, with Pebble Bed Modular Reactor (Pty) Ltd. and M-Tech Industrial (Pty) Ltd. (South Africa); The Shaw Group; Technology Insights; Air Products and Chemicals, Inc.; Nuclear Fuel Services; and Kadak Associates.

All three designs use TRISO fuel, graphite moderation, and high-temperature helium coolant in the primary system in the $800-950^{\circ} \mathrm{C}$ temperature range. All of the concepts feature various passive neutronic design features that result in a core with relatively low power density and a negative temperature coefficient of neutron reactivity. The shut-down cooling system, the secondary reactivity shut-down system, and the control rod design are all similar among the three designs. All of the reactor concepts could be used as a basis for the NGNP HTGR concept. The designs are not presented in detail in this document. Rather, this report primarily discusses the features that relate to intermediate heat exchanges (IHX) material selection and challenges. The key operating parameters and design features for all three designs are listed in Table 2.1, along with information for the Fort St. Vrain HTGR, the largest and most recent gas-cooled reactor to operate in the United States.

\subsubsection{General Atomics-GT-MHR concept}

General Atomics recommended a direct-power-conversion-cycle prismatic reactor design that is essentially the same as the GT-MHR with an additional primary coolant loop to transfer heat to the IHX.13,16 The core consists of graphite blocks with an annular-fueled region of 1020 prismatic fuel blocks arranged in three columns. The designers argue that a prismatic reactor inherently allows higher reactor-power density levels, resulting in better 
Table 2.1. Key operating parameters for the NGNP designs and the Fort St. Vrain HTGR

\begin{tabular}{|c|c|c|c|c|}
\hline Condition or feature & $\begin{array}{c}\text { Fort St. Vrain } \\
\text { HTGR }\end{array}$ & $\begin{array}{l}\text { General } \\
\text { Atomics } \\
\text { GT-MHR }\end{array}$ & $\begin{array}{l}\text { AREVA } \\
\text { ANTERES }\end{array}$ & $\begin{array}{l}\text { Westinghouse } \\
\text { PBMR PHP }\end{array}$ \\
\hline Power output (MWt) & 842 & $550-600$ & 565 & 500 \\
\hline $\begin{array}{l}\text { Average power density } \\
\left(\mathrm{w} / \mathrm{cm}^{3}\right)\end{array}$ & 6.3 & 6.5 & & 6.0 \\
\hline Moderator & Graphite & Graphite & Graphite & Graphite \\
\hline Core geometry & Cylindrical & Annular & Annular & Annular \\
\hline Reactor type & Prismatic & Prismatic & Prismatic & Pebble bed \\
\hline $\begin{array}{l}\text { Safety design } \\
\text { philosophy }\end{array}$ & Active & Passive & Passive & Passive \\
\hline $\begin{array}{l}\text { Plant design life } \\
\text { (Years) }\end{array}$ & 30 & 60 & 60 & 60 \\
\hline Fuel-coated particle & $\begin{array}{l}\text { HEU-Th/ }{ }^{235} \mathrm{U} \\
\text { (93\% enriched) }\end{array}$ & $\begin{array}{l}\text { TRISO UCO } \\
\text { (startup } \cup_{2} \text { ) }\end{array}$ & $\begin{array}{l}\text { TRISO UCO } \\
\text { (backup UO } \cup_{2} \text { ) }\end{array}$ & TRISO $\cup_{2}$ \\
\hline $\begin{array}{l}\text { Fuel max temp- } \\
\text { normal operation }\left({ }^{\circ} \mathrm{C}\right)\end{array}$ & 1260 & 1250 & 1300 & 1057 \\
\hline $\begin{array}{l}\text { Fuel max temp- } \\
\text { emergency conditions } \\
\left({ }^{\circ} \mathrm{C}\right)\end{array}$ & $\begin{array}{l}\text { NA-Active } \\
\text { Safety System } \\
\text { cools fuel. }\end{array}$ & 1600 & 1600 & 1600 \\
\hline $\begin{array}{l}\text { Power conversion } \\
\text { configuration }\end{array}$ & Direct & Direct & Indirect & Indirect \\
\hline PCS Cycle Type & Reheat steam & Brayton & Steam rankine & Rankine \\
\hline $\begin{array}{l}\text { IHX Design Power } \\
\text { Process }\end{array}$ & NA & $\mathrm{PCHE}$ & $\begin{array}{l}\text { Shell \& tube } \\
\text { PCHE or fin- } \\
\text { Plate }\end{array}$ & PCHE \\
\hline $\begin{array}{l}\text { Core outlet } \\
\text { temperature }\left({ }^{\circ} \mathrm{C}\right)\end{array}$ & 785 & Up to 950 & 900 & 950 \\
\hline $\begin{array}{l}\text { Core inlet temperature } \\
\left({ }^{\circ} \mathrm{C}\right)\end{array}$ & 406 & 590 & 500 & 350 \\
\hline $\begin{array}{l}\text { Coolant pressure } \\
(\mathrm{MPa})\end{array}$ & 4.8 & 7 & 5 & 9 \\
\hline Coolant flow rate $(\mathrm{kg} / \mathrm{s})$ & 428 & 320 & 272 & 161 \\
\hline $\begin{array}{l}\text { Secondary outlet } \\
\text { temperature }\left({ }^{\circ} \mathrm{C}\right)\end{array}$ & 538 & 925 & $850 / 875 \mathrm{PCS} / \mathrm{H}_{2}$ & 900 \\
\hline $\begin{array}{l}\text { Secondary inlet } \\
\text { temperature }\left({ }^{\circ} \mathrm{C}\right)\end{array}$ & NA & 565 & $450 / 475 \mathrm{PCS} / \mathrm{H}_{2}$ & NA \\
\hline Secondary fluid & Steam & $\mathrm{He}$ & $\mathrm{He}$ & $\mathrm{He}-\mathrm{N}$ \\
\hline $\begin{array}{l}\text { IHX pressure drop } \\
(\mathrm{kPa})\end{array}$ & NA & 50 & 55 & 45 \\
\hline $\mathrm{IHX}$ material & NA & $\ln -617$ & $\ln -617$ & In-617 or $800 \mathrm{H}$ \\
\hline Core barrel material & Steel & Not specified & $800 \mathrm{H}$ & $316 \mathrm{H} \mathrm{SS}$ \\
\hline Control rod cladding & $800 \mathrm{H}$ & $\begin{array}{l}800 \mathrm{H} \text { (backup } \\
\mathrm{C}_{\mathrm{f}} / \mathrm{C} \text { composite) }\end{array}$ & $\mathrm{C}_{f} / \mathrm{C}$ composite & $800 \mathrm{H}$ \\
\hline
\end{tabular}


plant economics, involves fewer uncertainties (and therefore less risk), and allows more flexibility with respect to the use of alternate fuel cycles, such as those fabricated from surplus weapons-grade plutonium or transuranics separated from spent LWR fuel.

The temperature rise of the coolant in the various flow paths through the core varies over a wide range. Good mixing of the outlet coolant is needed to avoid excessive thermal stresses in the downstream components resulting from large temperature gradients and fluctuations, and to ensure that the gas entering the turbine has a uniform mixed mean temperature. Figure 2.3 is an illustration of the GT-MHR reactor system cutaway that shows the metallic internals structures, core, control rod guide tubes, and cross vessel.

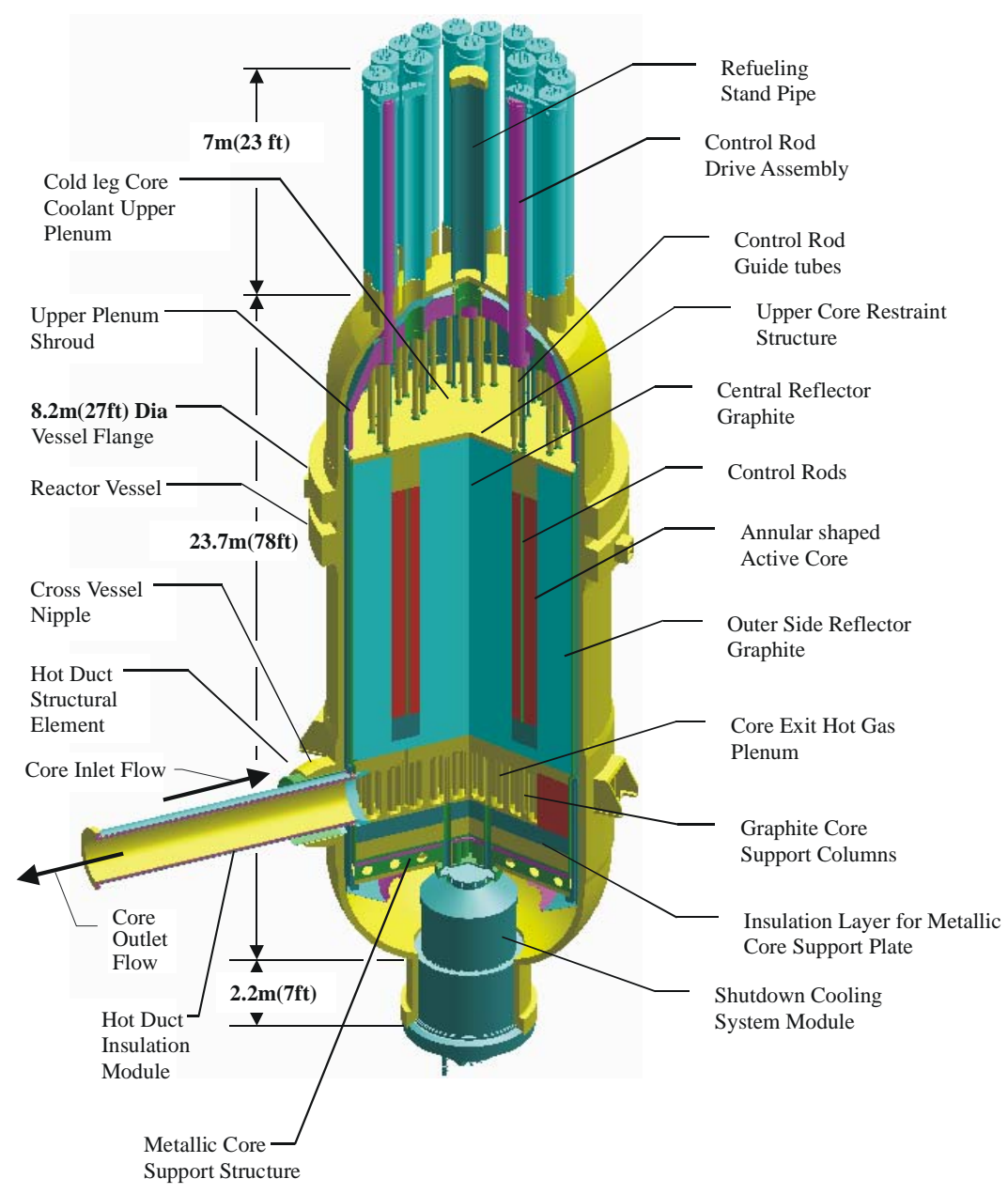

Fig. 2.3. GT-MHR reactor system cutaway showing the metallic internals structures, core, control rod guide tubes, and cross vessel (labeled as hot duct).

Reactivity control rods. The control rods use $\mathrm{B}_{4} \mathrm{C}$ absorbers enclosed in Incoloy $800 \mathrm{H}$ canisters for structural support. Carbon/carbon composite $\left(\mathrm{C}_{f} / \mathrm{C}\right)$ control rod sleeves may be used as an alternative. The control rod is lowered and raised with a flexible high-nickel-alloy (not specified) cable.

Cross vessel. General Atomics specifies that the cross vessel and IHX vessel both be made out of the same material as the RPV. The cross vessels connect the lower portion of the RPV to the lower portion of the power conversion system and IHX vessels. The cross vessels include a concentric duct (primary hot gas duct) that separates the hot (core exit) 
and the cold (core inlet) gas flow streams. The hot duct material will be a high-temperature alloy (such as $800 \mathrm{H}$ or 617 ). The hot gas duct is insulated with a ceramic-fiber insulation such as Kaowool. A similar insulation may also be included on the inside diameter of the cross vessel. The insulation is intended to reduce heat losses to the core inlet cold gas stream, and the insulation assemblies are designed to be remotely removed and replaced (if needed) during the 60-year plant life.

Power conversion and intermediate heat exchanger. General Atomics recommends the use of a direct Brayton Cycle vertical power conversion system (PCS) for electricity generation and an indirect heat transport loop to transport thermal energy to the hydrogen production plant arranged in parallel (see Fig. 2.4). The primary loop and the hydrogen heat transport loop would both use helium at $7 \mathrm{MPa}$ as a heat transport medium. The hydrogen heat transport loop would be sized to transmit up to $65 \mathrm{MWt}$. The assumed operating temperatures of the primary loop and hydrogen heat transport loop are $950^{\circ} \mathrm{C}$ and $925^{\circ} \mathrm{C}$, respectively.

The plan calls for a compact printed circuit heat exchanger (PCHE) metallic heat exchanger module to serve as the IHX for the hydrogen heat transport loop. General Atomics believes that compact heat exchangers will offer the best performance and will be most economical. The flow rates and pressures on the primary and secondary sides are essentially the same (Fig. 2.5). Two alternate PCHE IHX designs were developed as well as an alternate shell and tube counter-flow design with a helically coiled tube. Although the shell and tube design results in a much larger IHX, it allows for in-service inspection and has a successful service record at $950^{\circ} \mathrm{C}$ in Japan's HTTR.

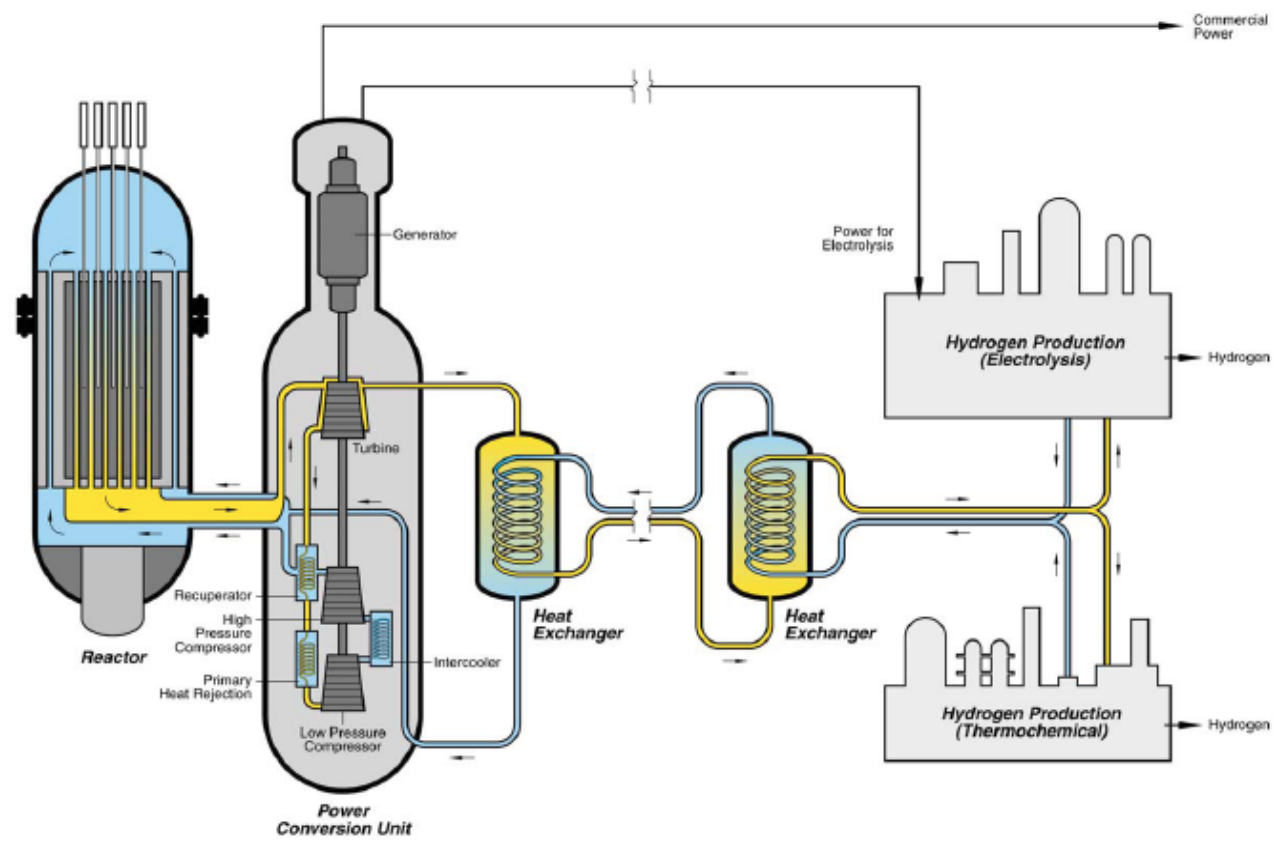

Fig. 2.4. NGNP configuration as proposed by General Atomics.

*These temperatures are from the heat transport study and are not consistent with the gas outlet temperature of $900^{\circ} \mathrm{C}$ assumed in the preconceptual design report. 


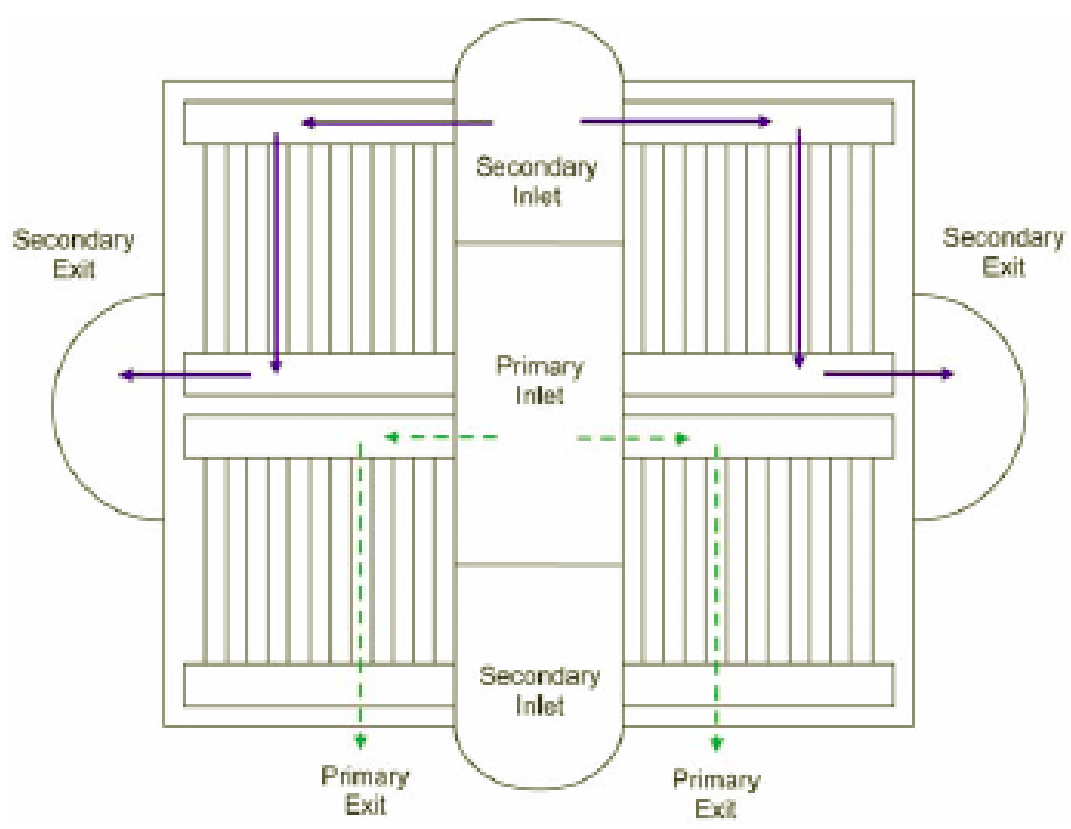

Fig. 2.5. General arrangement of helical-coil IHX.

The hydrogen heat transport loops are parallel hot and cold transport pipes that use internal and external pipe insulation in order to lower the temperature of the metallic pipe so that metals less expensive than Alloy 617 can be used for the long-distance (i.e., 90-m) loop. The use of molten salt as a heat transport medium for the hydrogen heat transport loop was examined, and it was determined that molten salt is not yet ready to be deployed. There are issues of corrosion and materials compatibility and concerns about the cost of the pipe materials, since it is believed that internal insulation could not be used to protect the heat transport pipes against the temperature.

\subsubsection{AREVA-ANTARES concept}

AREVA recommended that the NGNP be a $565 \mathrm{MWt}$ prismatic reactor, citing advantages over a pebble-bed reactor design including greater economic potential, higher power level and passive safety, more useable power, greater design flexibility, greater ease in obtaining a license (because the concept was previously licensed for Fort St. Vrain), and a higher degree of predictability in core performance, forced outages, and scheduled outages. AREVA suggested a gas outlet temperature of $900^{\circ} \mathrm{C}$ as the best compromise between energy efficiency and the ability to produce hydrogen, and the durability of equipment. AREVA proposes using a $\mathrm{He} / \mathrm{N}_{2}$ mixture in the power conversion unit (PCU), and $900^{\circ} \mathrm{C}$ is the maximum temperature they advise for nitrogen-bearing gas because of nitriding concerns. ${ }^{14,20}$

The ANTARES design ${ }^{14,21}$ is also based in part on the GT-MHR concept, with 1020 fuel blocks arranged in three columns to form the annular core between inner and outer graphite reflectors. The primary loop pressure is limited to $5.5 \mathrm{MPa}$, which is substantially less than the 7 to $9 \mathrm{MPa}$ specified by the other contractors. AREVA believes the small operational losses resulting from the lower pressure would be offset by reduced capital costs associated with using thinner vessel walls for pressure containment. ${ }^{18}$

Reactivity control rods. The control rods in this design (Fig. 2.6) employ $\mathrm{B}_{4} \mathrm{C}$ and will be enclosed in $\mathrm{C}_{\mathrm{f}} / \mathrm{C}$ canisters (cladding). 

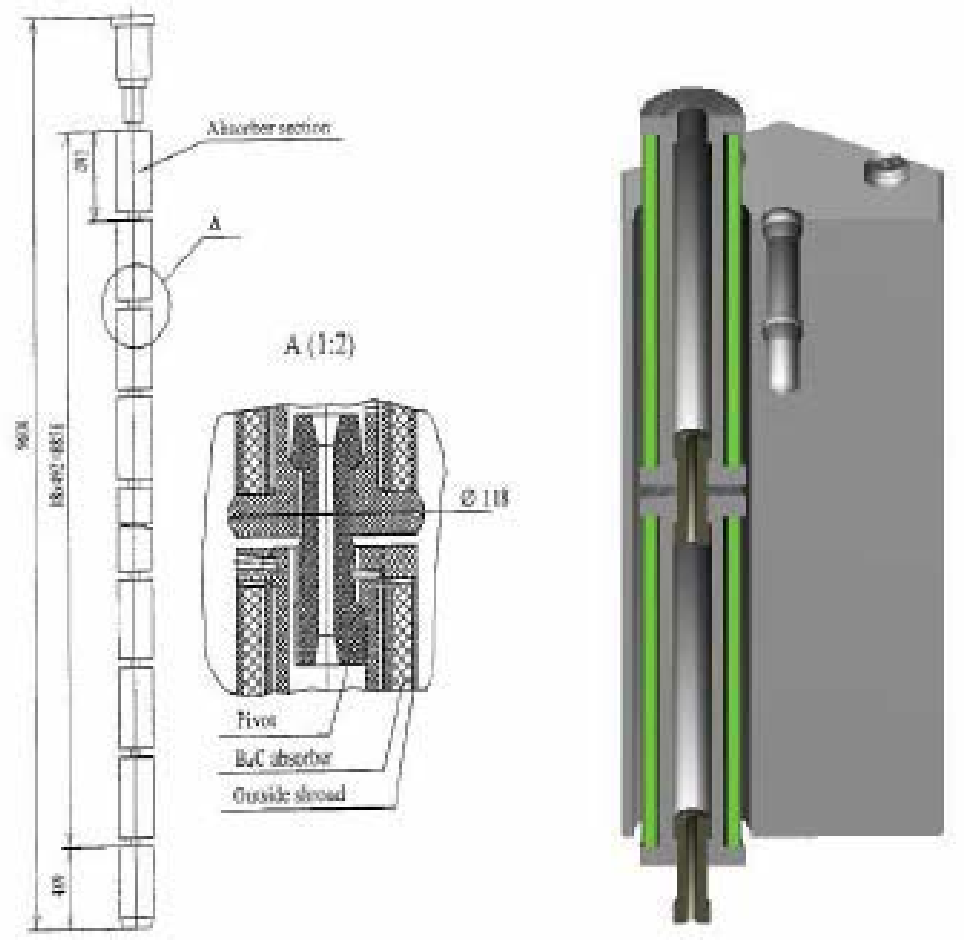

Fig. 2.6. AREVA control rod design.

Cross vessel. Like GA, AREVA has defined cross vessels (rather than pipes), with a concentrically arranged primary hot gas duct that separates the hot (core exit) and the cold (core inlet) gas flow streams. The hot gas duct is insulated to reduce regenerative heat losses to the outer flow stream (core inlet cold gas).

Core barrel. The core barrel suggested is a double-wall structure made from Incoloy $800 \mathrm{H}$.

Power conversion and intermediate heat exchanger. AREVA provided two plant configurations - a plant configuration with a Brayton Cycle to generate electrical power and a plant configuration with steam to generate electricity by using a Rankine Cycle. The Brayton Cycle configuration is based upon the original ANTARES design. AREVA has recently concluded that the Rankine Cycle is more mature and may be more adaptable to NGNP requirements, and therefore preferable (Fig. 2.7).

The combined Brayton Cycle configuration employs an indirect power conversion unit and an indirect hydrogen heat transport loop. The secondary loop used to provide energy to the Brayton Cycle turbines uses a $20 \% \mathrm{He} / 80 \% \mathrm{~N}$ gas mixture at $4.9 \mathrm{MPa}$. Heat recovery steam generators would be deployed following the Brayton Cycle turbines to supply a bottoming Rankine Cycle. The hydrogen heat transport loop would be designed to carry up to $60 \mathrm{MWt}$ to the hydrogen plant.

The indirect power conversion loop and indirect hydrogen heat transport loop are linked to the primary cooling loop in parallel. This design shows a potential for very high efficiency, $47 \%$ or more, while minimizing technological risk. In addition, the indirect combined cycle is quite flexible to accommodate the simultaneous generation of electricity and industrial heat at any level between $800^{\circ} \mathrm{C}$ and ambient. In addition, the indirect coupling has lower potential for contamination than direct coupling. 


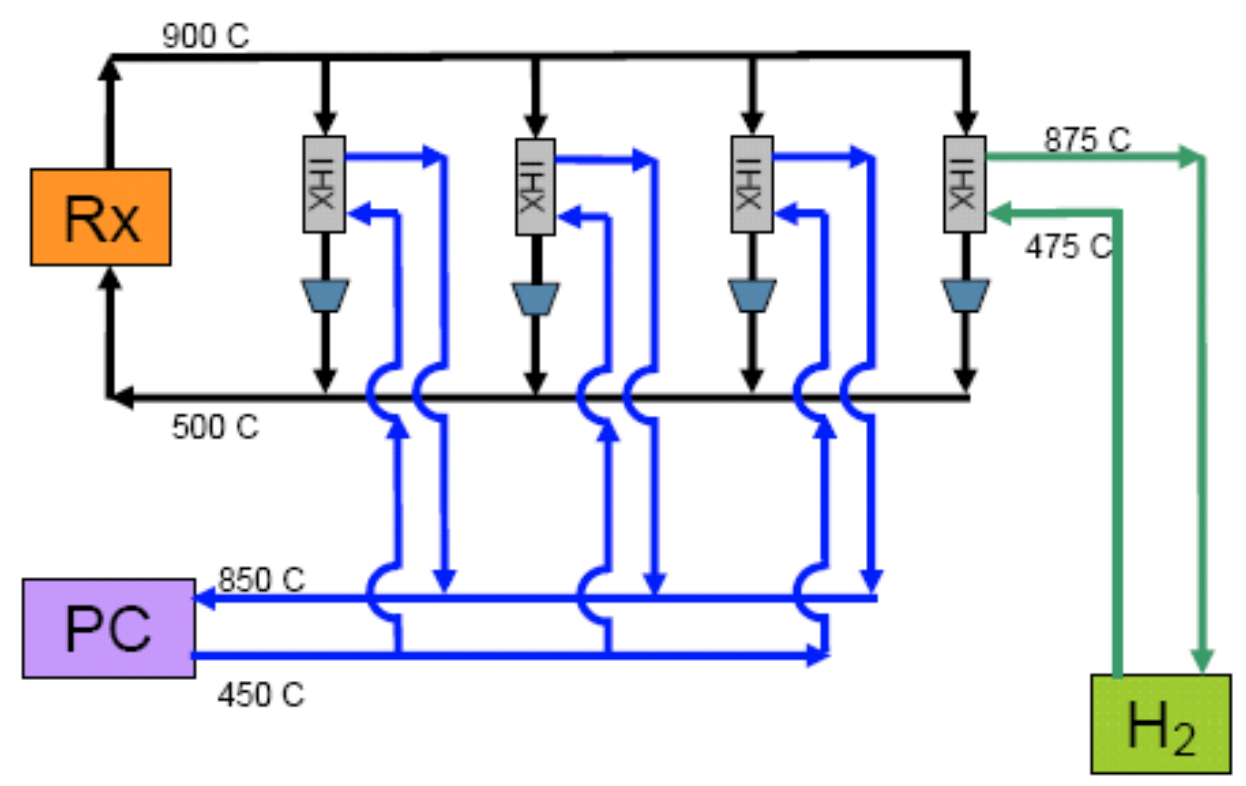

Fig. 2.7. NGNP configuration as proposed by AREVA.

AREVA recommends three primary-to-secondary heat transfer loops using metallic shell-and-tube heat exchangers to supply gas to the power conversion loop (Fig. 2.8). The designers argue that, although large, shell-and-tube heat exchangers are more mature in design, reliability, and operational experience. The parallel arrangement enables use of a smaller $(60 \mathrm{MWt})$ compact metallic heat exchanger with a reduced gas flow rate. They believe compact heat exchangers may offer economic breakthroughs and have a reasonable probability of being developed, tested, and ASME certified in the required time frame but should be replaceable. ${ }^{18}$

The Rankine Cycle configuration differs from the Brayton Cycle configuration in that shell-and-tube steam generators are directly coupled to the primary cooling loop in order to drive the steam turbines. The steam generators are arranged in parallel with the hydrogen heat transport loop. The steam system would operate at a temperature of approximately $550^{\circ} \mathrm{C}$. No recommendation of steam system pressure was provided. The direct-cycle concept has little flexibility to adapt to cogeneration because when operating parameters change, efficiency drops and operation may become difficult. AREVA concluded that the Steam-Rankine Cycle (possibly supercritical) is the best fit for near-term applications because it provides high-efficiency electricity production and can readily service near-term process heat markets.

\subsubsection{PBMR concept}

A reactor is being developed in South Africa by PBMR (Pty) Ltd. through a worldwide development effort. ${ }^{22-25}$ The program includes testing of mechanical systems and components, a comprehensive fuel development effort, and a testing and verification program to support the licensing process. A full-sized (400 MWt) demonstration reactor, the PBMR Demonstration Power Plant (DPP), will be built at the Koeberg nuclear reactor site (owned by Eskom, the South African national utility) near Capetown, South Africa. 


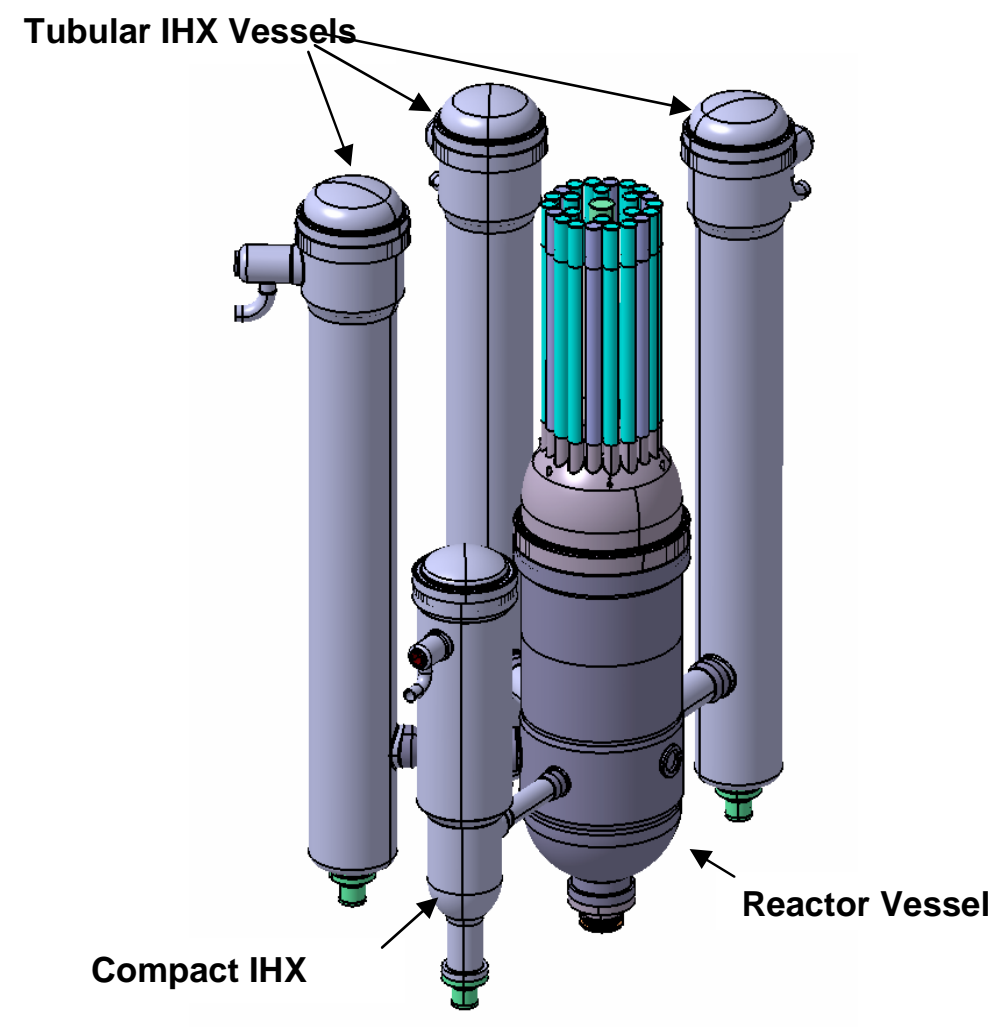

Fig. 2.8. AREVA vessels arrangement.

The PBMR utilizes 450,000 graphite-based spherical fuel elements, called pebbles, which are approximately $6 \mathrm{~cm}$ in diameter. In this design, based on the German HTR, the pebbles are located in an annular cavity in the reactor vessel. Pebbles proceed vertically downward until they are removed at the bottom. On removal they are checked, and if they are intact and not past the burn-up limit, they are circulated to the input queue again. Otherwise, they are replaced with fresh pebbles. This on-line refueling feature makes refueling shutdowns unnecessary, and it also allows the reactor to operate with almost no excess reactivity, which confers advantages in safety, economy, and resistance to nuclear weapons proliferation.

The building design for a single PBMR module consists of a reinforced concrete confinement structure, called the citadel, which houses the PCU. The PCU is located inside a more conventional concrete building that houses all of the auxiliary equipment. The citadel functions as a confinement structure to protect the nuclear components of the PCU from external missiles and to retain the vast majority of fission products that might be released in the event of a reactor accident. The limited total core power allows the reactor to be designed for passive heat conduction from the core, thermal radiation and convection from the vessel, and conduction to the confinement structure, keeping temperatures low enough to prevent core or fuel damage.

For the NGNP, Westinghouse recommended a PBR over a prismatic reactor design based on the fuel and fueling system demonstrated in Germany (AVR and THTR), minimal development costs and risks because of progress in South Africa, higher capacity leading to higher performance capability, lower fuel temperatures, and a strong vendor/supplier infrastructure. ${ }^{15}$ This $500 \mathrm{MWt}$ pebble-bed design, termed the PBMR Process Heat Plant (PHP), emphasizes use of readily available materials that conform to standards and codes 
(American Society for Testing and Materials [ASTM]/ASME) and have been found to be acceptable by the NRC in prior applications. The material choices for the high-temperature components of the PBMR-DPP are shown in Table 2.2 with the temperature and radiation exposures expected. These materials will not need any additional development or data base generation for use at the NGNP system design conditions.

Table 2.2. Material selections for elevated temperature components in the PBMR-DPP

\begin{tabular}{lcccc}
\hline Components & $\begin{array}{c}\text { Normal } \\
\text { operating } \\
\text { temperature } \\
\left({ }^{\circ} \mathbf{C}\right)\end{array}$ & $\begin{array}{c}\text { Design basis } \\
\text { event } \\
\text { maximum } \\
\text { temperature } \\
\left({ }^{\circ} \mathbf{C}\right)\end{array}$ & $\begin{array}{c}\text { Maximum fast } \\
\text { fluence }[\mathrm{E}>\mathbf{1 ~ M e V}] \\
\left(\mathbf{n} / \mathbf{c m}^{2}\right)\end{array}$ & $\begin{array}{c}\text { Candidate } \\
\text { materials }\end{array}$ \\
\hline Core Barrel & 400 & 556 & $3 \times 10^{18}$ & $316 \mathrm{SS}$ \\
Control Rods & 700 & 850 & $5 \times 10^{21}$ & $800 \mathrm{H}$ \\
Core Outlet Pipe Liner & 900 & - & Not significant & $800 \mathrm{H}$ \\
IHX & 900 & - & Not significant & 617 \\
\hline
\end{tabular}

Reactivity control rods. The PBMR preconceptual design study has the most detailed discussion of the control rod design. The control rods see the harshest conditions of all of the PBMR metallic materials with respect to high temperature and neutron irradiation. The control rods are part of the Reactivity Control System (RCS). The design aims to limit the stresses in the RCS cylinders to a minimum, and the RCS is designed to be replaceable. The life of the RCS is limited by the creep strength of the material and the embrittlement due to temperature and thermal neutron exposure.

There are 24 control rods that are located in the side graphite reflector blocks. Half of the rods are used for control, and the other half are used for shutdown. The shutdown rods are longer, running the length of the reflector blocks, while the control rods only run in the upper half of the reflector blocks. The control rod assembly is illustrated in Fig. 2.9. The rods consist of a $\mathrm{B}_{4} \mathrm{C}$ ring between two coaxial cladding tubes. Although the clad material was not specified in the preconceptual design report, previous documents list Incoloy $800 \mathrm{H}$ as the most suitable material for the control rods for the following reasons:

- Adequate high-temperature strength at the normal operating temperature of $700^{\circ} \mathrm{C}$

Fig. 2.9. Schematic of the control rod assembly in the PBMR. ${ }^{26}$

- Creep resistance sufficiently qualified for long-term operation at $700^{\circ} \mathrm{C}$

- Limited operation at $850^{\circ} \mathrm{C}$ under abnormal events is allowed as per available data

- Irradiation response has been characterized to high levels of fast fluence

- Extensive qualification of Incoloy $800 \mathrm{H}$ control rods in previous German HTR programs

Core outlet pipe liner. The arrangement of the RPV core outlet pipe liner is shown in Fig. 2.10. The liner forms an integral part of the insulation held between the liner and the outer pressure-boundary material. The insulation in the core outlet piping is a necessary 


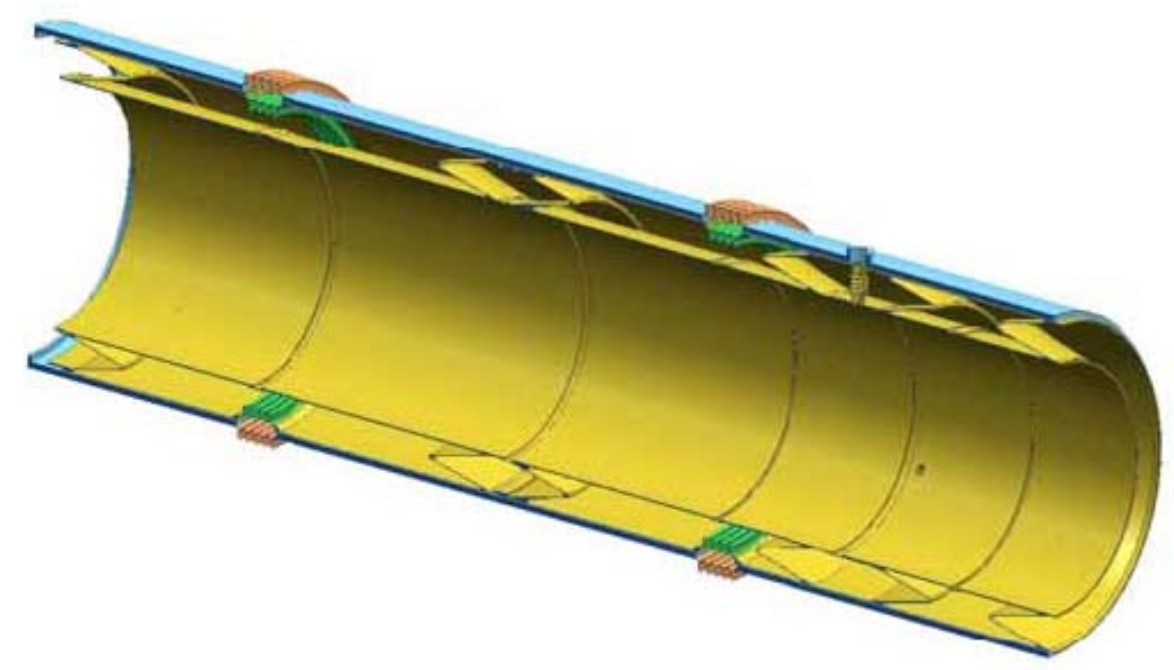

Fig. 2.10. PBMR core outlet pipe liner.

component of the insulation system required for keeping the outer pressure-boundary (ferritic steel) temperatures within operational limits.

The inner liner material of the core outlet pipe is specified as Incoloy $800 \mathrm{H}$. The liner has virtually no load-bearing function, and the use of Incoloy $800 \mathrm{H}$ is dictated by its oxidation resistance to the impure helium and adequate high-temperature strength. As a liner material, Incoloy $800 \mathrm{H}$ has the following advantages:

- Adequate high-temperature strength and creep resistance

- Extensive fabrication experience in large-diameter pipe sections

- Extensively tested as liner material for qualification of the insulated "hot pipe" design in the German HTR program up to $950^{\circ} \mathrm{C}$

Core barrel. The core barrel (Fig. 2.11) will be made from $316 \mathrm{H}$ stainless steel but will not require a core barrel conditioning system because of the low reactor inlet temperature.

Power conversion and intermediate heat exchanger. Westinghouse recommends the use of an indirect power conversion cycle and an indirect hydrogen heat transport loop arranged in a serial fashion (Fig. 2.12). The serial arrangement is simpler mechanically and less expensive and is used in Japan's HTTR. ${ }^{18}$ The IHX for the hydrogen heat transport loop would be placed first in the series in order to obtain the highest temperature gas from the nuclear reactor. After the IHX extracts $50 \mathrm{MW}$, the cooled primary loop gas would then go to the PCU. The pressure of the primary loop is $9 \mathrm{MPa}$, and the secondary loop between 8.1 and 8.5 $\mathrm{MPa}$. The power conversion cycle uses steam generators and a traditional Rankine Cycle to generate electricity and would be designed to receive the full power of the reactor (Fig. 2.13).
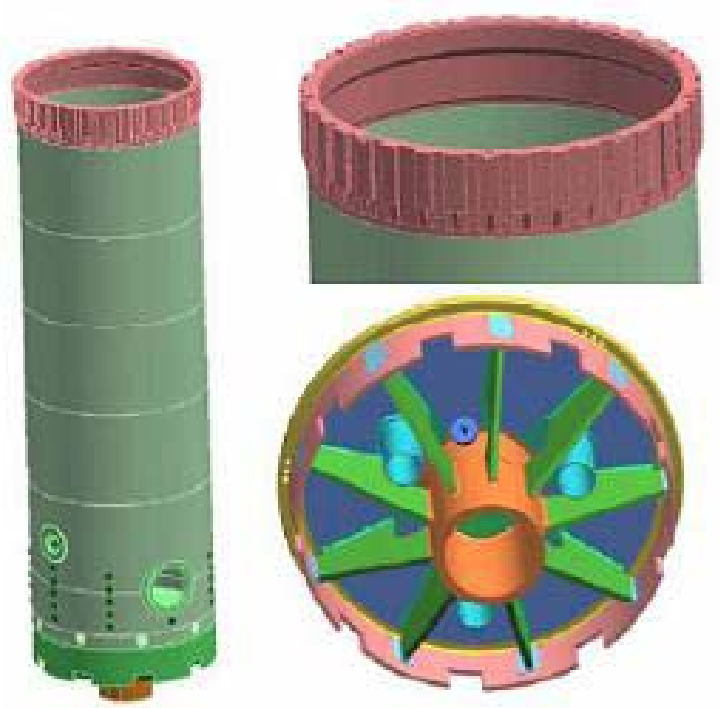

Fig. 2.11. Westinghouse core barrel. 


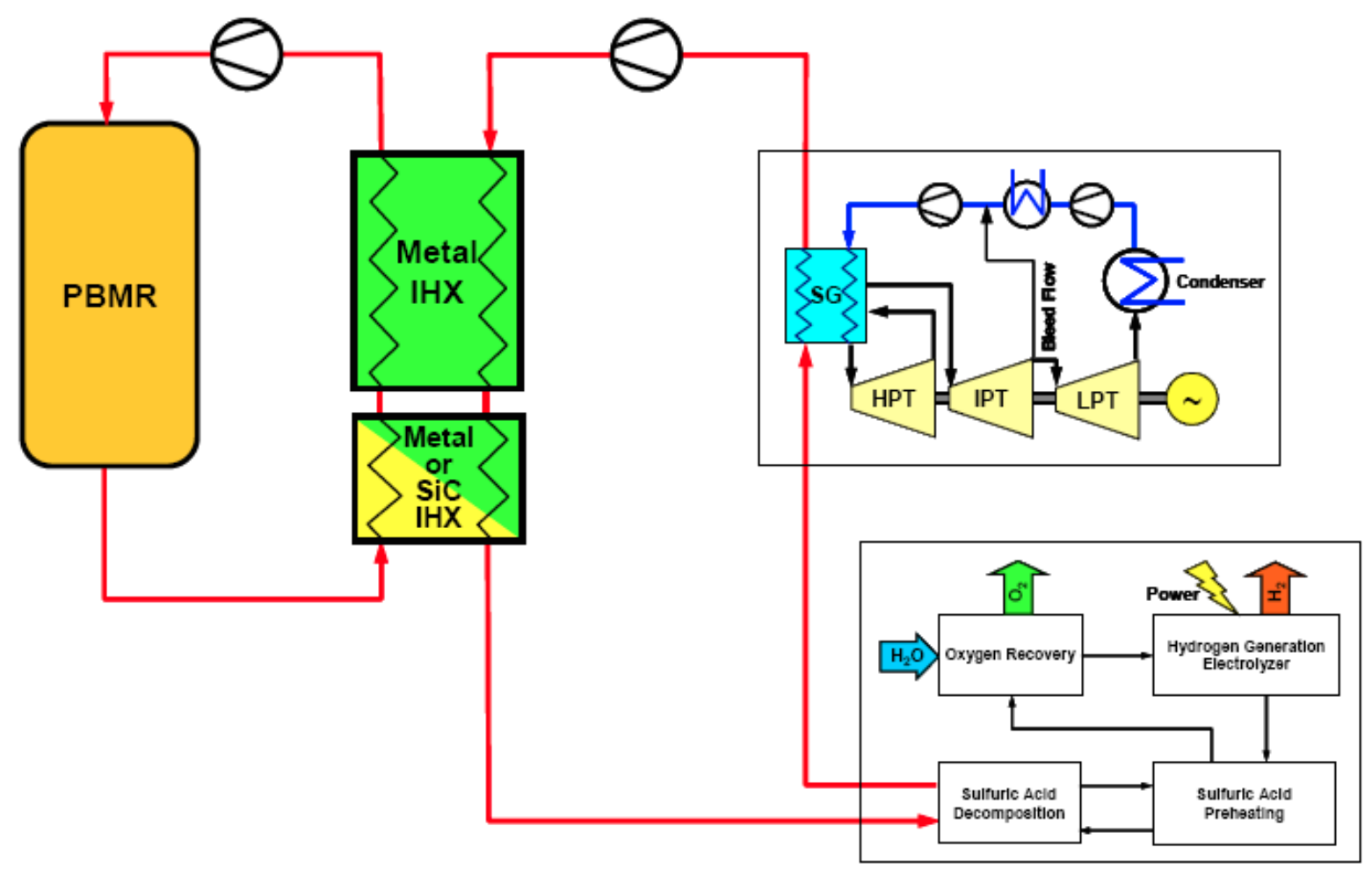

Fig. 2.12. NGNP configuration as proposed by Westinghouse.

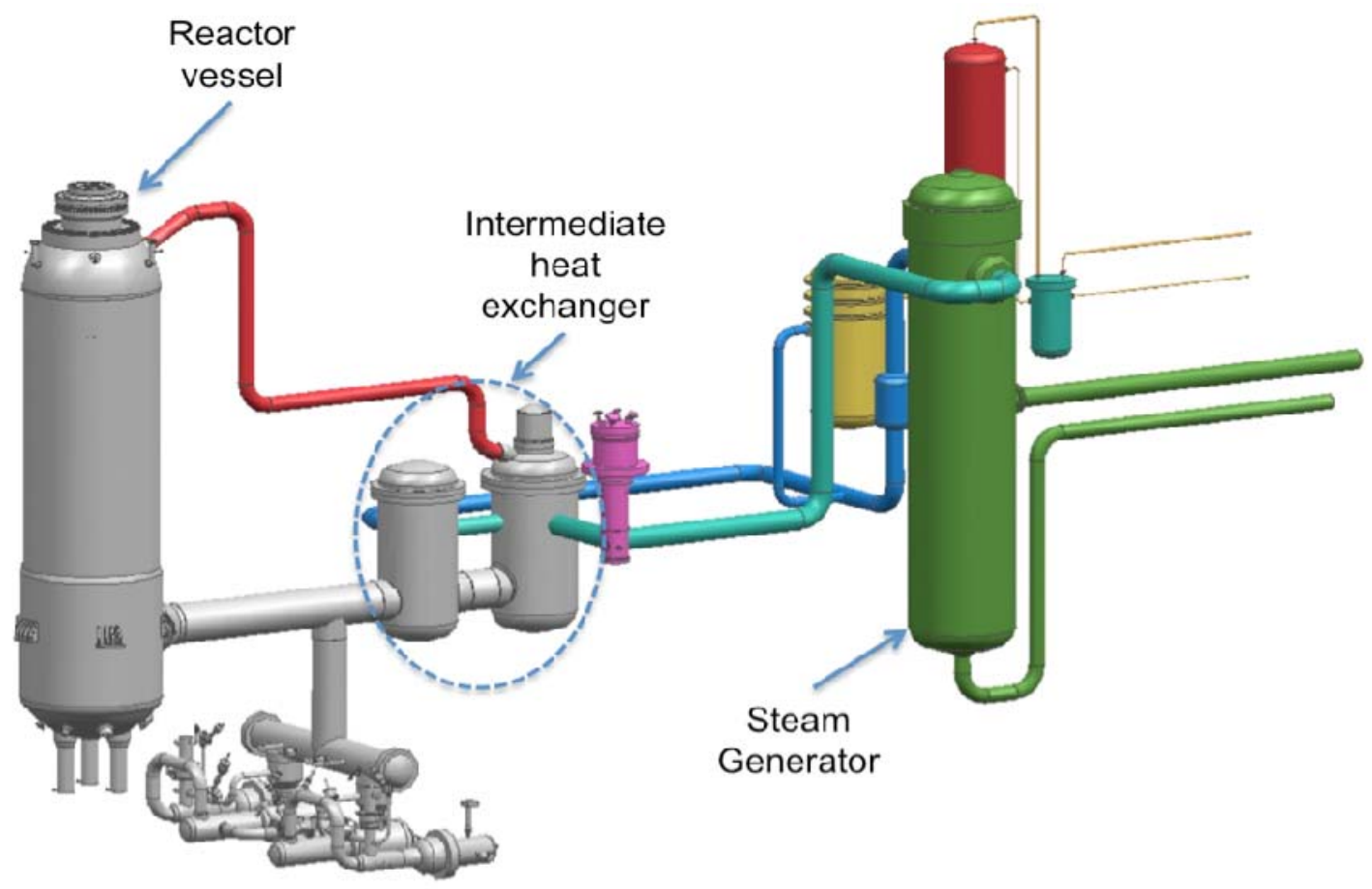

Fig. 2.13. Proposed layout of the reactor unit. 
A two-part compact heat exchanger is suggested. Section 1 (IHX A), expected to be replaceable and made of metal or ceramic, would operate at temperatures between 760 and $900^{\circ} \mathrm{C}$. If the NGNP schedule prevents the use of ceramic materials, metallic materials may have to be used during initial deployment until ceramic components can be tested and certified. ${ }^{18}$ Section 2 (IHX B), made of an ASME codified metal, would be expected to operate at temperatures below $760^{\circ} \mathrm{C}$ and would be designed for a 60 -year lifetime. Alloys 617 and $800 \mathrm{H}$ are currently recommended for the IHX A and IHX B, respectively. Both IHX sections are envisioned as compact heat exchanger modules, as it is believed that tubular heat exchangers would be too large and costly to be economical.

Control rods. A prior report ${ }^{27}$ studied the potential materials that may be selected for the control rod sleeves and the issues associated with the selection of each material including how these issues relate to the reactor designs. The report examined past reactor designs and control rod performance, as well as the two reactor design concepts under consideration for NGNP in detail as they pertain to control rod design and performance. In addition to evaluating the material requirements, the report reviewed the irradiation behavior, testing, codification, cost, availability, and manufacturing issues of three materials $\mathrm{SiC}_{f} / \mathrm{SiC}$ and $\mathrm{C}_{f} / \mathrm{C}$ composites and Alloy $800 \mathrm{H}$.

Core barrel. The core barrel is positioned between the pressure vessel and the graphite outer side reflector. It is not a pressure vessel and does not see significant stress although it supports the graphite core and helps maintain core geometry. The core barrel will be exposed to moderate radiation and temperatures but must last the lifetime of the plant. Alloy $800 \mathrm{H}$ and 316 stainless steel have been suggested as materials. There may be procurement and fabrication issues because of its large size. It is expected that construction will require some on-site welding. 


\section{NGNP MATERIALS RESEARCH PROGRAMS}

Three primary factors will most affect the properties and choice of the structural materials from which the NGNP components will be fabricated. These are effects of irradiation, high-temperature exposure, and interactions with the gaseous environment to which they are exposed. An extensive testing and evaluation program will be required to assess the effects that these factors have on the properties of the materials and qualify them for NGNP construction.

Subsequent portions of this section describe the research plans for the major classes of materials that will be performed directly as a part of DOE's NGNP project: metals, graphite, and ceramics and their composites. These plans will be more fully refined as the overall system and component operating conditions become better defined.

\subsection{GENERAL CONSIDERATIONS FOR NGNP MATERIALS RESEARCH}

\subsubsection{Irradiation}

When a material is irradiated, virtually every property may change. This includes physical dimensions as well as mechanical, electrical, magnetic, thermo-physical, and other properties. The reason for this is that the existing crystal and defect structure is deconstructed and reconstructed on an atom-by-atom basis during irradiation. In a highdose irradiation, each atom may be displaced from its lattice site numerous times. The standard measure of radiation dose in metallic materials is the displacement per atom (dpa). Conditions during irradiation, such as temperatures, dose, dose rate, and local materials composition, determine the property changes that will ultimately result. Three of the irradiation-induced changes of greatest concern are swelling, irradiation creep, and embrittlement.

Swelling is the isotropic volume expansion of an irradiated material. It occurs by the net absorption of interstitials at dislocations, with a corresponding net number of vacancies accumulating at cavities. It may reach tens of percent or more at high doses (e.g., tens to hundreds of dpa). In graphite, which has a very anisotropic crystal structure, swelling can itself be anisotropic and is highly dependent upon the texture of the graphitic microstructure and the macroscopic direction of a component with respect to the crystal texture.

Irradiation creep is a shape change in compliance with an applied stress, in excess of ordinary thermal creep. It occurs even at quite low temperatures, where thermal creep is entirely negligible. Dislocation-climb creep occurs by the asymmetrical partitioning of selfinterstitials and vacancies to dislocations differently oriented to the stress axis. Climbenabled glide creep occurs when a dislocation climbs and overcomes an obstacle, permitting it to glide. Creep may therefore result directly from net climb of particularly oriented dislocations or indirectly from any climb that triggers glide in response to the applied stress.

Embrittlement occurs, broadly speaking, by two processes. In the first type of process, hardening of the material progresses by creation of many types of obstacles by radiation. This hardening reduces ductility. Many irradiation-induced hardening centers are so small they are beyond the ability to detect with transmission electron microscopy. However, atom probe field-ion microscopy has contributed significantly to the knowledge of the structure and properties of these ultra-fine hardening features. The second type of process is grain boundary weakening, caused by preferential diffusion of transmutation products, such as helium, or tramp elements, such as phosphorus, to the grain boundary.

Swelling, irradiation creep, and embrittlement have received a great deal of experimental and theoretical attention. As a result, a certain measure of understanding of these 
phenomena has been achieved, but investigation of these processes in the particular alloys, graphites, and structural composites being considered for NGNP applications will still be required under the particular conditions of interest. The activities needed to assess these changes are incorporated into the following sections of experimental plans.

\subsubsection{High-Temperature Exposure}

At high temperatures, thermally activated processes such as microstructural changes, plastic flow, and some types of fractures produce a number of time-related degradation mechanisms that must be recognized in the design and operation of high-temperature components.

In regard to microstructural changes, there are several concerns to the NGNP. First, the RPV will most likely be fabricated from bainitic, martensitic or ferritic-martensitic (F-M) steels that derive strength from a fine precipitate of carbides formed on highly dislocated martensite lath boundaries. With time, these precipitates will coarsen and the lath structure will reform into a fine-grain structure with much lower tensile and creep strength than the starting steel. The rate at which this aging process occurs is highly dependent on the elemental constituents that make up the carbide microstructure. A second time-related degradation mechanism that occurs on the structural steels is that of intermetallic phase precipitation. In this process, coarse intermetallic phases precipitate that rob the matrix of solid-solution strengtheners and impart brittleness to the grain boundaries. In stainless steels and nickel-base alloys that will likely be used for the core internal components, piping, and other high-temperature components, some strengthening is often derived from stable carbides and fine dispersions of intermetallics that develop in-service. With time, these beneficial precipitates may coarsen or dissolve in preference to less desirable precipitate phases. Again, loss of strength and embrittlement are concerns. Work is needed in the NGNP materials program to define the kinetics of the precipitation processes and predict the development of metastable and, eventually, the stable microstructures.

High-temperature yield strength and resistance to plastic flow are properties that are important in structural components. Good resistance to thermal transients, mechanical fatigue, ratcheting, and buckling depends on materials with good short-time strength properties. At the extreme temperatures expected in the NGNP components, the yield and flow properties of the structural materials are expected to be very rate sensitive and will be more sensitive to loading rates in the components. To address these issues, the materials testing program needs to produce information that can lead to improved analysis methods that accommodate greater rate dependency of short-time deformation and fracture. For very long service times there are additional concerns. The database on which allowable stresses are based is quite limited for several of the candidate materials, particularly at the upper temperature range that service in the NGNP will require. New deformation and fracture mechanisms may prevail at the long time and low stresses thought to represent steady-state operation of the NGNP. It is critical that predictive continuum damage mechanics models be developed on a sound metallurgical basis. The activities needed to assess both the microstructural stability and effects of temperature on both short- and long-term mechanical properties are incorporated into the following sections of experimental plans.

\subsubsection{Helium-Gas-Cooled Reactor Environment}

From a corrosion viewpoint, the internals of the reactor will operate in an impure helium environment, and the externals of the reactor, including the pressure vessel, will operate in air. The internal metallic components of the reactor will operate at temperatures up to $950^{\circ} \mathrm{C}$. 
The interactions between structural materials in the helium atmospheres associated with gas-cooled reactors have been the subject of numerous studies. The United States, Germany, England, Norway, Japan, and other places have demonstrated the importance of small changes in impurity levels, high temperatures, and high gas flow rates. Metallic materials can be carburized or decarburized and oxidized internally or at the surface. These corrosion reactions, depending on their rate, can substantially affect long-term mechanical properties such as fracture toughness, fatigue, crack-growth rate, etc.

Typical simulated advanced HTGR helium chemistries used in various previous test programs are shown in Table 3.1. Because of the low partial pressures of the impurities, the oxidation/carburization potentials at the metallic surface of a gas mixture are established by the kinetics of the individual impurity-catalyzed reactions at the surface. As shown, the main impurities are $\mathrm{H}_{2}, \mathrm{H}_{2} \mathrm{O}, \mathrm{CO}$, and $\mathrm{CH}_{4}$. The hot graphite core is considered as reacting with all free $\mathrm{O}_{2}$ and much of the $\mathrm{CO}_{2}$ to form $\mathrm{CO}$, and with $\mathrm{H}_{2} \mathrm{O}$ to form $\mathrm{CO}$ and $\mathrm{H}_{2}$. In addition, in cooler regions of the core, $\mathrm{H}_{2}$ reacts with the graphite via radiolysis to produce $\mathrm{CH}_{4}$. Because of the change in surface temperatures around the reactor, and associated changes in reaction mechanisms and rates of reaction on bare metal versus on scaled surfaces, reaction rates and order of reactions are important.

Table 3.1. Composition of helium environments (advanced HTGR) used in past reactor development programs

\begin{tabular}{|c|c|c|c|c|c|c|c|}
\hline Program & 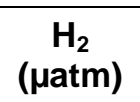 & $\begin{array}{c}\mathrm{H}_{2} \mathrm{O} \\
(\mu \mathrm{atm})\end{array}$ & 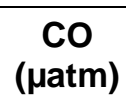 & 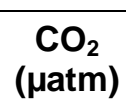 & 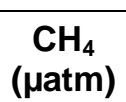 & 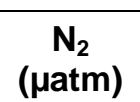 & $\begin{array}{c}\mathrm{He} \\
\text { (atm absolute) }\end{array}$ \\
\hline $\mathrm{NPH} / \mathrm{HHT}$ & 500 & 1.5 & 40 & & 50 & $5-10$ & 2 \\
\hline PNP & 500 & 1.5 & 15 & & 20 & $<5$ & 2 \\
\hline AGCNR & 400 & 2 & 40 & 0.2 & 20 & $<20$ & 2 \\
\hline
\end{tabular}

$\mathrm{NPH}$ : nuclear process heat

HHT: high-temperature helium turbine systems

PNP: prototype nuclear process heat

AGCNR: advanced gas-cooled nuclear reactor

The overall stability of the proposed helium environment that will be representative of the NGNP must be evaluated in order to ensure that testing proposed in the various experimental sections that follow is performed in environments that have consistent chemical potentials. In addition, the corrosion of metals and nonmetals must be evaluated to establish baseline data where it does not exist. Therefore, testing in both the helium environment to be used for mechanical properties and general corrosion evaluations of the candidate materials to establish their overall compatibility with that environment will be performed at temperatures up to at least $50^{\circ} \mathrm{C}$ above the proposed operating temperature for the various metallic components.

The bulk of the experimental plans needed to assess the effects of the helium environment on mechanical properties of the metallic internal materials is included in the following sections that deal with individual components. However, in addition to those studies, it will be necessary to assess the stability of the helium environment itself as well as the general effects of corrosion on the various structural materials being considered for use within the primary circuit. 


\subsection{NGNP HIGH-TEMPERATURE METALLIC COMPONENTS}

\subsubsection{Overall R\&D Planning Assumptions}

Several assumptions are incorporated into R\&D planning for the NGNP and are fundamental to estimating the scope, cost, and schedule for completing the materials R\&D processes. Most importantly, NGNP will be a full-sized reactor plant capable of electricity generation with a hydrogen demonstration unit of appropriate size. As described in more detail in previous sections, the reactor will be a helium-cooled, graphite-moderated core design fueled with TRISO-design fuel particles in carbon-based compacts or pebbles. NGNP must demonstrate the capability to obtain a NRC operating license. The design, materials, and construction will need to meet appropriate Quality Assurance (QA) methods and criteria and other nationally recognized codes and standards. The demonstration plant will be designed to operate for a nominal 60 years. All of these assumptions affect the choice of activities and their priorities within the NGNP materials research and qualification plan.

Beyond theses general assumptions, the research plan primarily addresses materials for the most critical components in a baseline design case for the first NGNP, specifically the RPV and the IHX at this time. The baseline design case incorporates the design features and conditions that are currently though to be most likely. An outlet gas temperature of $850^{\circ} \mathrm{C}$ and an indirect cycle are assumed. Based on technical maturity and experience gained from application in LWR plants, and availability and fabricability, a cooled pressure vessel fabricated from conventional pressure vessel steels, such as A508 Grade 3 Class 1 for forgings and A533 Grade B Class 1 for rolled plate, is the most likely RPV material (referred to as "A508" and "A533" in this summary). Based primarily on high-temperature properties, the IHX will be fabricated from a nickel-based solid solution alloy; Alloy 617 is currently the leading candidate based on technical maturity with Alloy 230 as a potential alternative.

Lastly, the research plan has been designed to specifically address the list of highpriority issues that has been recently compiled by the NRC, based on several reviews of various high-temperature reactors including both VHTRs and sodium-cooled reactors. These concerns are described in more detail in Sect. 4.1 on High-Temperature Design Methodology and Implementing Codes.

The schedule for completing required high-temperature metals R\&D for the NGNP is still somewhat tentative. The highest priority activity is to obtain sufficient data to prepare an ASME Code Case to incorporate Alloy 617 into the Boiler and Pressure Vessel Code by about 2015. Additional data for Alloy 617 will be needed to support the design effort on the same schedule. Long-term aging and environmental effects studies for Alloy 617 and A508 will be required to support the licensing effort in about 2015 and continuing after that date to support reactor operation. Plans for addressing additional metallic components, such as piping, turbo-machinery, metallic internals, etc., will be formulated as the system design matures and project priorities are further defined.

\subsubsection{RPV Research and Development}

The NGNP program has not yet determined whether the reactor will be of the pebble bed or prismatic type. Modeling and analysis of the two different configurations have indicated that there are small differences in the expected operating conditions of the RPV depending on which type is selected. However, for purposes of this development plan, the base case adequately addresses either configuration. Although the current understanding of NGNP operating conditions is consistent with the parameters listed above, the design 
philosophy is to do nothing for the initial plant that would preclude eventual operation at an outlet temperature of $950^{\circ} \mathrm{C}$. Variations of this baseline design to allow higher outlet temperature or incorporation of materials that are not currently of sufficient technical maturity to use in the design of the first plant will be discussed in less detail. The RPV R\&D plan ${ }^{28}$ is based on NGNP program analysis that has been informed by pre-conceptual design analysis performed by teams assembled by potential reactor vendors. ${ }^{14-16}$

Base case conditions assume an outlet gas temperature of $850^{\circ} \mathrm{C}$. The maximum operating temperature of the RPV will depend on the NGNP design (pebble bed or prismatic block), outlet gas temperature, and power level selected. The PBMR-based design has calculated an RPV nominal operating range of $260-300^{\circ} \mathrm{C}$, achieved by using an independent cooling stream. The normal operating temperature for the uncooled vessel condition has not been finalized in the preconceptual design. If the design is constrained to have negligible creep in the vessel, this temperature will be limited to about $425^{\circ} \mathrm{C}$.

The NGNP RPV will be 8 to $9 \mathrm{~m}$ in diameter and 200 to $300 \mathrm{~mm}$ thick, maximum. Although the reactor's height varies somewhat with the particular design, it is on the order of $20 \mathrm{~m}$. The size of the vessel suggests that onsite fabrication will be necessary. The preferred structure would consist of stacked ring forgings assembled using circumferential welds. The alternative is to weld rolled plates, although these are to be avoided to the extent possible.

The Westinghouse preconceptual design provides a maximum end-of-life fast fluence of $2 \times 10^{18} \mathrm{n} / \mathrm{cm}^{2}(>0.1 \mathrm{MeV})$; this estimate is based on PBMR documents. This is a very low fluence relative to a 40-year life for current LWR RPVs. Assuming that the radiation exposure for the RPV is relatively low for all the NGNP conceptual designs, irradiation embrittlement is not anticipated to be a major issue based on current knowledge accumulated for $250-300^{\circ} \mathrm{C}$ irradiation temperatures for these steels. However given the anticipated irradiation temperature of $\sim 350^{\circ} \mathrm{C}$, there is an obvious gap in knowledge regarding potential synergism between low flux irradiation and long-time aging at temperatures as high as $370^{\circ} \mathrm{C}$.

\subsubsection{RPV candidate materials}

Based on the vendor recommendations, three primary candidate alloys were considered for the RPV: low alloy steel A 508 (UNS K12042), Fe-21/4Cr-1Mo steel (UNS K21590), and Grade 91 steel (UNS K90901).

A sufficient database is available to validate the mechanical properties of A508/533 steel for the cooled vessel option. Data supporting the thermal aging effects on mechanical properties is promising, but additional information on long-term aging effects is needed. At present no data are available on the effects of impure helium on the long-term corrosion and mechanical properties of the material.

Alternative materials for a hot vessel option using materials currently in the ASME Code include $2 \frac{1}{4} \mathrm{Cr}$-1Mo steel in the annealed condition. In this condition, $2 \frac{1}{4} \mathrm{Cr}-1 \mathrm{Mo}$ steel has relatively low strength and would require very thick plates or forgings to accommodate the NGNP pressure. For this reason, $21 / 4 \mathrm{Cr}-1 \mathrm{Mo}$ steel is no longer under serious consideration.

The primary reference material for the hot vessel RPV option is Grade 91, a ferriticmartensitic steel developed for relatively high-temperature applications. A substantial database on the baseline mechanical properties of the Grade 91 steel is currently available. Sufficient data are also available on the long-term thermal aging effects on the mechanical properties for this steel. However, additional data are needed for the mechanical properties of thick sections, where there is the possibility of retained ferrite in this martensitic steel that can lead to embrittlement. As with the other alloys under consideration, properties in impure helium must also be explored. Grade 91 is a relatively mature material, as indicated by its 
inclusion in Section III of the ASME Boiler and Pressure Vessel Code (BPVC), including in subsection $\mathrm{NH}$ on high-temperature materials. Code qualification applies for operation to $300,000 \mathrm{~h}$, whereas the current design concept of 60 years would require over $420,000 \mathrm{~h}$, if operated at $80 \%$ efficiency.

\subsubsection{ASME boiler and pressure vessel code considerations}

The NGNP RPV must be designed using the ASME Section III Code rules. If the RPV wall temperature can be maintained at a sufficiently low temperature $\left(\leq 371^{\circ} \mathrm{C}=700^{\circ} \mathrm{F}\right)$ with only limited excursions as defined under Code Case N 499, Subsection NB of the Code can be used. Otherwise, Subsection NH must be applied.

A 508 and A 533 steels are ASME Code approved for Class 1 nuclear components and Subsection NB rules apply for the actively cooled case. Without active cooling, A 508 steel is unacceptable. Grade 91 steel is approved in Section III of the ASME Code for nuclear applications for higher temperature operation; however, the creep-fatigue limits for the steel in the code are highly conservative and may preclude its selection for the NGNP RPV application. Stress analysis of the depressurized conduction cooldown condition for both pebble bed and prismatic designs showed the peak temperatures to be within the creep range for the steel, but the stresses are too low to cause any significant creep deformation $\left(<10^{-6}\right)$.

Areas that need particular attention for A 508 Class 3 and A 533B steels and their weldments for NGNP RPV application are creep-rupture and fatigue damage. The major concern on Grade 91 steel for NGNP RPV application is the adequacy of thick-section properties of the base metal, as-received and post-weld heat treated, and weldments. The current specification for Grade 91 forgings is A182. Products made to this specification are limited to a maximum weight of $4540 \mathrm{~kg}$ that is too small for NGNP RPV applications. Addition of specification A336 for Grade 91 steel, which permits weight greater than $4540 \mathrm{~kg}$, in Subsections NB and NH is required to support NGNP RPV application.

The current concept on the design of the RPV in the hot vessel option is to restrict the RPV metal temperature to be below the negligible creep temperature for Grade 91 steel. This does not necessarily imply that the Subsection NH rules of construction can be completely exempted. However, it does reduce the design analysis burden as creep-fatigue interaction is no longer a structural integrity issue within the negligible creep regime.

\subsubsection{Vessel fabrication}

Japan Steel Works has capability and experience with forging $8 \mathrm{~m}$ diameter rings from A 508 pressure vessel steel and is willing to forge sections for NGNP; however, the lead time is substantial and an early decision to purchase these forgings will be necessary. An assessment of the potential vendors from all over the world showed that capability and experience to fabricate a Grade 91 vessel of the size required for NGNP are severely lacking.

At present, several vendors around the world have substantial experience in fabrication of RPVs from A 508. Procurement of a vessel of this material may depend primarily on the availability of a vendor to meet the schedule and not on the technical issues with the material. The RPV will be much larger than the current LWR vessels, requiring field welding of either ring forgings or plates. While ring forgings are preferred, since they would result in fewer welds (no longitudinal welds) to assemble the RPV, this may not be possible. Welding procedures will likely include pre- and post-weld heat treatment in the field.

The superior mechanical properties of the Grade 91 weldment strongly depend on creation of a precise microstructure and maintaining it throughout the service life of the 
welded component. Welding procedure and post-weld heat treatment play critical roles in creating the desired microstructure and producing a stress-free weld. The most significant problem with welding of Grade 91 steel is its propensity to Type IV cracking in the heataffected zone. Material that has exceeded the minimum transformation temperature during the welding process can partially reaustenitize and coarsen, resulting in substantially reduced creep-rupture strength and leading to cracking at relatively low operating temperatures and early component lifetimes. Boron addition seems to reduce cracking susceptibility, but additional data are needed to quantify the effect over the long term. Overtempering, under-tempering, cold-work, dissimilar metal welds, and stress corrosion cracking are also potential problems encountered in Grade 91 weldments. Welding this steel requires more care in fabrication procedure and joint design than lower alloy steels being sensitive to temperature variations both during welding and post-weld heat treatment.

Creep-fatigue interaction could be more severe in Grade 91 weldments compared with A 508 weldments. Creep-fatigue data show that the number of cycles to failure decreases with the introduction of hold time, and the effect is more severe for the weldment than for the base metal. Significant additional data are needed to quantify this effect and establish the maximum reduction in life, if any.

Some compositions within the standard specifications of Grade 91 have delta ferrite, which is stable at all temperatures. In addition, chemical micro-segregation during welding could produce conditions in weld deposits that effectively stabilize the delta ferrite. The presence of delta ferrite is generally undesirable in $9 \mathrm{Cr}$ steels because it may be detrimental to toughness and creep properties. The influence of delta ferrite on the properties of weld deposits and weldments should be thoroughly characterized, and delta ferrite minimizing measures should be developed for the intended nuclear application.

Maintaining properties for thick section welds. Although the high strength of Grade 91 allows relatively thinner wall designs compared to low-alloys candidate materials, the RPV still requires a heavy section wall and large size. Controlling residual stresses could therefore be an important fabrication issue in the thick section weldment. The need for residual stress control should be established for critical components. Strategies for controlling residual stresses should be developed and verified.

Inhomogeneous weld microstructures are often found in complex property gradient in the weld region. The current experimental testing and weld design approach often oversimplify the effect of these complex microstructure and property gradients in the design and assessment of structural performance and integrity of such large welded structural components. Compared to the standard $9 \mathrm{Cr}-1 \mathrm{Mo}$ chemical composition, the Grade 91 steel includes additions of $\mathrm{V}, \mathrm{Nb}, \mathrm{N}, \mathrm{Al}$, and $\mathrm{Ni}$. Elements such as $\mathrm{Nb}$ are prone to segregation in heavy section product forms. The through-wall macro-segregation can further complicate the property gradient in the welded region. New or improved design approaches that can realistically incorporate the complex microstructure and property gradients of the weld joint should be developed and verified. Advanced computational models to predict the microstructural changes and their impact on the fracture behavior and long-term creep resistance should also be developed.

During fabrication, heavy section weldments may be held at temperatures below those used for post-weld heat treatments for extended time periods (possibly days). This may be done to maintain preheating temperatures and for hydrogen bake-out treatments. Depending on their temperatures and their chemical compositions, weld deposits could contain metastable austenite when low-temperature holds begin. This austenite could transform during long holding periods, and the resulting microstructures could be different from those expected under conditions where extended low-temperature holds are not used. The need for extended low-temperature holds should be established and their effects on microstructures and properties determined. 
Hydrogen-induced cold cracking is always a concern for heavy section components. To ensure RPV safety, the materials susceptibility to cold cracking needs to be investigated. The information obtained from the investigation will provide crucial guidance for developing temperature control procedures before, during, and after the welding process.

Limited existing data on Grade 91 suggest that creep may become negligible at the temperature range of $425-450^{\circ} \mathrm{C}$. The observation initiated the attempt to design the RPV in negligible creep regime so that expensive creep and creep crack monitoring programs can be eliminated throughout the reactor operation life of 60 years. If this design approach is taken, negligible creep behavior of heavy section welds may become the weakest area that must be thoroughly investigated for defining the desired operation temperature. Existing data also suggest that hold times may reduce fatigue life of the Grade 91 weldment. Heavy section welds again may become the weakest area that must be investigated.

Post-weld heat treatment. Post-weld heat treatment (PWHT) has a great impact to the final microstructure and long-term mechanical properties of the welds. Grade 91 steel requires great care in PWHT because the material air-hardens and exhibits very little ductility in the as-welded condition. Further, critical points for phase transformations can change significantly, depending on subtle variations in the chemical composition of the weld and base metal within the specifications. For the intended RPV application, the heavy section of the component and the envisioned onsite welding requirements add more difficulties to the control of the PWHT parameters to achieve the desired final microstructures that provide the expected superior high-temperature strength of the material. Experience from fossil energy programs in fabricating Grade 91 welds suggests that customized PWHT procedures must be developed in detail, and the entire process should be closely monitored with an array of thermocouples.

To achieve optimum microstructures and the required superior high-temperature strength, not only the PWHT but the entire thermal progression or heat treatments for fabricating the weld must be strictly controlled with great care. This usually includes proper preheating, inter-pass temperature control, post-weld hydrogen bake-out, and PWHT. Detailed procedures for each step of the thermal processing should be developed with special considerations for onsite welding of thick sections in various weather conditions. Tabulated continuous cooling transformation diagrams can only be considered as approximate, and the heat-treating temperatures must be adjusted according to the actual heat chemistry.

Type IV cracking. Type IV cracking occurs in the fine-grained region close to the intercritically annealed zone of the heat affected zone (HAZ) as a result of an accelerated formation rate of creep void in these regions. The cracking can lead to a shortened creep rupture time of HAZ compared with that of the base metal. The accelerated formation rate of creep voids may result from a combination of the fine-grained microstructure and coarse carbide particles contained in the region. The coarse carbide particles can serve as void nucleation sites. With the high diffusion rate along the grain boundaries of the fine-grained region, formation and growth of creep voids can be greatly accelerated, leading to premature creep failure.

Although Type IV cracking arises from the heterogeneous microstructure in HAZ, it is usually impractical to eliminate it by a reaustenitization and tempering heat treatment, especially for the large-scale and onsite RPV construction. Unfortunately, it may be pragmatic to define a creep strength reduction factor for design through creep testing of cross-welds. Factors that affect propensity to Type IV cracking should be investigated. Major known factors that have apparent effects on Type IV cracking may include service temperature, heat treatment temperature (preheating, tempering, and normalization temperatures), and chemical composition (e.g., boron). The PWHT time, energy input, and other chemical contents may also have limited effects. More investigations are needed to 
study these factors and develop means to minimize or hopefully eliminate the propensity to Type IV cracking.

\subsubsection{Emissivity of RPV materials}

For the passive heat removal system to function properly, it is necessary that the reactor pressure vessel be able to radiate heat to the external environment under accident conditions. While a target emittance has not yet been established, it is necessary to have a stable, high-emissivity layer on the proposed pressure vessel material that will likely need to exceed 0.7. While there is significant LWR experience with A 508/533B, the higher temperature involved in the NGNP requires an evaluation of the rate of formation and longterm stability of the emissivity layer on the outer surface of the reactor pressure vessel, which is exposed to air. There is considerable less information available for the proposed chrome variant reactor vessel materials at the proposed temperatures. In addition the effects of field welding on the emissivity layer must be evaluated.

\subsubsection{Mechanical property testing required for A 508/533 RPV steel}

The existing database does not provide adequate creep rupture data to address the issue of whether or not creep effects for the RPV need to be considered under normal operating temperature of $350^{\circ} \mathrm{C}$. Longer term creep rupture data are needed, and testing is proposed to address this issue. Base metal and weldment creep rupture test data in air are needed in time to support conceptual and preliminary design (CPD) activities, and final design/licensing (FDL) efforts. Test temperatures should be $350^{\circ} \mathrm{C}, 371^{\circ} \mathrm{C}$, and $390^{\circ} \mathrm{C}$ to cover the normal operating temperature of $350^{\circ} \mathrm{C}$ and to provide some acceleration of the creep process. Both base metals and weldments should be tested and should receive a simulated stress relief (SSR) treatment before they are machined into test specimens. Some environmental creep rupture tests are also planned to assess the potential impact of NGNP helium on the creep rupture strengths of $A$ 508/533B steels and their weldments.

Limited temperature excursions above the subsection NB cut-off temperature of $371^{\circ} \mathrm{C}$ but within the time-and-temperature restrictions of Code Case N-499 could occur for the RPV. Code Case N-499 permits excursions to within $427^{\circ} \mathrm{C}$ for a total of 3000 accumulated hours, while excursions beyond $427^{\circ} \mathrm{C}$ and within $538^{\circ} \mathrm{C}$ are limited to three occurrences. There is a concern that creep-fatigue damage accumulated during these excursions would degrade the creep rupture strengths of the base metals and their weldments, if it is concluded that creep effects need to be considered at the normal operating temperature of $350^{\circ} \mathrm{C}$. Creep rupture tests on specimens in the stress-relieved condition will be given a "damage" treatment by subjecting the specimen to strain-controlled cycling, with a tensile strain hold of $1000 \mathrm{~min}$, for 180 cycles at $427^{\circ} \mathrm{C}$. This will accumulate creep-fatigue damage for about $3000 \mathrm{~h}$. Since the stress relaxes during the strain hold, this form of cycling is called fatigue-stress relaxation. Creep rupture tests are then performed on the "damaged" specimens.

Longer term creep rupture tests in air are also necessary for the A 508/533B steels and their weldments at the normal operating temperature of $350^{\circ} \mathrm{C}$. Five-year and 20 -year data are targeted for these tests. The 5-year data will be used to check the adequacy of the extrapolation based on the statistical analysis of the shorter term data. The 20 -year tests are designed to lead the reactor operations. This would provide lead time to develop mitigation strategy if an unanticipated rupture event occurs in one of the tests.

Relaxation strengths. The relaxation strength is required to provide the limit to ensure that shakedown takes place so ratcheting does not occur. Some testing is needed for A 508/533B steels and their associated weldments. Relaxation strengths are to be 
determined from the stress relaxation curves developed from the testing at $350^{\circ} \mathrm{C}, 371^{\circ} \mathrm{C}$, $427^{\circ} \mathrm{C}$, and $538^{\circ} \mathrm{C}$, covering the normal operating temperature and the temperatures permitted in Code Case N-499. Longer relaxation durations are needed for the two lower temperatures as the relaxation process is slower at those temperatures. Shorter durations are selected for the two higher temperatures to cover the range of applications permitted by Code Case N-499. Adjustment to the initial stress and relaxation period will be made before the commencement of the tests if necessary.

Creep-fatigue tests. To assist the assessment of whether creep needs to be considered for the RPV under normal operating temperature, creep-fatigue tests at $350^{\circ} \mathrm{C}$ are proposed for fatigue-stress relaxation for A 508/533B steels and their associated weldments. Continuous cycling data will be compared with those with strain hold times to provide additional information on the assessment of the creep effects at $350^{\circ} \mathrm{C}$. The strain hold times will be adjusted after initial results are obtained, if deemed necessary.

Tensile properties. Potential degradation of tensile properties due to thermal aging and creep-fatigue damage accumulated during short-term high-temperature excursions would impact the ratcheting resistance. Each set of tensile properties should include test data at $20^{\circ} \mathrm{C}, 150^{\circ} \mathrm{C}, 250^{\circ} \mathrm{C}, 350^{\circ} \mathrm{C}, 450^{\circ} \mathrm{C}$, and $550^{\circ} \mathrm{C}$. Two thermal aging protocols, $20,000 \mathrm{~h}$ at $450^{\circ} \mathrm{C}$ and $70,000 \mathrm{~h}$ at $450^{\circ} \mathrm{C}$, are suggested. The aging temperature of $450^{\circ} \mathrm{C}$ is selected to accelerate the aging process. Adjustment to this aging condition will be made, if needed, at the commencement of the aging program. The 70,000-h aging preconditioning would best be conducted in the dedicated Long-Term Aging Facility. In addition to providing data to assess the potential tensile properties degradation, these tensile data will be needed in the analysis of the fracture toughness data which is described in the next subsection.

Fracture toughness. A 508/533B steels and their associated weldments are bodycentered cubic materials that exhibit ductile-brittle transition behavior. In the transition and lower shelf regions where the temperatures are low, the fracture mechanism is a brittle failure mode of transgranular cleavage, while the fracture mechanism changes to a void nucleation and growth type of ductile tearing mode at higher temperatures. In the brittle regime, the toughness of the material can be characterized by the "Master Curve" reference temperature $T_{0}$, while the resistance to ductile tearing and tearing instability are characterized by $J_{I C}$ and the resistance curve, or the J-R curve.

Fracture toughness and J-R curve have been studied extensively for these LWR pressure vessel materials. However, the LWR data do not cover most of the conditions that the NGNP RPV would likely encounter as the temperatures of interest for LWR are $300^{\circ} \mathrm{C}$ and below. The issue for NGNP RPV in the low-temperature, brittle regime is the potential negative impact on the fracture toughness due to long-term thermal embrittlement (thermal aging) accumulated during the normal operations at $350^{\circ} \mathrm{C}$ for a very long time ( 60 years), and creep-fatigue damage accumulated during the short-term high-temperature excursions that are permitted by Code Case N-499. The former would be of concern for transients such as shutdown towards the end of design life of the reactor as it takes a very long time to accrue thermal embrittlement. The latter could possibly be of concern towards the latter part of the reactor design life as more creep-fatigue damage would be accumulated toward that stage.

The high-temperature toughness, as characterized by $J_{I C}$ and the $\mathrm{J}$-R curve, decreases as the temperature is increased. The decrease is small to about $400^{\circ} \mathrm{C}$, and it is expected to drop more rapidly as the yield and tensile strengths of these materials start to drop more significantly at temperatures beyond $400^{\circ} \mathrm{C}$. This could be a potential threat to NGNP RPV as Code Case $\mathrm{N}-499$ permits short-term high-temperature excursions to within $473^{\circ} \mathrm{C}$ and $538^{\circ} \mathrm{C}$ with restrictions. Thus $J_{I C}$ and $\mathrm{J}-\mathrm{R}$ curve data are needed to address this issue for both base metal and weldments which is related to the leak-before-break criteria. 
Cyclic stress-strain curve. Cyclic stress-strain curves are required to determine the cyclic response. Cyclic hardening, cyclic softening, or cyclic neutral material behavior is important in establishing the negligible creep criterion. Cyclic stress-strain curves had been determined for A 533B to support the Code Case N-499 effort, and they are available for use, but data are required for A 508 as well.

\subsubsection{Additional considerations for Grade 91}

In addition to the microstructural stability issues identified above, for Grade 91 it will be necessary to improve understanding of the cyclic behavior at high temperature and to validate creep-fatigue procedure. Two creep-fatigue protocols are recommended. One involves keeping the strain constant during hold time, and hence the stress relaxes during hold time. This is referred to as fatigue-relaxation test. The other involves keeping the stress constant during hold time, and the material will creep. This is called creep-fatigue test.

Fatigue-relaxation tests for thick-section cross-welds, produced by submerged arc (SA), gas tungsten arc (GTA), and shielded metal arc (SMA) welding processes, are needed. The weldments will be given a simulated PWHT before test specimens are machined. Creep rupture and tensile tests on Grade 91 specimens that have been softened by creep-fatigue pre-conditioning are also needed.

\subsubsection{Intermediate Heat Exchanger (IHX) Materials Issues}

A number of solid solution strengthened nickel-based alloys have been considered for application in heat exchangers and core internals for the NGNP. ${ }^{29}$ The primary candidates are Inconel 617 and Haynes 230, although Incoloy 800H and Hastelloy XR have also been mentioned as candidates. Based on the technical maturity, availability in required product forms, experience base, and high-temperature mechanical properties, all of the vendor preconceptual design studies ${ }^{14-16}$ have specified Alloy 617 as the material of choice for heat exchangers. Also a draft code case for Alloy 617 was developed previously. Although action was suspended before the code case was accepted by ASME, this draft code case provides a significant head start for achieving codification of the material.

\subsubsection{IHX design alternatives}

The IHX design has not been determined, but a plate with fin, countercurrent tube and shell, involute heat exchangers, micro-channel heat exchangers, and printed circuit heat exchanger ( $\mathrm{PCHE}$ ) designs are all under consideration. As a result, both thin and thick product forms must be considered for research and development. These different product forms may have different microstructures and properties. There is no requirement that the $\mathrm{IHX}(\mathrm{s})$ last the design lifetime of the plant (60 years), although this would be ideal. Replacing the IHX is possible and, in reality, probable.

The size and number of heat exchangers is also unknown at this time. One design approach would use two IHX in series. A replaceable one subjected to temperatures in the range of $710-900^{\circ} \mathrm{C}$ and a second designed for temperatures less than $710^{\circ} \mathrm{C}$, intended to last the full lifetime of the plant. In this configuration, the second IHX processes gas already cooled by the first, thus enduring much less harsh conditions. In time, higher temperature materials or different designs could be tested by installing them in the position of the replaceable IHX. 


\subsubsection{IHX candidate materials}

Alloy 617 and Alloy 230 are the two leading candidate materials considered for the NGNP IHX application. Both alloys have attractive properties for high-temperature applications. Standard specifications have been developed and accepted by ASTM and ASME, so either alloy can be produced by other manufacturers. Since their introduction, significant research activities have been conducted to characterize both alloys and explore their potentials. Generally speaking, Alloy 617 has been more thoroughly studied with more data available compared to Alloy 230 , due to its earlier introduction into the marketplace, while as a newer alloy, Alloy 230 may have valuable potential for Generation IV application.

Alloy 617 (52Ni-22Cr-13Co-9Mo). Alloy 617, also designated as Inconel 617, UNS N06617, was initially developed for high-temperature applications above $800^{\circ} \mathrm{C}$. This alloy was considered and investigated for the HTGR programs in the United States and Germany in the late 1970s and early 1980s. Alloy 617 exhibits unique behavior that includes (1) lack of clear distinction between time-independent and time-dependent behavior, (2) high dependence of flow stress on strain rate, and (3) softening with time, temperature, and strain.

The high nickel and chromium contents provide the alloy with high resistance to a variety of reducing and oxidizing environments. The aluminum, in conjunction with chromium, offers oxidation resistance at high temperatures. In addition, the aluminum also forms intermetallic compound $y^{\prime}$ over a range of temperatures, which results in precipitation strengthening in addition to the solid solution strengthening imparted by the cobalt and molybdenum. Strengthening is also derived from $\mathrm{M}_{23} \mathrm{C}_{6}, \mathrm{M}_{6} \mathrm{C}, \mathrm{Ti}(\mathrm{C}, \mathrm{N})$ and other precipitates when in appropriate sizes, distributions, and volume fractions. The kinetics of the precipitation and coarsening processes were important in determining the effects of aging on properties.

The grain size also plays an important role in the strength of the alloy. For general applications, a grain size of ASTM No. $6(\sim 45 \mu \mathrm{m})$ or coarser is typically preferred, but it has been shown that creep strength increases with increasing grain size, so microstructures of 100-200 $\mu \mathrm{m}$ grain size are often produced. A trade-off exists, however, when fatigue is an issue, since finer grain sizes are preferred for fatigue resistance. In addition, for compact $\mathrm{IHX}$, the thin sheet form restricts large grain size. Whether the grains will significantly coarsen after the dissolution of certain grain boundary precipitates at long-term exposure is not clear.

Germany also extensively investigated Alloy 617 for its HTGR. The data generated were collected in the Online Data \& Information Network (ODIN) including original test curves. Collaborations to access the ODIN data on Alloy 617 are under way, in addition to negotiation to obtain the data and relevant study results from investigations by Honeywell Aerospace. Another database from the European Creep Collaborative Committee (ECCC) is also of interest.

Alloy 617 has adequate creep strength at temperatures above $870^{\circ} \mathrm{C}$, good cyclic oxidation and carburization resistance, and good weldability. It also has lower thermal expansion than most austenitic stainless steels and high thermal conductivity relative to the other candidates. It retains toughness after long-time exposure at elevated temperatures and does not form intermetallic phases that can cause embrittlement. Preliminary testing indicates Alloy 617 has better carburization resistance than Alloy 230.

While allowable stresses for Alloy 617 are currently not covered in Section II or Section III nuclear applications, there is a wealth of user experience base in non-nuclear applications that would be leveraged in establishing the allowable stresses for Alloy 617 . The creep properties of Alloy 617 have been characterized to rupture times of more than 10 years in both air and anticipated NGNP environments. The deleterious effects of the environment are well understood for those conditions. Carbide redistribution under creep 
load has been observed; however, the influence of carburization on creep properties is unknown, and the impact of the creep strain on grain boundary cavitation is little understood.

Currently, for ASME III Subsection NH materials, the time-dependent allowable stress, $\mathrm{S}_{\mathrm{t}}$, is partially based on time-to-onset-of-tertiary-creep. Unlike the classical creep curves of the materials covered in $\mathrm{NH}$, the secondary creep regime hardly exists for Alloy 617 (and 230) at elevated temperatures and the onset of tertiary creep occurs at very short times. Including time-to-onset-of-tertiary-creep would be very restrictive in setting the timedependent allowable stress and was not used in setting $S_{t}$ in the Draft Alloy 617 Code Case. However, justification is required for dropping onset-of-tertiary-creep from the allowable stress criteria. Information is needed on the deformation mechanism during the tertiary creep regime.

In German HTGR Alloy 617 creep-fatigue tests at $950^{\circ} \mathrm{C}$ in impure helium there is a dramatic reduction in cycles to failure for very long hold times when the data are extrapolated linearly on the log-log plot. The data were not indicating saturation.

Solution-annealed Alloy 617 in the as-received condition is very ductile. $J_{0}$ undergoes a small increase between $35^{\circ} \mathrm{C}$ and $200^{\circ} \mathrm{C}$, remains constant from $200^{\circ} \mathrm{C}$ to $725^{\circ} \mathrm{C}$, and then a strong increase at $750^{\circ} \mathrm{C}$. No onset of stable tearing was detectable up to a J-integral value of $2500 \mathrm{~kJ} / \mathrm{m}^{2}$ at temperatures of $775^{\circ} \mathrm{C}$ and above. The room-temperature Charpy-V notch CVN energy dropped significantly, with thermal exposure temperature and time, from an averaged unaged value of $200 \mathrm{ft} \mathrm{lb}$ to below $10 \mathrm{~J}$ after exposure at $800^{\circ} \mathrm{C}$ and $900^{\circ} \mathrm{C}$ for $10,000 \mathrm{~h}$. Limited CVN data for thermally aged Alloy 617 welds showed similar behavior. Nonductile failure is a significant failure mode for Alloy 617 for long-term elevated temperature service.

Alloy 230 (57Ni-22Cr-14W-2Mo). Alloy 230, also designated as Haynes 230, UNS N06230, or W. Nr. 2.4733, is a newer alloy than Alloy 617. The nickel base and high chromium content impart great resistance to high-temperature corrosion in various environments, and oxidation resistance is further enhanced by the micro-addition of rare earth element lanthanum. Compared to Alloy 617, Alloy 230 has a high tungsten concentration and its relatively high in boron content. The tungsten and molybdenum in conjunction with carbon are largely responsible for the strength of the alloy, and boron can be controlled to achieve optimized creep resistance. Boron can also help improve ductility but must be carefully controlled to achieve optimized performance.

In the supplied-solution annealed condition, the grain size is typically ASTM No. 6. After aging, Alloy 230 typically precipitates $\mathrm{M}_{6} \mathrm{C}$ and $\mathrm{M}_{23} \mathrm{C}_{6}$. After aging for $1000 \mathrm{~h}$ at $850^{\circ} \mathrm{C}$, quite large carbide precipitates rich in tungsten, presumably $M_{6} C$, and very small carbide precipitates rich chromium, $\mathrm{M}_{23} \mathrm{C}_{6}$, were observed along the grain boundaries. No grain coarsening was observed. Creep strength is believed to be brought about by solid solution strengthening, low stacking fault energy, and precipitation of $\mathrm{M}_{23} \mathrm{C}_{6}$ carbides on glide dislocations. However, room temperature elongation decreased from approximately $50 \%$ to $35 \%$ with precipitation of $\mathrm{M}_{23} \mathrm{C}_{6}$ after aging at $871^{\circ} \mathrm{C}$ for $8000 \mathrm{~h}$, but an additional $8000 \mathrm{~h}$ of aging did not further decrease ductility.

There are fewer data on Alloy 230 than on Alloy 617. The major large-scale study was tensile and creep tests by Haynes International. Creep times ranged from 15.3 to 28,391 h. Preliminary Generation IV program tests on Alloy 230 conducted in air include tensile and toughness data. Alloy 230 has higher tensile strength than Alloy 617 up to $800^{\circ} \mathrm{C}$, but above that the difference is insignificant. Welds exhibit room temperature strength that is the same or is slightly better than the base metal strength, but a considerable decrease in ductility at elevated temperatures occurs. Preliminary tests also suggest a decrease in creep ductility in the weld metal.

The creep behavior of Alloys 617 and 230 are extremely similar, although Alloy 617 has slightly better creep properties. It is not known if Alloy 230 is susceptible to carbide 
redistribution under creep load as is observed for Alloy 617. Based on the measured creep rupture time, a correlation for standard grain size Alloy 230 is used to compute the bestestimate creep rupture stress of the fine-grained material. Alloy 230 has better thermal fatigue crack initiation resistance but worse thermal cycling resistance than Alloy 617.

\subsubsection{Code status}

Alloy 617 is not currently qualified for use in ASME Code Section III, although it is allowed in Section I and Section VIII, Division 1 (non-nuclear service). Yield and tensile strengths for Alloy 617 are tabulated in Section II, Part D, from room temperature to $525^{\circ} \mathrm{C}$. The existing database that supported the development of these tables for Alloy 617 is judged to be adequate for developing a Code Case. A draft code case was completed in 1989 and later approved but did not progress because of the lack of further interest from DOE and its contractor.

The draft Code Case for Alloy 617 provides design rules for HTGRs limited to $982^{\circ} \mathrm{C}$, and a maximum service life (total life at temperatures $>427^{\circ} \mathrm{C}$ ) of $100,000 \mathrm{~h}$ or less because of the uncertainties of data extrapolation at very high temperatures, and the lack of experience in designing reliably at low allowable stresses for long times. The allowable stresses are less than $1 \mathrm{ksi}$ at the highest temperature. The code case focused on all the failure modes that are addressed by Subsections $\mathrm{NB}$ and $\mathrm{NH}$, including non-ductile failure. Extended exposure at elevated temperature may cause a significant reduction in fracture toughness of Alloy 617. Because of this concern, Alloy 617 bolting was excluded from the draft case. In addition, exposure of cold-worked material to very high temperatures results in recrystallization. Therefore, cold-worked Alloy 617 was also excluded from the draft case.

Like Alloy 617, Alloy 230 is not currently qualified for use in ASME Code Section III, although it is allowed in Section VIII, Division 1 (non-nuclear service). At present, the database for Alloy 230 is significantly smaller than that for Alloy 617, and a much larger effort will be required to develop an Alloy 230 Code Case for elevated temperature application.

\subsubsection{Unified constitutive model development}

In the design of high-temperature components such as an IHX for the NGNP made of Alloy 617 or Alloy 230, inelastic analysis is inevitable. In the design of Japan's HTTR IHX, a high-temperature structural design guideline was developed in the 1980s. Since then, significant advances have been made in the development of unified viscoplasticity constitutive equations, including for Alloy 617 for very high temperature applications. These equations are one dimensional and capable of modeling cyclic response, and the predictions compare quite well with short-term data. A renewed effort in developing a new unified constitutive model is necessary. It is essential that the new unified constitutive model can make accurate predictions, particularly for longer time, and be qualified by test data from key feature tests.

\subsubsection{Joining}

Welding. Alloy 617 has excellent weldability, and the welding process is well established. Alloy 230 is more difficult to weld, but process development also appears to be complete. Although the filler metals are not specifically designed for nuclear application, the composition of the filler metals match that of the base metals, and deposited weld metal is comparable with the wrought alloy in strength and corrosion resistance. 
Gas tungsten arc welding (GTAW) or gas metal arc welding (GMAW) can be used for joining Alloy 617 and 230. Shielded Metal Arc Welding (SMAW) and resistance welding techniques can also be used. Submerged-arc welding is not recommended as this process is characterized by high heat input to the base metal and slow cooling of the weld which can increase weld restraint and promote cracking. Preheat is not required; generally room temperature (typical shop conditions) are acceptable. The interpass temperature should be maintained below $93^{\circ} \mathrm{C}$. Post-weld heat treatment is not generally required either. No unique issues for examining welds in the IHX have been identified. The ASME rules for inspection are applicable to this welding application.

Cross-weld creep testing indicates that weldment strengths are usually in the range of $50-80 \%$ of those of base metals. Consequently, significant performance reductions are required for design of welded constructions of most Ni base alloys. Failures at the reduced loadings are usually in the weld deposits. The Alloy 230 welds exhibit room temperature strength that matches or is slightly better than the base metal but a considerable decrease in ductility at elevated temperatures. Preliminary tests also suggest a decrease in creep ductility in the weld metal. Depending on the design, the NGNP IHX may be joined to piping or components of materials other than Alloy 617 or 230 , for example $800 \mathrm{H}$. Extended annealing of mixed-metal joints, both austenitic-austenitic and austenitic-ferritic, can lead to unique microstructures that result in unexpected results. Approaches should be developed to adjust weld filler metal compositions to eliminate diffusion of critical alloying elements.

Diffusion bonding. Diffusion bonding may be used for joining the compact core if a PCHE design is chosen for the IHX. However, because of the complex shapes of the channels on the stacking sheet surface and relatively large size of the stacking sheets, applying the load evenly to the contact interface to form bonds of uniformly high quality can be a great challenge.

Diffusion-bonding is a solid-state joining process where metal surfaces are brought together under load at an elevated temperature (about $50 \%-90 \%$ of the absolute melting point of the parent material) for a period ranging from a few minutes to a few hours. The key for achieving a satisfactory bond in this process is to prepare extremely clean, fresh contact surfaces that form a high contact ratio. Under carefully controlled conditions neither metallurgical discontinuities nor porosity exist across the interface, and the diffusion-bonded joints can reach parent metal properties. Good dimensional tolerances for the products can be attained resulting in high-precision components with intricate shapes or cross sections without the need for subsequent machining.

While some diffusion bonding of Alloy 617 has been demonstrated, the optimum process parameters are not well defined. Adequate processing parameters must be developed including diffusion bonding temperature, applied loading level, and holding time. A significant portion of this effort has been carried out by the compact heat exchanger vendors, and at present they choose to hold this information proprietary. The manufacturer Heatric reports that either Alloy 617 or 230 lends itself to the diffusion-bonding process involved in the manufacture of their heat exchangers. Microstructural stability during the high-temperature exposure associated with diffusion bonding is a concern. As with most superalloys, the reformation of the surface oxide is virtually instantaneous. The potential for detrimental effects associated with high-temperature thermal cycles during diffusion bonding must be determined. There are no ASME code requirements for diffusion-bonded joints; therefore, inspection criteria must be developed. Compact heat exchangers use multiple layers of diffusion-bonded sheets or plates, and inspection methods are lacking for these structures.

Some data are available on room-temperature tensile properties of diffusion-bonded Alloy 617; however, processing conditions to achieve those bonds are not specified. There is no known data for Alloy 230. No known data on cyclic properties exists for either alloy. An 
extensive program of tensile, creep, fatigue and creep-fatigue testing, as a function of process conditions, will be required for either alloy. In addition, resistance to thermal fatigue in the impure helium environment should be investigated.

Brazing. Brazing is a joining process where a metallic filler material is heated to melting temperature and distributed by capillary action between closely fitted surfaces. The molten filler material interacts with the base metal and cools to form a bond from grain structure interaction. Because of the melting flux in the joining process, the surface preparation for brazing is much easier than that for diffusion bonding. However, significant work is needed to develop adequate filler material, especially for the very high temperature application desired for the IHX.

Little is known about brazing these alloys. Brazing uses low melting material, which raises concerns about the stability and mechanical properties of brazed joints. Extensive process development will be required, especially to develop adequate filler material for the very high temperature application desired for the IHX. Any microstructural instability associated with the braze material or chemical interaction between the braze material and the base metal must be investigated. The joint must be specifically tested, and effects of long-term exposure to high temperature and impure helium on properties must also be evaluated. Currently ASME does not allow the use of structural brazes in primary system pressure boundaries; therefore, usage and inspection criteria must be justified and developed.

\subsubsection{Environmental effects}

Coolant in high-temperature helium-cooled reactors has been found to contain low levels of impurities after steady-state operation. The impurities can lead to environmental degradation of the high-temperature alloys used for heat exchangers. However, all reactors to date have had similar impurity levels, and there have been no reported problems with failure associated with environmental effects of primary side components. Perhaps fortuitously, the impurity levels in the coolant for past-operating HTGRs were in the stable oxidizing condition that results in effective chromia-layer protection against corrosion for these alloys.

Depending on the impurity concentration and the temperature, high-temperature alloys can undergo oxidation, carburization, or decarburization. Carburization is associated with low-temperature embrittlement, and decarburization is linked to reduced creep rupture strength. The optimum coolant chemistry for long-term stability of high-temperature alloys is slightly oxidizing and results in formation of a tenacious and protective $\mathrm{Cr}_{2} \mathrm{O}_{3}$ scale. The concentrations of $\mathrm{H}_{2} \mathrm{O}$ and $\mathrm{CO}$ are of particular interest because they essentially control the oxygen partial pressure and carbon activity, respectively.

The NGNP materials program has extended previous studies on environmental effects of prototype impure helium on Alloy 617 by increasing temperatures and using test coupons that incorporate fusion welds in controlled chemistry test loops. In addition, parallel studies have been initiated with Alloy 230. The ultimate goal is to be able to predict the corrosion mechanism in effect for any particular gas chemistry at a given temperature for the selected alloy.

Alloy 617 developed a relatively thick chromium oxide scale with significant formation of grain boundary aluminum oxides after exposure to oxidizing atmospheres at $1000^{\circ} \mathrm{C}$. Alloy 230 had less surface oxidation and notably fewer grain boundary oxides. A decarburization region is apparent for both alloys, but is particularly notable in Alloy 230 .

Carburization of Alloy 617 was largely consistent with behavior reported in the literature. For low-water chemistries, there was little formation of a surface oxide scale after $500 \mathrm{~h}$ at $1000^{\circ} \mathrm{C}$ for either alloy. Carbon uptake in the material is manifested by an increased volume 
fraction of grain-boundary carbide precipitate. In Alloy 230, there is a marked difference in the larger volume fraction of carbide formation that heavily decorates both grain and twin boundaries found through the entire thickness of the approximately $3 \mathrm{~mm}$ thick coupon. The behavior observed for the carburizing atmosphere at 800 and $900^{\circ} \mathrm{C}$ was qualitatively similar; however, the depth of carburization was reduced.

A similar test plan would be used for either Alloy 617 or Alloy 230 in controlled chemistry gas representative of the NGNP on plate and weldments. Testing must include characterization of microstructure and mechanical property changes after long-term exposure: crack growth measurements during creep in the range of about 650 to $800^{\circ} \mathrm{C}$; crack growth measurements as a function of oxygen partial pressure in the vicinity of $600^{\circ} \mathrm{C}$; and testing with NGNP pressure (approximately $7 \mathrm{MPa}$ ) from 800 to $1000^{\circ} \mathrm{C}$ in quasi-static gas and with gas velocity from 25 to $75 \mathrm{~m} / \mathrm{s}$. Particle erosion effects will be included in the high-velocity tests using particles selected to represent relatively soft graphite dust as well as harder oxides spalled from alloy surfaces (pressure vessel and IHX). The IHX should experience little to no radiation; therefore, activated materials should not be an issue for this component. However, the high cobalt content of Alloy 617 does raise concerns about significant activation of any entrained dust from the IHX that may circulate back into the reactor pressure vessel.

\subsubsection{Fabrication}

Material considerations for the different heat exchanger designs are essentially similar, with the exception of some fabrication issues. The high strength and work hardening rate of the candidate alloys could make some plate or fin forming difficult. Fabrication of thin sheets and foils requires very carefully controlled processing parameters different from those for other product forms such as plate and tubing. There are some vendor-raised concerns about cold and hot workability of Alloy 617, which may impact fabricating thin product forms, in which significant thickness reductions will be required. Also, specific grain size must be achieved to ensure proper creep resistance of thin product forms.

\subsection{NGNP HIGH-TEMPERATURE NON-METALLIC COMPONENTS}

\subsubsection{Materials Selection and Issues for Reactor Core Graphite, Reflector, and Supports}

The NGNP will be a helium-cooled HTGR with a large graphite core. Graphite physically contains the fuel, acts as the neutron moderator for this thermal reactor, provides an enormous heat sink for passive safety measures during off-normal (accident) conditions, and comprises the majority of the core volume. The basic technology for inert gas-cooled HTGR design is well established from the early graphite piles of the 1940s to the fully commercial reactor designs operating in the 1980s. These past designs represent the two primary core configurations commercially favored for gas reactors: the solid-block prismatic or the pebble-bed graphite core. While the United States has focused on a prismatic design, active interest in the pebble bed design is increasing primarily from the activities of PBMR (Pty.) Ltd. in South Africa ${ }^{30,31}$ and in China. Graphite research for both designs are similar with the pebble bed core experiencing higher cumulative doses and the prismatic core experiencing higher temperatures. Estimated thermal and irradiation conditions for both prismatic and pebble bed core designs are listed in Table 3.2. 
Table 3.2. Expected reactor operating conditions ${ }^{32}$

\begin{tabular}{lll}
\hline \multicolumn{1}{c}{ Parameter } & \multicolumn{1}{c}{ Prismatic } & \multicolumn{1}{c}{ Pebble bed } \\
\hline $\begin{array}{l}\text { Temperature (normal operations) } \\
\text { Inner reflector blocks }\end{array}$ & \multicolumn{1}{c}{$1050^{\circ} \mathrm{C}$} & \\
Fuel centerline & $1200-1250^{\circ} \mathrm{C}$ & $600-1040^{\circ} \mathrm{C}$ \\
& & $<1100^{\circ} \mathrm{C}$ \\
Peak fast fluence $(>0.1 \mathrm{MeV})$ & & \\
Inner reflector & $1.7-12.2 \times 10^{20} \mathrm{n} / \mathrm{cm}^{2}$ & $1.6-12.2 \times 10^{20} \mathrm{n} / \mathrm{cm}^{2}$ \\
Dose $\left(0.78 \times 10^{21} \mathrm{n} / \mathrm{cm}^{2}=1 \mathrm{dpa}\right)$ & $0.19-0.85 \mathrm{dpa} / \mathrm{FPY}$ & $0.18-0.85 \mathrm{dpa} / \mathrm{FPY}$ \\
\hline
\end{tabular}

All HTGR designs utilize keyed (interlocked) graphite blocks to form an annular core configuration (Fig. 3.1). The inner graphite reflector structure is expected to receive the highest operating temperature and dose rate in the reactor core (other than the actual graphite fuel elements). The primary material issue for these inner and outer reflector blocks is one of long-term irradiation stability, since the expected temperature ranges and applied stress levels are well within the limits for graphite.

The reflector blocks are the primary structural component of the active core and for the pebble bed design are expected to stay inside the reactor as long as possible (15-20 years). At those exposure times, the physical dimensions of the graphite blocks are expected to change dramatically as a result of irradiation-induced dimensional changes (new basal plane formation between existing crystal planes arising from free interstitials created during irradiation) and in-plane shrinkage due to accumulation of basal plane vacancies. Irradiation-induced swelling well after turnaround is expected with increasing temperature accelerating these dimensional changes.

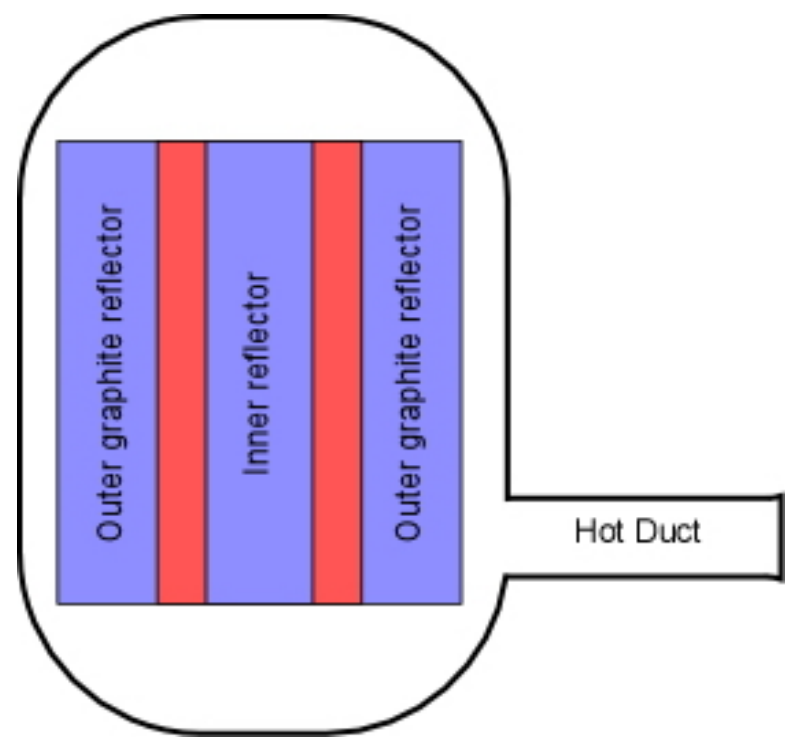

Fig. 3.1. Schematic of annular graphite core for HTGR.

Unfortunately, neither graphite-moderated HGTRs (other than small test reactors) nor new nuclear graphite grades have been built or fabricated since the 1980s. Thus new HTR design and construction requires the development of new nuclear graphite grades and also re-establishing expertise in utilizing nuclear graphite in support of the NGNP program. The individual research and development activities ongoing with the NGNP graphite program are described in the sections that follow. These include the thermal, physical, and mechanical 
testing programs for the selected graphite types, an irradiated material property (irradiation creep) testing program, microstructural as well as whole-core modeling efforts, and the development of new ASTM test standards deemed necessary for graphite components in nuclear applications. A schedule for the graphite technology development program in support of the NGNP is reported. Finally, the process of gaining approval of the design data (vetted by the ASME) by the NRC will be discussed.

\subsubsection{Development of nuclear-grade graphite}

The nuclear graphite type H-451 previously used in the United States for HTGR graphite components is no longer available. New graphite types have been developed and are considered suitable candidates for the new NGNP reactor design. However, to support the design and licensing of NGNP core components within a commercial reactor design, a complete properties database for these new, available, candidate grades of graphite must be developed. Data are required for the physical, mechanical (including radiation-induced creep), and oxidation properties of the graphite types. ${ }^{33}$ Moreover, the data must be statistically sound and take account of intra-billet, inter-billet, and lot-to-lot variations of properties within the graphite. These data are needed to support the ongoing development of the risk-derived (probabilistic) ASME graphite design code, which is a departure from the deterministic approach traditionally used for codification. This is a consensus code being prepared under the jurisdiction of the ASME by gas-cooled reactor vendors and NGNP researchers and other stakeholders.

The reactor type and operating conditions have major influences on the selection of graphite (Table 3.2). For a prismatic core design, graphite with small grain size is necessary to accommodate the many fuel and coolant channels drilled throughout the fuel block. Pebble bed reflector block designs do not have this requirement for the graphite since the fueled region does not have solid fuel blocks. ${ }^{34}$ Larger grain sized material can therefore be used in this design. In addition, due to anticipated operating conditions, the reflector blocks in the pebble bed core will experience much longer service times and thus much higher doses than anticipated for a prismatic graphite type. With such contrasting requirements, the testing of multiple graphite types is needed.

Six graphite types (from four manufacturers) have been selected as commercially available, or near commercially available, candidates for the NGNP graphite R\&D program (Table 3.3). Since the NGNP reactor is a near-term project, only mature graphite types were

Table 3.3. Candidate nuclear-grade graphite types for NGNP ${ }^{33}$

\begin{tabular}{|c|c|c|c|}
\hline Grade & Manufacturer & Coke type & Comments \\
\hline IG-430 & Toyo Tanso & Pitch coke & $\begin{array}{l}\text { Isostatically molded; candidate for high- } \\
\text { dose regions of NGNP concepts }\end{array}$ \\
\hline NBG-17 & SGL & Pitch coke & $\begin{array}{l}\text { Vibrationally molded; candidate for high- } \\
\text { dose regions of NGNP prismatic core } \\
\text { concepts (not currently commercially } \\
\text { available) }\end{array}$ \\
\hline NBG-18 & SGL & Pitch coke & $\begin{array}{l}\text { Vibrationally molded; candidate for high- } \\
\text { dose regions of NGNP pebble bed } \\
\text { concepts; PBMR reflector graphite }\end{array}$ \\
\hline PCEA & GrafTech International & Petroleum coke & $\begin{array}{l}\text { Extruded; candidate for high-dose } \\
\text { regions of NGNP prismatic core } \\
\text { concepts }\end{array}$ \\
\hline$P G X$ & GrafTech International & Petroleum coke & $\begin{array}{l}\text { Large blocks for permanent structure in a } \\
\text { prismatic core (used in HTTR) }\end{array}$ \\
\hline 2020 & Carbone of America & Petroleum coke & $\begin{array}{l}\text { Isostatically molded; candidate for } \\
\text { permanent structures in a prismatic core }\end{array}$ \\
\hline
\end{tabular}


considered for this R\&D program. Of these selected candidates the NBG-18 and PCEA grades are considered major grades most likely to meet the initial pebble bed and prismatic design requirements, respectively. To determine the long-term material property changes to these candidates, an extensive characterization program has been implemented. The primary activities are outlined below.

\subsubsection{Baseline material property characterization}

As noted earlier, a material property database recording the as-received material property values for each graphite type and the changes in those properties resulting from inreactor exposure must be developed. Physical, mechanical, and thermal properties of the graphite types as well as the statistical variations of those properties within the graphite billets are being characterized in support of the as-received material database.

Baseline, "as-received" material properties for each graphite type is needed to establish accurate thermal and mechanical response of the graphite core. Since material properties are expected to vary throughout the rather large graphite billets, mapping the magnitude and spatial variability is important to determining an individual component's material properties. To enable credible core designs and to support the ongoing development of a probabilistic graphite design methodology, the maximum variability within graphite components must be well characterized. A typical cutting plan illustrating the size, number, and positions of various test coupons from a graphite billet is shown in Fig. 3.2.

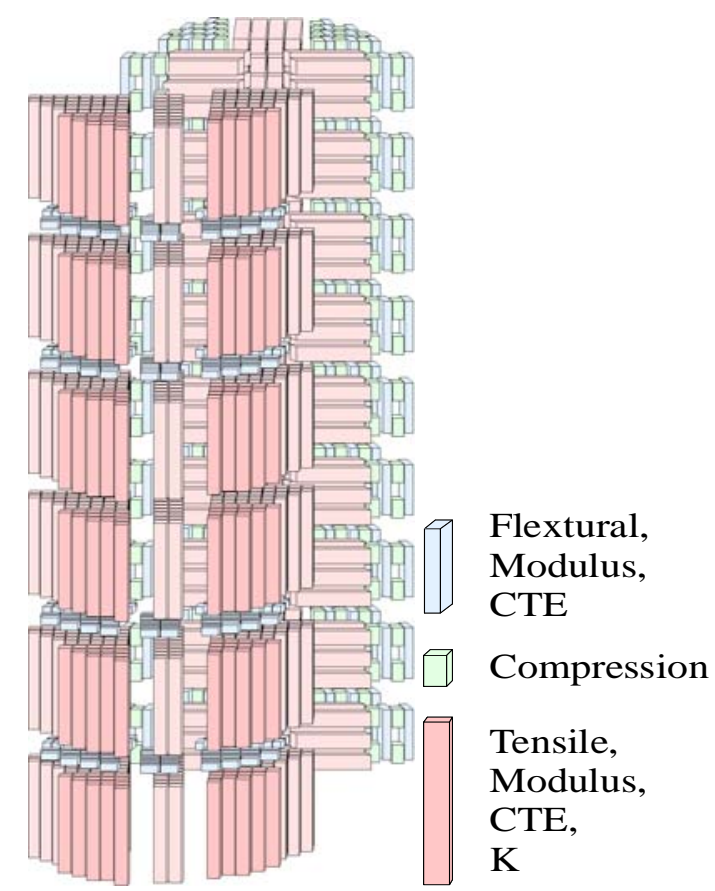

Fig. 3.2. Schematic illustrating the different types of test blanks machined from a billet and the anticipated tests associated with those test coupons.

As depicted in Fig. 3.2, a number of different tests can be conducted from the same test coupons, allowing material property relationships to be determined (i.e., the effects of bulk density on thermal conductivity values). Both "with-grain" and "against-grain" material properties are tested to map differences resulting from fabrication processes. The NGNP 
program has developed an extensive sample cutting and sectioning plan for the graphite billets to guarantee not only statistically valid sample numbers but also spatial validity so that microstructural changes within the bulk material affecting material property changes are well characterized.

Once the baseline material properties for each graphite type have been established, the irradiation-induced or enhanced changes must be determined. The most important of these properties is the irradiation-induced creep rate as a function of temperature and dose. Thermal creep of graphite is not expected at the temperatures experienced in the reactor core $\left(<1100^{\circ} \mathrm{C}\right)$. However, irradiation-induced creep in graphite is expected at these temperatures and will play a significant role in the irradiated behavior of the graphite during reactor service. A series of irradiation experiments will be required to determine the graphite response under irradiation as compared with the baseline material properties from "asreceived" graphite billets.

\subsubsection{Irradiated material property characterization}

The ATR Graphite Creep (AGC) experiments are designed to provide irradiation creep rates for moderate doses and higher temperatures of leading graphite types that will be used in the NGNP reactor design. The experiments are designed to provide not only static irradiation material property changes but also to determine irradiation creep parameters for actively stressed (i.e., compressively loaded) specimens during exposure to a neutron flux. The temperature and dose regimes covered by the AGC experiment are illustrated in Fig. 3.3.

As shown in Fig. 3.3, the dose and temperature is bounding for the prismatic reactor design (dpa 5-6 at $1100^{\circ} \mathrm{C}$ ) for both fuel and front facing reflector blocks. The dose limit of the experiment is intentionally below the expected point of turnaround for the current NGNP graphite types for normal operating temperatures. Only AGC-6 experiment (6-7 dpa at $1200^{\circ} \mathrm{C}$ ) may approach expected turnaround limits for the selected NGNP graphite types. As such, to determine when (and if) turnaround will occur for the selected NGNP graphite

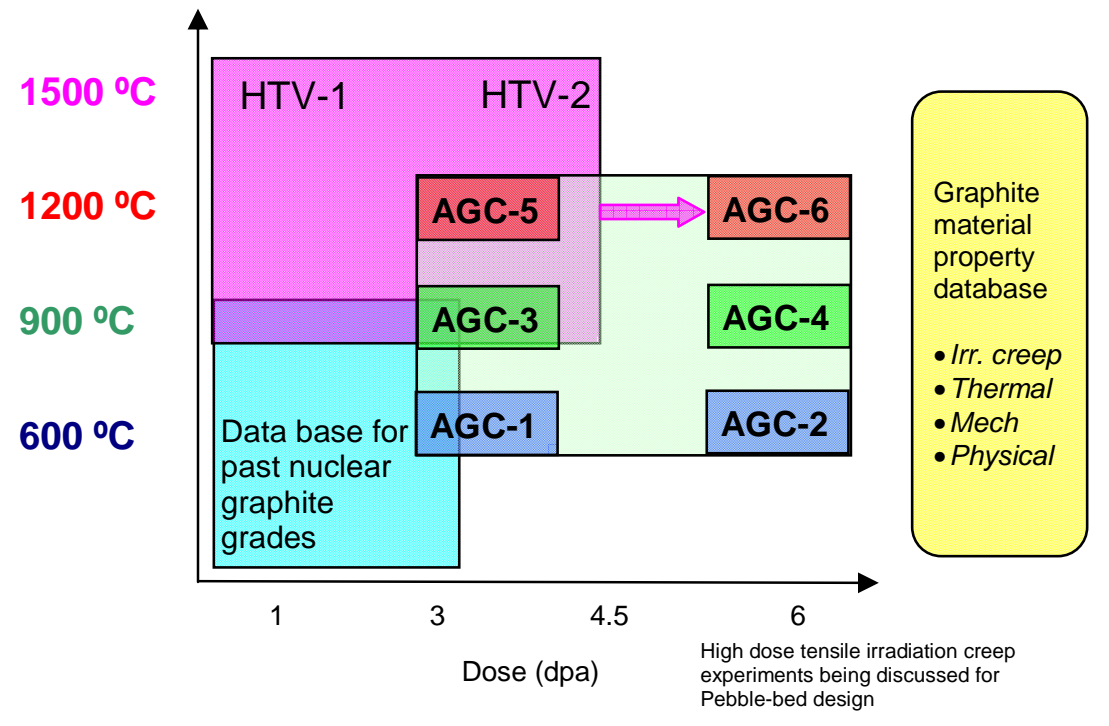

Fig. 3.3. Schematic diagram illustrating dose and temperature ranges for AGC and high-temperature vessel (HTV) experiments. 
during exposure in the AGC-6 capsule, an additional experiment-the high-temperature vessel (HTV) has been postulated. The HTV 1 and 2 capsules are simple "drop-in" capsules with the exposure parameters illustrated in Fig. 3.3. As shown, these experiments are operated at much higher temperatures (inducing faster turnaround) but at lower doses. As this is a simple dimensional change experiment to determine when turnaround may occur, the graphite is not loaded during irradiation.

The prismatic NGNP design assumes that fuel and reflector blocks can be replaced well before turnaround should occur at normal operating temperature (typically $<5-6 \mathrm{dpa}$ ). The AGC experiment should fully bound the graphite operating conditions within a prismatic design. However, the pebble-bed NGNP design assumes that the front facing reflector blocks will stay in reactor well beyond turnaround (typically 12-15 dpa), allowing minimal reactor shutdown time. While the AGC experiment will not fully bound pebble bed graphite requirements, it will certainly provide preliminary data for the first $30-40 \%$ of the expected dpa levels for these graphite components. Once the preliminary data has been established for the pebble bed graphite, high-dose experiments can be considered at a later time. Since the graphite in these experiments is expected to experience turnaround, the applied loads will need to be tensile loads.

Post-irradiation examination and testing of the irradiated samples will follow. The dimensional changes of the loaded specimens will establish the creep rate, while changes in the measured material properties of the unloaded specimens can be determined for the candidate graphite types.

\subsubsection{Modeling}

Mathematical models will be required to allow designers to assess the condition of graphite components and core structure design margins at any point in the lifetime of the reactor. These models should describe any anticipated interactions between graphite components, specifically, the behavior of the stack of graphite blocks making up the core moderator and reflector. Specific models should be able to calculate external loads imposed upon the graphite components, internal stresses resulting from radiation- and temperatureinduced dimensional changes, movement of components (i.e., dimensional clearances for control rod insertion), and estimates of residual strength both with and without environmental attack (i.e., air-ingress during off-normal event).

Modeling the behavior of a graphite core is complex and will require some fundamental understanding of the graphite physical, thermal, and mechanical behavior as a function of irradiation temperature and neutron fluence. However, the primary objective of these models is to provide the ability to calculate in-service stresses and strains in graphite components and estimate the structural integrity of the core as a whole. Thus, understanding of fundamental mechanistic material behavior during operation will be limited to those aspects required to understand the response of the entire core both during normal operation and during off-normal events (e.g., predict seismic behavior of the core). While a physics-based understanding of microstructural damage and its effects on material structure and properties will provide an initial start to estimating the amount of changes to a graphite component, the actual degree of change is unique to the specific nuclear graphite grade and these fundamental principles must be supplemented with actual experimental material property data to provide a complete analysis of the core behavior.

Finally, microstructural and even experimental material tests obtain data from small volumes of material, not large components. Behavioral models can provide point-to-point flux, temperature, and stress-state estimates for all components (or parts of components) throughout the entire core. A whole-core model will therefore use a combination of experimentally derived material properties underpinned by an understanding of the 
fundamental physics to account for all variations possible within the graphite components of the core. Consequently, a major goal is the development and validation of multi-scale models for determining the behavior of graphite core components, and whole graphite cores for use in licensing and continued operational safety assessments. This activity is considered critical to obtaining a commercial operating license for the nuclear graphite from the NRC.

\subsubsection{Standards and codification activities}

The NGNP graphite program will use the ASME codification process to verify the viability and validity of the nuclear-grade graphite used in the reactor core. The ASME simply provides an independent and rigorous method of vetting the graphite material property data and models. This decision was made with the assumption that the licensing review process should be accelerated since the regulators are already assured that the data and models were developed through an approved ASME methodology.

Recently, there has been significant activity within the ASME to develop appropriate codes for using graphite in nuclear reactor applications. This is a consensus code being prepared by an international working group of graphite experts to ensure universal acceptance by all countries worldwide. One of the significant issues being addressed by this working group is the use of a probabilistic failure methodology rather than the traditional deterministic approach that is more conservative. It is believed that a probabilistic approach is more accurate for the brittle, ceramic-like graphite than the deterministic methodology used traditionally for ductile metallic systems.

Graphite fabrication results in a distribution of flaws (i.e., pores and microcracks) throughout the graphite microstructure( Fig. 3.4). Due to the brittle nature of graphite

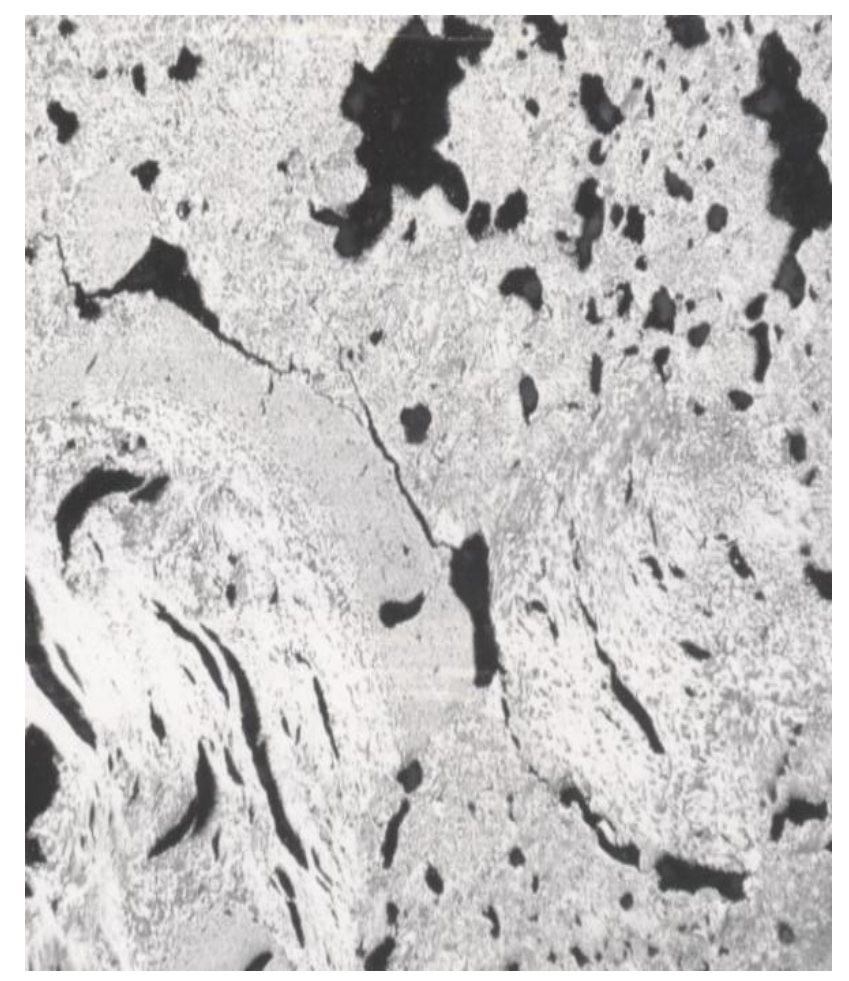

Fig. 3.4. An optical photomicrograph of the microstructure of grade $\mathrm{H}-451$ graphite revealing the presence of pores, coke filler particles, and cracks. 
failure and this distribution of flaws within the microstructure, the graphite has a distribution of ultimate strengths within the billet and from billet to billet. Deterministic design approaches that rely on a single failure load are not adequate for this type of material. Statistical or probabilistic design approaches must be used to accurately reflect the stochastic material strengths. Probabilistic design methodology combines the statistical nature of the strength-controlling flaws with the mechanics of the crack growth to allow for the multiaxial stress states, concurrent flaw populations, and component size/scaling effects.

This probabilistic design approach requires an adequate failure theory of graphite under multiaxial loads and a program that takes the statistical behavior of graphite strengths and integrates over the population of flaws to obtain survival probability. To this end, the ASME code stresses material property data of graphite over a large range of billets and lots to provide not only the statistical variability needed but also the multiaxial material properties necessary to support such a probabilistic failure methodology.

Finally, it is assumed that the ASME will only approve of a nuclear graphite material property database if it is populated with data obtained from ASTM-approved test standards. Most of the non-irradiated standards already exist with some small exceptions such as oxidation testing and fracture toughness testing. Irradiated material property standards are problematic due to the limited size of the irradiation volumes inside material test reactors. At issue is the small test specimen size necessary for irradiation tests and the statistical validity of the resulting material properties measured from these diminutive samples. A large portion of the ASTM-approved tests is affected by this issue. Consequently, there are significant activities in this area. However, it is believed that the existing ASTM standards are adequate to fully characterize these new, available candidate grades of graphite.

\subsubsection{Summary and schedule}

The NGNP graphite program has selected six candidate graphite types viewed as commercially available. Both non-irradiated and irradiated characterization programs are actively gathering data on these candidate graphite types. Irradiation-induced creep is of primary importance to determine the long-term radiation stability of these candidate graphite types. Probabilistic design methodology is being pursued for ASME codification of graphite using multi-scale whole core behavior models. Serious consideration must be given to establishing alternative coke sources. Currently, no coke source is capable of sustaining long-term (60+ years) consistent graphite production. Graphite recycle and reuse options must also be explored.

The proposed schedule for the NGNP graphite technology program is given in Fig. 3.5. The graphite technology development activities should be complete by 2016 .

\subsubsection{Ceramic Materials Selection and Issues for Thermal Insulation}

High-temperature insulation must be used throughout the reactor system and the power conversion unit notably in the hot duct, upper plenum shroud, SCS helium inlet plenum, and turbocompressor. These materials are typically considered for lifetime operation. The insulation is required to retain its resiliency and physical characteristics during normal operating and conduction cooldown accident conditions.

Operating conditions for insulation include low neutron fluence $(<0.01 \mathrm{dpa})$ and gamma flux and high temperatures. The currently envisioned design will require insulation to operate at normal and off-normal temperatures of up to or beyond $1000^{\circ} \mathrm{C}$. Mechanical loads on the thermal insulation result from differential thermal expansion, acoustic vibration, seismic vibration, fluid flow friction, and system pressure changes. Typical operating conditions are listed in Table 3.4. 


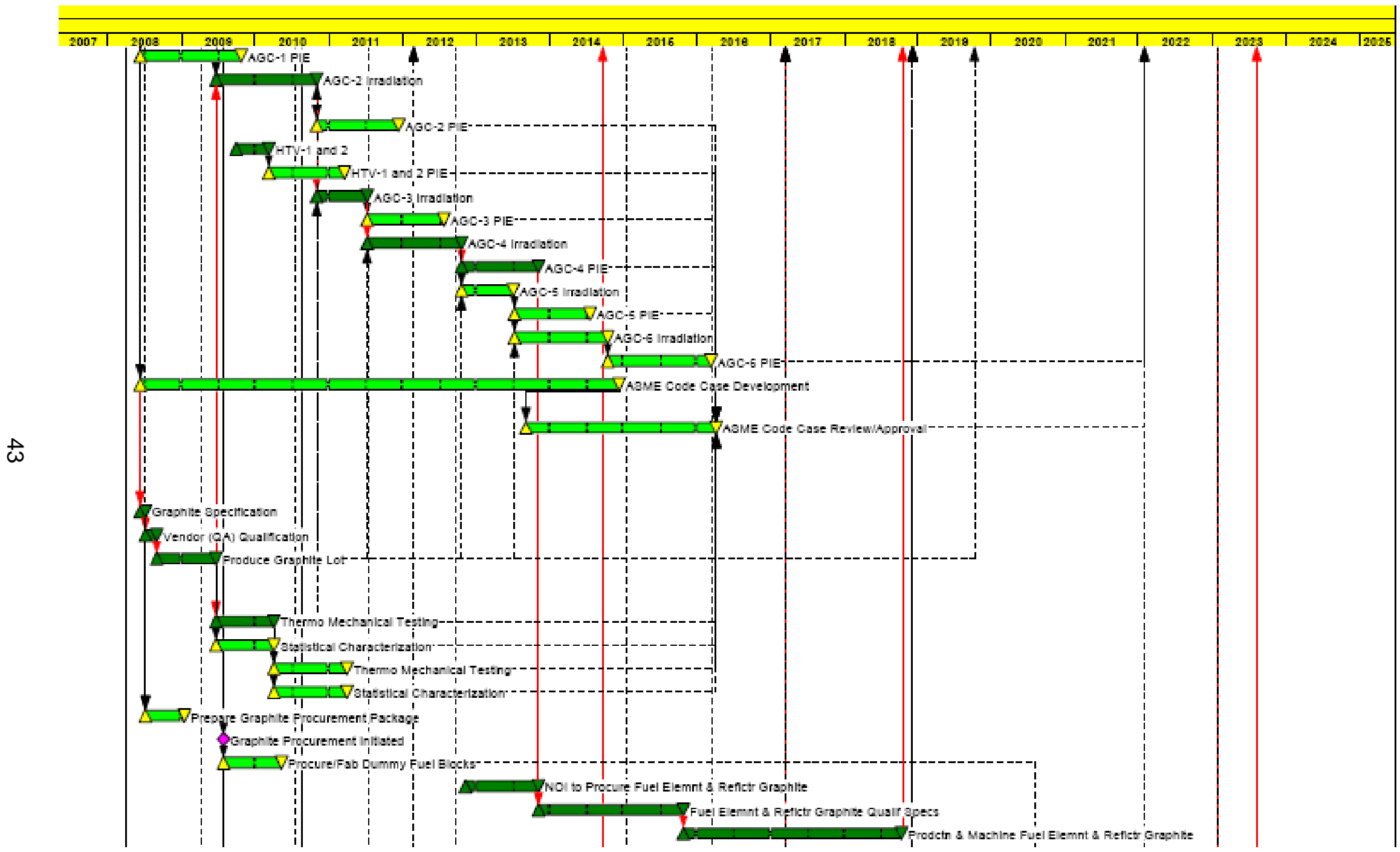

Fig. 3.5. Schematic of master schedule for graphite R\&D effort. ${ }^{32}$ 
Table 3.4. Conditions affecting materials selection for reactor internals thermal insulation and potential candidate NGNP materials

\begin{tabular}{|c|c|c|c|c|c|c|}
\hline \multirow[b]{2}{*}{ Component } & \multirow[b]{2}{*}{ Subcomponents } & \multicolumn{3}{|c|}{ Normal NGNP operating conditions } & \multirow[b]{2}{*}{$\begin{array}{l}\text { Abnormal operating } \\
\text { conditions }\end{array}$} & \multirow[b]{2}{*}{$\begin{array}{c}\text { Potential Candidate NGNP } \\
\text { Materials }\end{array}$} \\
\hline & & $\begin{array}{l}\text { Nominal } \\
\text { Temp. } \\
\left({ }^{\circ} \mathrm{C}\right)\end{array}$ & $\begin{array}{c}\text { Neutron } \\
\text { fluence with } \\
\mathrm{E} \geq 0.1 \mathrm{MeV}\end{array}$ & Medium & & \\
\hline $\begin{array}{l}\text { SCS unit } \\
\text { metalworks } \\
\text { Insulation }\end{array}$ & Conical shell at SCS HX & 950 & $\begin{array}{l}3 \cdot 10^{16} \mathrm{~cm}^{-2} \\
\text { per } 60 \text { years }\end{array}$ & Helium & $\begin{array}{l}>1000^{\circ} \mathrm{C} \text { at start of cool down. } \\
\text { Then } \sim 950^{\circ} \mathrm{C}\end{array}$ & $\begin{array}{l}\text { Carbon-carbon composite } \\
\text { canisters with refractory } \\
\text { fibrous mat }\end{array}$ \\
\hline \multirow{3}{*}{ Hot gas duct } & $\begin{array}{l}\text { Outer shell of thermal } \\
\text { insulation element unit }\end{array}$ & 950 & \multirow{2}{*}{$\begin{array}{l}2 \cdot 10^{17} \mathrm{~cm}^{-2} \\
\text { per } 60 \text { years }\end{array}$} & \multirow{2}{*}{ Helium } & $950^{\circ} \mathrm{C}$ at start of cooldown & $\begin{array}{l}\text { Carbon-carbon composite } \\
\text { canisters with refractory } \\
\text { fibrous mat }\end{array}$ \\
\hline & $\begin{array}{l}\text { Inner shell of thermal } \\
\text { insulation element unit }\end{array}$ & 650 & & & $950^{\circ} \mathrm{C}$ at start of cooldown & $\begin{array}{l}\text { Carbon-carbon composite } \\
\text { canisters with refractory } \\
\text { fibrous mat }\end{array}$ \\
\hline & Thermal Insulation & $600-950$ & & & $950^{\circ} \mathrm{C}$ at start of cool down & $\begin{array}{l}\text { (Mix of refractory fibers held } \\
\text { with high temperature screen } \\
\text { and wire stays.) }\end{array}$ \\
\hline \multirow{6}{*}{$\begin{array}{l}\text { In-vessel } \\
\text { metalworks } \\
\text { Insulation }\end{array}$} & $\begin{array}{l}\text { Metal support bottom Plate } \\
\text { insulation }\end{array}$ & \multirow{3}{*}{600} & \multirow{3}{*}{$\begin{array}{l}2.0 \cdot 10^{17} \mathrm{~cm}^{-2} \\
\text { per year }\end{array}$} & \multirow{3}{*}{ Helium } & $\sim 700^{\circ} \mathrm{C}$ & $\begin{array}{l}\text { Carbon-carbon composite } \\
\text { blocks }\end{array}$ \\
\hline & $\begin{array}{l}\text { SCS entrance structural } \\
\text { tubes Insulation }\end{array}$ & & & & $\begin{array}{l}>1000^{\circ} \mathrm{C} \text { at start of cool down. } \\
\text { Then } \sim 950^{\circ} \mathrm{C}\end{array}$ & $\begin{array}{l}\text { Carbon-carbon composite } \\
\text { canisters with refractory } \\
\text { ceramic fiber mats }\end{array}$ \\
\hline & $\begin{array}{l}\text { Upper Plenum Shroud } \\
\text { Insulation }\end{array}$ & & & & $\begin{array}{l}>1000^{\circ} \mathrm{C} \text { at start of cool down. } \\
\text { Then } \sim 950^{\circ} \mathrm{C}\end{array}$ & $\begin{array}{l}\text { Carbon-carbon composite } \\
\text { canisters with refractory } \\
\text { ceramic fiber mats }\end{array}$ \\
\hline & Ceramic Floor Block & 600 & $\begin{array}{l}4.5 \cdot 10^{16} \mathrm{~cm}^{-2} \\
\text { per year }\end{array}$ & Helium & $600^{\circ} \mathrm{C}$ & $\begin{array}{l}\text { Graphite, Alumina, Mullite, } \\
\text { Composite }\end{array}$ \\
\hline & $\begin{array}{l}\text { Top Insulator } \\
\text { Block }\end{array}$ & 700 & $\begin{array}{l}1.5 \cdot 10^{16} \mathrm{~cm}^{-2} \\
\text { per year }\end{array}$ & Helium & $>1000^{\circ} \mathrm{C}$ & $\begin{array}{l}\text { Graphite, Alumina, Mullite, } \\
\text { Composite }\end{array}$ \\
\hline & Bottom Insulator Block & 1050 & $\begin{array}{l}1.5 \cdot 10^{16} \mathrm{~cm}^{-2} \\
\text { per year }\end{array}$ & Helium & $600^{\circ} \mathrm{C}$ & $\begin{array}{l}\text { Graphite, Alumina, Mullite, } \\
\text { Composite }\end{array}$ \\
\hline
\end{tabular}




\subsubsection{Fibrous insulation}

Fibrous insulation was used in The Fort Saint Vrain HTGR and in other gas reactors in Germany and Japan. Test programs to support the acquisition of design and performance data were conducted on Kaowool (mullite) and Quartz-et-Silica fibrous mats. Limited irradiation effects test data is available. Tests to determine fatigue properties as a function of acoustic noise were planned but not conducted.

Insulation design surveys have indicated that a suitable insulation system, where significant structural support is not required, for NGNP applications is the use of $\mathrm{Al}_{2} \mathrm{O}_{3}$ and $\mathrm{SiO}_{2}$ mixed ceramic fiber mats $\left(\mathrm{K}_{\mathrm{th}}<0.1 \mathrm{~W} / \mathrm{m}-\mathrm{K}\right)$ contained between metallic or carboncarbon composite cover plates attached to the primary structure that requires insulation. However, the operating normal and off-normal temperatures are aggressive for application of the Kaowool. As example, the pumpable Kaowool temperature limit for continuous operation is $1093^{\circ} \mathrm{C}$. Maximum temperature rating is typically $1260^{\circ} \mathrm{C}$ for the highest performing $\mathrm{Al}_{2} \mathrm{O}_{3}$ and $\mathrm{SiO}_{2}$ mixed ceramic fiber mat insulation. Typically, by reducing the fraction of silica in the wool, or through simultaneous reduction of silica and addition of $\mathrm{ZrO}_{2}$, insulating mats can achieve continuous and maximum operating temperatures of 1300 and $1400^{\circ} \mathrm{C}$, respectively. High-purity alumina mat can achieve operating temperatures above $1500^{\circ} \mathrm{C}$. However, these higher temperature mats would not take advantage of previous data and experience gained with the Kaowool product, therefore a premium would be paid for their use.

The insulation canisters are in direct contact with the hottest gas conditions in the reactor. Thus, the materials chosen for these canisters will need to withstand up to $1000^{\circ} \mathrm{C}$ for 60 years or higher during a loss of flow condition (LOFC) followed by a conduction cooldown transient. For this reason, non-metallic materials such as carbon-carbon composites may be required for some of these canisters. The metallic canister materials would be chosen from the materials described previously for very high temperature service. The carbon-carbon composites will be chosen from those materials identified in Table 3.4.

\subsubsection{Structural insulating materials}

The insulating materials previously discussed require fairly modest mechanical performance, therefore low specific density fibrous materials can be considered. However, for applications such as the top and bottom insulator blocks, the ceramic floor block, and possibly the canisters holding the fibrous insulation of the hot gas duct, the mechanical loading and need for creep resistance are such that monolithic or composite materials are needed. Typical operating parameters for these systems are also provided in Table 3.4. Given that the operating temperatures are modest and the neutron fluence is low, achieving a lifetime material appears a desirable, attainable goal. Graphite is a potential candidate material for both top and bottom insulator blocks. The bottom insulator block will most likely be a refractory ceramic. However, consideration will be given to improved low-thermal conductivity graphites for all three functions along with commercially available refractory ceramics such as alumina, mullite and composite materials. Assuming a high-quality, highpurity commercial material, radiation effects will not be an issue. The properties that will drive the selection are the non-irradiated thermophysical properties in particular thermal conductivity, compressive strength and fracture toughness, and cost. When comparing full density brick forms of mullite and alumina, significant differences in properties are noted. In particular, high-density alumina brick will possess significantly higher thermal conductivity as compared to mullite (and very similar to low-conductivity graphites) but exhibit extremely high compressive stress and somewhat higher fracture toughness as compared to mullite. 
Creep, which will be of particular importance, will also be lower for alumina as compared with the mullite.

\subsubsection{Expected research, testing, and qualification needs for ceramic insulation materials}

Detailed tasks and schedules for ceramic insulation testing have not been prepared, as this is an overall lower priority than the metals and graphite research programs. The first step in developing the research program on ceramic insulation materials for the NGNP will be a comprehensive and detailed review of the potential candidate materials identified in Table 3.4. Preparation of a materials test program in support of ceramic insulation materials requires knowledge and understanding of the materials requirements dictated by the operating conditions of those components.

Data on the manufacture and performance of fibrous insulation are needed to ensure that the selected materials are capable of lasting for the life of the plant. The data include physical properties (heat resistance, heat conductivity, and heat capacity), long-term thermal and compositional stability, mechanical strength at temperature, resistance to pressure drop, vibrations and acoustic loads, radiation resistance, corrosion resistance to moistureand air-helium mixtures, stability to dust release and gas release, thermal creep, and manufacturing tolerances and mounting characteristics. The acquisition of these data requires testing of insulation specimens or small assemblies of thermal insulation panels and application of appropriate ASTM standards. This standards development work will be supported within this program. Moreover, application of current non-destructive evaluation techniques, especially in support of the monolithic insulators, is included within this test plan. Specific test rigs and facility requirements include helium flow, vibration, and acoustic test equipment as well as an irradiation facility and hot cell. Prototype assemblies testing is not planned to include neutron irradiation. However, this decision will be made following the neutron and gamma irradiation testing.

\subsubsection{Reactor Structural Composites Materials Selection and Issues}

The use of continuous ceramic fiber-reinforced ceramic-matrix composite (ceramic composite) is desired for many applications within the reactor because of its strength retention at high temperatures and its exceptional rigidity. For example, ceramic composite will likely be needed for core restraint structures and ultimately components of the control systems for a prismatic NGNP because metallic materials may not withstand the high temperature found in the core.

\subsubsection{Candidate ceramic composite materials}

The anticipated ceramic composite material components and operating conditions of the NGNP are listed in Table 3.5.

Ceramic composite materials are typically designed and manufactured for specific applications, and their off-the-shelf availability is limited. The composite architecture (i.e., fiber type, fraction, orientation, lay-up) and processing conditions are selected to tailor the composite material for a specific application. Thus, prototype components must be produced from which material test specimens will be cut and subjected to the appropriate thermal and irradiation conditions in the materials test program. However, for example, in applications such as the elements of the core stabilizing structure of the PBMR Pty Pilot Plant, off-theshelf carbon fiber composite will be used as the thermo-mechanical properties of materials and are more than adequate for the application. 
Table 3.5. Conditions affecting materials selection for structural composites and potential candidate NGNP materials

\begin{tabular}{|c|c|c|c|c|c|c|}
\hline \multirow[b]{2}{*}{ Component } & \multirow[b]{2}{*}{ Subcomponents } & \multicolumn{3}{|c|}{ Normal NGNP operating conditions } & \multirow[b]{2}{*}{$\begin{array}{l}\text { Abnormal } \\
\text { operating } \\
\text { conditions }\end{array}$} & \multirow{2}{*}{$\begin{array}{l}\text { Potential } \\
\text { alternative } \\
\text { composite } \\
\text { candidate } \\
\text { materials } \\
\end{array}$} \\
\hline & & $\begin{array}{l}\text { Nominal } \\
\text { temp. } \\
\left({ }^{\circ} \mathrm{C}\right)\end{array}$ & $\begin{array}{c}\text { Neutron } \\
\text { fluence with } \\
\mathrm{E} \geq 0.1 \mathrm{MeV}\end{array}$ & Medium & & \\
\hline CPS drive & $\begin{array}{l}\text { Control rod guide } \\
\text { tube }\end{array}$ & $\begin{array}{l}600 \text { at } \\
\text { CRD to } \\
\text { UPS } \\
\text { Interface }\end{array}$ & $\begin{array}{c}3 \cdot 10^{16} \mathrm{~cm}^{-2} \\
\text { per year }\end{array}$ & Helium & $\begin{array}{l}\text { Working fluid } \\
\text { temperature } \\
\text { in cooldown } \\
\text { mode } \\
\text { through } \\
\text { RCCS can } \\
\text { increase to } \\
>1000^{\circ} \mathrm{C} \\
\text { within } 100 \mathrm{~h}\end{array}$ & $\begin{array}{l}\mathrm{C}_{f} / \mathrm{C} \\
\mathrm{SiC}_{f} / \mathrm{SiC}\end{array}$ \\
\hline $\begin{array}{l}\text { SCS unit } \\
\text { metalwork }\end{array}$ & $\begin{array}{l}\text { Conical shell at } \\
\text { SCS HX }\end{array}$ & 950 & $\begin{array}{l}3 \cdot 10^{16} \mathrm{~cm}^{-2} \\
\text { per } 60 \text { years }\end{array}$ & Helium & $\begin{array}{l}>1000^{\circ} \mathrm{C} \text { at } \\
\text { start of cool } \\
\text { down. } \\
\text { Then } \sim 950^{\circ} \mathrm{C}\end{array}$ & $\mathrm{C}_{f} / \mathrm{C}$ \\
\hline Hot gas duct & $\begin{array}{l}\text { Outer shell of } \\
\text { thermal insulation } \\
\text { element unit } \\
\text { Inner shell of } \\
\text { thermal insulation } \\
\text { element unit }\end{array}$ & 950 & $\begin{array}{l}2 \cdot 10^{17} \mathrm{~cm}^{-2} \\
\text { per } 60 \text { years }\end{array}$ & Helium & $\begin{array}{l}950^{\circ} \mathrm{C} \text { at } \\
\text { start of } \\
\text { cooldown } \\
950^{\circ} \mathrm{C} \text { at } \\
\text { start of } \\
\text { cooldown }\end{array}$ & $\mathrm{C}_{f} / \mathrm{C}$ \\
\hline $\begin{array}{l}\text { Vessel } \\
\text { internals }\end{array}$ & $\begin{array}{l}\text { SCS entrance } \\
\text { tubes and } \\
\text { chamber } \\
\text { insulation } \\
\text { assembly } \\
\text { Upper core } \\
\text { restraint }\end{array}$ & 600 & $\begin{array}{l}2.0 \cdot 10^{17} \mathrm{~cm}^{-2} \\
\text { per year }\end{array}$ & Helium & $\begin{array}{l}>1000^{\circ} \mathrm{C} \text { at } \\
\text { start of cool } \\
\text { down. } \\
\text { Then } \sim 950^{\circ} \mathrm{C} \\
\sim 950^{\circ} \mathrm{C}\end{array}$ & $\mathrm{C}_{f} / \mathrm{C}$ \\
\hline
\end{tabular}

Types of ceramic composites presently considered for application in the NGNP are carbon fiber, carbon matrix $\left(\mathrm{C}_{f} / \mathrm{C}\right)$, and silicon carbide fiber, silicon carbide matrix $\left(\mathrm{SiC}_{f} / \mathrm{SiC}\right)$ composites. A fortunate aspect for ceramic composites is that existing data has shown that the potential composite components that are not in the high-flux regions of the reactor core are not expected to experience neutron exposures high enough to cause any problems with strength, swelling, thermal conductivity, etc., in $\mathrm{C}_{f} / \mathrm{C}$. In Fig. 3.6, this irradiation/temperature regime corresponds to a Class 1 composite. Within the Class 1 regime, existing data has shown that $\mathrm{C}_{\mathrm{f}} / \mathrm{C}$ can easily withstand these neutron doses in all the components. However, for the higher dose, high-temperature application such as control rod sheaths, or so-called Class 2 composite application, recent data indicates that $C_{f} / C$ are unlikely to be lifetime components and therefore have little benefit over unstable structural alloys such as Alloy $800 \mathrm{H}$. However, data indicates that nuclear-grade $\mathrm{SiC}_{\mathrm{f}} / \mathrm{SiC}$ composites are radiation stable within the Class 2 composite regime and therefore considered candidate lifetime materials. 


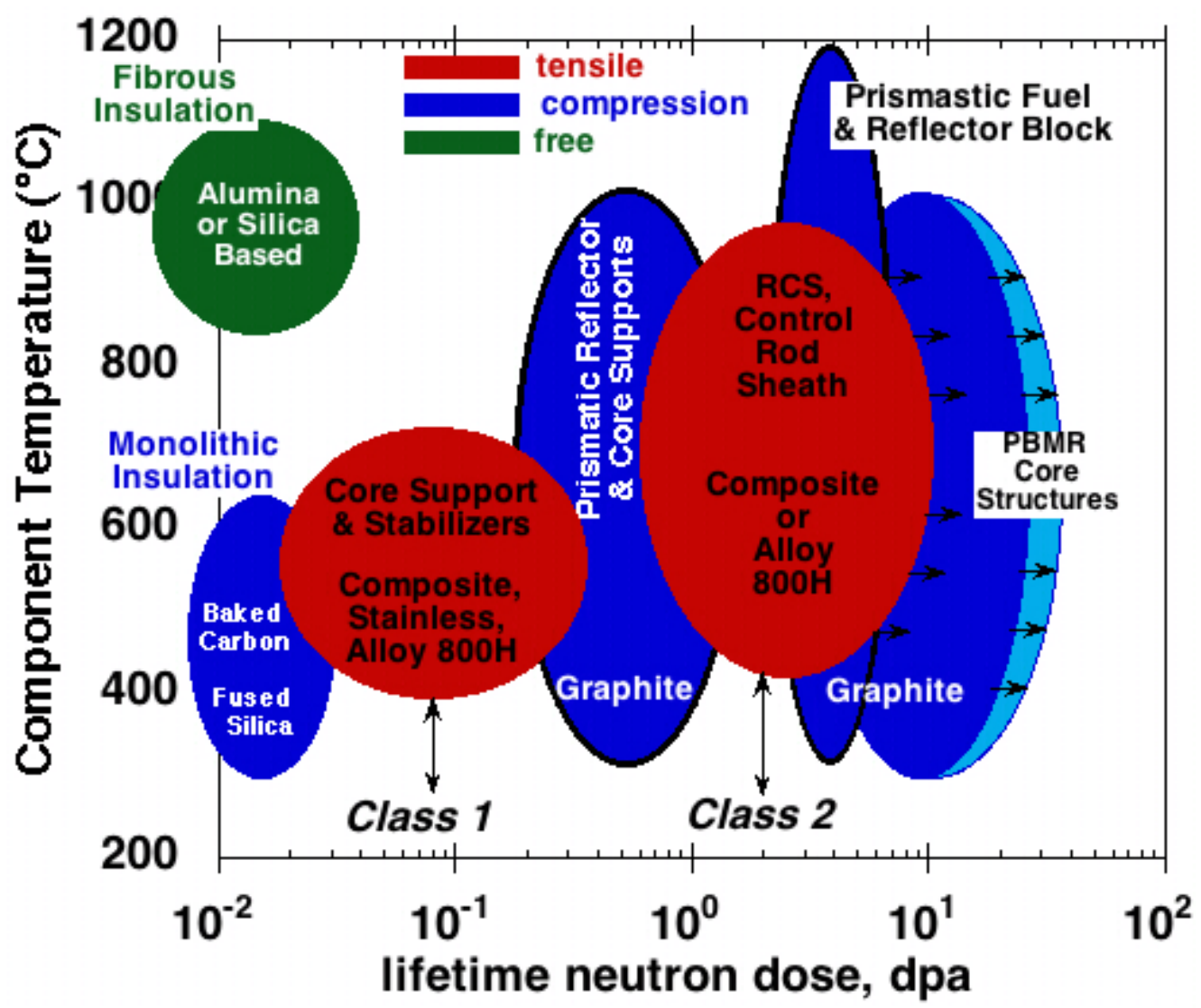

Fig. 3.6. Dose temperature classification for various components discriminating Class 1 and Class 2 composites.

There is recent evidence that control rods fabricated from $\mathrm{SiC}_{\mathrm{f}} / \mathrm{SiC}$ composites survive for the full reactor lifetime within the high-radiation environment within the core. Early work in the NGNP Composite R\&D program has eliminated critical technical uncertainty in the applicability of $\mathrm{SiC}_{\mathrm{f}} / \mathrm{SiC}$ composites to control rods. Therefore, the technical development plan for the ceramic composite will include the qualification of $\mathrm{SiC}_{f} / \mathrm{SiC}$ composites in addition to $\mathrm{C}_{\mathrm{f}} / \mathrm{C}$.

A preliminary list of selection factors for primary ceramic composites candidate materials is provided in Table 3.6.

\subsubsection{Expected research, testing, and qualification needs for NGNP structural composites}

Currently there are several manufacturers of $\mathrm{C}_{\mathrm{f}} / \mathrm{C}$ composites that may be suitable for reactor-core components. However, these manufacturers have not qualified any of their recent high-performance materials for nuclear applications. Additionally, large-sized $\mathrm{SiC}_{f} / \mathrm{SiC}$ composites are not as available as $\mathrm{C}_{\mathrm{f}} / \mathrm{C}$ composites and much of the knowledge about the behavior of $\mathrm{SiC}_{f} / \mathrm{SiC}$ composites has been generated with laboratory-sized samples using simple testing conditions. Moreover, because these composite materials have undergone rapid development within the last 10 years, only limited data are available for the newest, radiation-resistant materials. Therefore, an extensive effort for data generation will be needed for composite components. 
Table 3.6. Relative strengths of ceramic composite materials for NGNP applications

\begin{tabular}{|c|c|}
\hline Pros & Cons \\
\hline \multicolumn{2}{|c|}{$\begin{array}{l}\text { C } C_{f} / C \text { Composites } \\
\text { (Note: Replacement for super alloys. Could be used for guide tubes } \\
{[\sim 10 \text { feet long, telescope feature] and the upper core restraint structure) }}\end{array}$} \\
\hline $\begin{array}{l}\text { Good material for accident situation } \\
\text { Eliminates metal from the core }\end{array}$ & $\begin{array}{l}\text { More radiation damage/shrinkage than } \mathrm{SiC}_{\mathrm{f}} / \mathrm{SiC} \\
\text { Qualification-different makes require a new } \\
\text { qualification. ASME specification issue }\end{array}$ \\
\hline $\begin{array}{l}\text { Good Residual properties (e.g., strength). Strength } \\
\text { and fracture resistance is greater than graphite } \\
\text { Good industrial experience }\end{array}$ & Lack of design criteria \\
\hline \multicolumn{2}{|c|}{$\begin{array}{c}\mathrm{SiC}_{\mathrm{f}} / \mathrm{SiC} \text { Composites } \\
\text { (Note: for use in high-radiation environment) }\end{array}$} \\
\hline $\begin{array}{l}\text { Good oxidation resistance } \\
\text { Higher cracking stress than } \mathrm{C}_{f} / \mathrm{C} \\
\text { Greater radiation damage resistance than } \mathrm{C}_{\mathrm{f}} / \mathrm{C} \\
\text { Longer life: control rod needs no change-out } \\
\text { Little properties variations among different makes }\end{array}$ & $\begin{array}{l}\text { Higher cost than } C_{f} / C \\
\text { Less industrial experience than } C_{f} / C \\
\text { ASME specification issue } \\
\text { Lack of design criteria }\end{array}$ \\
\hline
\end{tabular}

For composite materials, there are limited mechanical and thermal-physical property data at elevated temperatures that will need to be augmented. In addition, the manufacturers and their prime candidate materials must be examined for repeatability and quality. More importantly, the particular composite architectures that will be evaluated in this program have never been examined in this application. Thus, the composite components must be baselined to determine if they indeed meet the specification required for both thermal and mechanical properties. The scale-up of parts will be aided by stress-analysis codes, which are quite mature for $\mathrm{C}_{\mathrm{f}} / \mathrm{C}$; however, the codes will need to be adapted for the specific fiber architectures selected.

The first experimental areas for research in this program were to examine the two most potentially life-limiting processes of irradiation effects and oxygen effects. The irradiation effects program performed a side-by-side comparison of the two most radiation-resistant forms of $\mathrm{C}_{f} / \mathrm{C}$ and $\mathrm{SiC}_{f} / \mathrm{SiC}$ currently available. Following a pre-irradiation evaluation of $\mathrm{SiC}_{f} / \mathrm{SiC}$ tubular structures, irradiation to NGNP-relevant doses on statistically meaningful populations of samples was carried out. In parallel, an environmental effects study was initiated on $\mathrm{SiC}_{f} / \mathrm{SiC}$ to ascertain the stability of the fiber matrix interface in NGNP atmosphere. Additionally, the primary failure mode under stress was studied to determine whether the composite tubular structures can withstand long-term loading produced by NGNP control rod applications.

The graphite composite studied was manufactured by Fiber Materials Inc. (FMI-222) and is a balanced weave, pitch fiber, pitch matrix composite. It has been selected because of its high-quality and radiation-effects database. SiC composites for this study were fabricated by Hypertherm in collaboration with ORNL, Idaho National Laboratory, and Pacific Northwest National Laboratory. Both flat plate and tubular geometries were studied. The architecture to be manufactured was studied in the initial phases of the collaboration and was decided to be bi-axial and tri-axial braiding. The fiber used was Hi-Nicalon Type-S, based on its excellent radiation performance. The matrix was fully crystalline beta-SiC deposited by chemical vapor infiltration.

The first phase of the composite R\&D effort above focuses on providing verification of the viability of the composite control rod concept. The following R\&D phase will primarily provide the engineering data that are more relevant to the reactor system design and the 
confidence regarding the practical reliability of the NGNP-grade $\mathrm{C}_{f} / \mathrm{C}$ and $\mathrm{SiC}_{\mathrm{f}} / \mathrm{SiC}$ in the reactor environment and the accident scenario. For these purposes, properties and mechanisms governing the lifetime and reliability will be thoroughly characterized, including aging, creep/fatigue, fracture toughness, and the irradiated lifetime envelope. Fortunately, the effect of neutron irradiation at very high temperatures on various mechanical and thermophysical properties was positively addressed; hence, the remaining neutron irradiation studies may not have to be very extensive. Full-scale prototype components will also be fabricated with the most promising constituents/architectures for both $\mathrm{C}_{\mathrm{f}} / \mathrm{C}$ and $\mathrm{SiC}_{f} / \mathrm{SiC}$ and will be subjected to the complete baseline characterization. Continued support to the ASTM testing guidelines and the ASME code development is also essential in all R\&D phases. A technical development plan for ceramic composite component qualification will be established based on the most up-to-date information at the end of the first phase R\&D effort.

\section{Irradiation program}

Long-term stability, strength, and thermal properties. Irradiation was carried out in the peripheral target tube position of the High Flux Isotope Reactor (HFIR). The irradiation matrix is given in Table 3.7. This matrix compliments ongoing ORNL fusion irradiations $18 \mathrm{~J}$ ( $7 \mathrm{dpa}, 800-1300^{\circ} \mathrm{C}$, data available $>2008$ ) and the Futurix-Ml irradiation being conducted in the Phoenix reactor $\left(>50 \mathrm{dpa}, \sim 1000^{\circ} \mathrm{C}\right.$, data available $\left.>2009\right)$. The primary target irradiation temperature $\left(800^{\circ} \mathrm{C}\right)$ was selected based on the draft NGNP materials plan. ${ }^{5}$ Additional irradiation of $\mathrm{C}_{\mathrm{f}} / \mathrm{C}$ composite samples newly fabricated in NGNP program was considered but was not executed. The highest dose group capsules of $\mathrm{SiC} / \mathrm{SiC}$ composite are still under irradiation. If desirable, a subset of those capsules could be irradiated to a higher dose for little extra cost. Data from these materials would be available 2009 .

Time-dependent deformation and failure. It is expected that the NGNP control rods will be subjected to low-stress, long-duration tensile loads within a high-temperature irradiation environment. A significant concern for these materials is creep or environmental degradation under combined load and irradiation. It will be necessary to first characterize the potential time-dependent deformation and failure behavior of composite materials in the absence of irradiation with helium atmospheres containing oxygen impurity levels that bracket the expected operating conditions for the NGNP. Irradiation creep tests in prototypic reactor environments are presently considered unnecessary due to the lack of steady-state irradiation creep deformation in the relevant temperature range and the small stress magnitude anticipated to occur during normal operation.

Table 3.7. HFIR irradiation matrix and status

\begin{tabular}{|c|c|c|c|c|c|}
\hline $\begin{array}{c}\text { Capsule } \\
\text { group }\end{array}$ & Material & $\begin{array}{c}\text { Temperature } \\
\left({ }^{\circ} \mathrm{C}\right)\end{array}$ & $\begin{array}{c}\text { Planned } \\
\text { dose } \\
\text { (dpa) }\end{array}$ & $\begin{array}{c}\text { Actual } \\
\text { dose } \\
\text { (dpa) }\end{array}$ & Status \\
\hline BS1 & \multirow{3}{*}{$\mathrm{SiC}_{f} / \mathrm{SiC}$} & \multirow{3}{*}{800} & 10 & $\sim 10$ & $\mathrm{PIE}^{a}$ complete \\
\hline BS2 & & & 20 & $\sim 20$ & In reactor \\
\hline BS3 & & & 30 & $>30$ & In reactor \\
\hline \multirow{2}{*}{$\mathrm{BC} 1$} & \multirow{5}{*}{$\mathrm{C}_{f} / \mathrm{C}$} & \multirow{5}{*}{800} & \multirow{2}{*}{10} & 4.1 & PIE complete \\
\hline & & & & 7.3 & PIE complete \\
\hline $\mathrm{BC2}$ & & & 20 & 9.5 & PIE complete \\
\hline \multirow{2}{*}{ BC3 } & & & \multirow{2}{*}{30} & 12 & In cooling \\
\hline & & & & 15 & In cooling \\
\hline
\end{tabular}

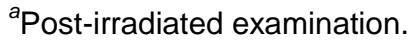


In the first phase of the program, time-dependent deformation and failure of $\mathrm{SiC}$ composite samples in braided architecture was proven in the laboratory setting. The techniques for such testing were validated experimentally and by comparison with the ongoing modeling at PNNL. An experimental program will be mounted to determine the outof-pile creep response for samples of relevant geometries in future program.

As an extension of this validation study, the sensitivity of composites to low-level impurities will be included. Long-term environmental effects derived from impurities such as oxygen, carbon dioxide, or moisture must be considered in terms of composite lifetime evaluation. Experimental and modeling data on $\mathrm{SiC} / \mathrm{SiC}$ tubular structures, especially in oxygen-containing environments, will be required similar to current studies on $\mathrm{C}_{\mathrm{f}} / \mathrm{C}$ composite structures.

Environmental effects. The high-purity helium environment presumed for the NGNP provides some interesting issues for materials degradation at high temperatures.

Carburization of metals is observed in low-oxygen-potential environments but is reduced in high-oxygen-potential environments. Control of the oxygen potential is seen as an effective means of reducing carburization of metals and alloys in the NGNP, but the effects of increased oxygen potential on the corrosion rates of $\mathrm{SiC}_{f} / \mathrm{SiC}$ and $\mathrm{C}_{f} / \mathrm{C}$ will need to be established. A focus of this research will be to determine the corrosion mechanisms and rates associated with degradation of the fiber/matrix interphase in the $\mathrm{SiC}_{f} / \mathrm{SiC}$ and $\mathrm{C}_{f} / \mathrm{C}$ materials. This has been shown to be the critical mechanism that shifts the degradation or failure modes from fiber creep domination to interphase degradation. Testing and modeling of newer $\mathrm{SiC}_{f} / \mathrm{SiC}$ will have to be performed to generate a failure mechanism map using simulated HTGR gas environments.

Typical simulated advanced HTGR helium chemistries used in various previous test programs are shown in Table 3.1. As shown, the main impurities are $\mathrm{H}_{2}, \mathrm{H}_{2} \mathrm{O}, \mathrm{CO}$, and $\mathrm{CH}_{4}$. The hot graphite core is considered as reacting with all free $\mathrm{O}_{2}$ and much of the $\mathrm{CO}_{2}$ to form $\mathrm{CO}$, and with $\mathrm{H}_{2} \mathrm{O}$ to form $\mathrm{CO}$ and $\mathrm{H}_{2}$. In addition, in cooler regions of the core, $\mathrm{H}_{2}$ reacts with the graphite via radiolysis to produce $\mathrm{CH}_{4}$. The overall stability of the proposed helium environment that will be representative of the NGNP must be evaluated in order to ensure that testing proposed is performed in environments that have consistent chemical potentials. Therefore, testing of both the helium environment to be used for mechanical properties and general corrosion evaluations of the candidate materials to establish their overall compatibility with that environment will be performed at temperatures up to at least $50^{\circ} \mathrm{C}$ above the proposed operating temperature for the $\mathrm{SiC}_{\mathrm{f}} / \mathrm{SiC}$ materials.

Creep-crack growth studies on $\mathrm{SiC}_{f} / \mathrm{SiC}$ composite bars will be used to investigate the degradation mechanisms at $1000^{\circ} \mathrm{C}$ in the simulated NGNP environment. Concurrent thermo-gravimetric measurements will be used to study environmental mass loss and corrosion mechanisms. A mechanical-chemical model of creep crack growth in $\mathrm{SiC}_{f} / \mathrm{SiC}$, which has been developed at PNNL, will be used to calculate crack growth rates and compare them to measured growth rates. ${ }^{35,36}$ Life-prediction models for $\mathrm{SiC}_{f} / \mathrm{SiC}$ in NGNP environments will be constructed and tested based on these results.

Post-irradiation examination. Post-irradiation testing was carried out in established hot-cell facilities at ORNL. Testing included the following elements:

- Thermal conductivity ASTM E 1461-01

- Irradiation-induced dimensional change

- Sonic Elastic Modulus

- Room temperature strength

- Scanning and transmission electron microscopy of irradiated materials 
ASTM guideline support. The need for continued ASTM guideline development has been highlighted as a critical issue for both $\mathrm{C}_{f} / \mathrm{C}$ and $\mathrm{SiC}_{f} / \mathrm{SiC}$ composites under NGNP. Currently there are few national or international full-consensus standards for evaluating advanced ceramics and ceramic matrix composites (CMCs) in particular. Technical and pragmatic issues related to standardization efforts for CMCs must be evaluated for full consensus standards [i.e., ASTM Subcommittee C28.07 on Ceramic Matrix Composites, Comité Européen de Normalisation (CEN) Subcommittee TC184/SC1 on Ceramic Composites, and International Organization for Standardization (ISO) Technical Committee TC206 on Fine, Advanced, Technical Ceramics]. This task has been providing for continued involvement of key personnel involved in these efforts and, in particular, ensuring guidelines for testing of tubular composite structures are moved forward. 


\section{OTHER VHTR MATERIALS RESEARCH PROGRAMS}

The other research activities associated with DOE's development of the VHTR system that are not directly part of the NGNP project area are described in this section. These include activities associated with the development and codification of high-temperature design methods, university and international nuclear research initiatives, Generation IV International Forum interactions, and other DOE Office of Nuclear Energy materials research that supports both near- and long-term VHTR systems development.

\subsection{HIGH-TEMPERATURE DESIGN METHODOLOGY AND IMPLEMENTING CODES}

\subsubsection{Challenges and Requirements for High-Temperature Structural Design}

The current elevated-temperature nuclear design criteria and material coverage contained with the ASME Code Section III Subsection NH originate largely from the liquidmetal reactor (LMR) program of the late 1960s, 1970s, and early 1980s. A HighTemperature Structural Design (HTSD) Technology task within the nationwide Materials and Structures Technology program supported the development and experimental confirmation of design criteria to guard against creep, creep-fatigue, and ratcheting failures. The Mechanical Properties Design Data task provided the uniaxial data for design and quantification of the criteria. In companion efforts, the HTSD Technology task provided simplified methods and recommended constitutive equations for inelastic design analyses, and the Design Data task provided the uniaxial stress-strain and creep data needed for designers to implement the equations. All of this work was based on experimental data from common heats of materials, so that the resulting design methods, criteria, and data were as consistent as possible. An Argonne National Laboratory report prepared for the NRC provides a good overview of Subsection $\mathrm{NH}$ and its associated cases and their shortcomings for HTGR components. ${ }^{37}$

Advanced high-temperature structural design and materials data development tasks are very dependent upon one another and as such are referred to jointly as HTDM. Today, DOE supports activities to update HTSD methods both within the NGNP program and through direct contracts with the ASME Code to address the overall limitations of HTDM that will affect the design of high-temperature metallic NGNP and VHTR components. The HTSD task activities being conducted directly under contracts with the ASME Code are outlined in this section but do not include specific testing for constitutive and life prediction model verification. Those activities, as well as additional materials-related tasks that will support HTDM in providing necessary material properties data, such as uniaxial creep testing of RPV materials, metallic internals, and metallics for the IHX, are discussed in the preceding sections of this report.

While not included explicitly within the research requirements for each individual component, time-dependent failure modes and time- and rate-dependent deformation response to time-varying thermal and mechanical loadings will characterize the design of NGNP and VHTR metallic components operating at high temperatures. It is necessary to provide the data and models required by ASME Code ${ }^{38}$ groups to formulate time-dependent failure criteria that will ensure adequate life for components fabricated from the selected NGNP materials. ${ }^{39}$ It is also required to provide the experimentally based constitutive models that are the foundation of the inelastic design analyses specifically required by Subsection NH of Section III of the ASME Boiler and Pressure Vessel Code, which governs design of elevated-temperature Class 1 nuclear components. Cumulatively, these activities are a key part of the codification and utilization of the selected NGNP structural materials and will be required for any future VHTRs. 
An additional issue of this technology is ensuring regulatory acceptance. Safety assessments, required by NRC, will depend on time-dependent flaw growth and the resulting leak rates from postulated pressure-boundary breaks. This requires a flaw assessment procedure capable of reliably predicting crack-induced failures as well as the size and growth of the resulting opening in the pressure boundary. Identification of an overall proven procedure is required.

The challenges, requirements, activities, and ASME Code considerations for designing high-temperature NGNP and VHTR components are summarized in the following sections, along with descriptions of the multiple tasks that comprise the contribution from activities supported directly with the ASME Code. Additional details are provided in an R\&D plan for development of HTSD Technology. ${ }^{40}$

High-temperature components respond to thermal and mechanical loadings inelastically. Their responses are very rate dependent, and both strain and cyclic softening can occur. Each time the secondary and peak stress is cycled due to start-ups, shutdowns, and other changes in operational levels, the stress-strain state at each location in the component undergoes a complex cycle involving plasticity and creep, or at higher temperatures, timedependent viscoplastic behavior. The subsequent stress state during operation may bear little resemblance to that envisaged for the primary pressure stress alone, and the accumulated cyclic strains can be considerably larger than those due to creep alone.

Early in the development of ASME Subsection NH (rules for Class 1 elevatedtemperature nuclear components), it was recognized that without a reasonably accurate prediction of the complex, multiaxial time-dependent stress-strain behavior throughout a component, structural integrity could not be ensured. This was especially true in light of the recognition that elevated-temperature failures are likely to occur at notch-like geometric discontinuities and at weldments (metallurgical discontinuities) where the material response is most complex. Subsection $\mathrm{NH}$ is thus predicated on the use of inelastic design analysis to accurately predict stress-strain-time response at critical component locations.

Simplified procedures based on simplifying models of stress-strain behavior are also provided, and these can often be used to avoid fully detailed inelastic analyses. The existing simplified inelastic design procedures in $\mathrm{NH}$ have not been proven adequate or inadequate for very high temperature design applications such as the NGNP. Furthermore, they have yet to be approved by ASME for application to materials that exhibit mostly tertiary creep behavior, such as Alloy 617. Confirmatory structural tests are also required to validate design criteria in Subsection $\mathrm{NH}$ and associated code cases. The process to develop design code and criteria for very high temperature applications is not always a straightforward one; it will require an iterative process between coupon testing, constitutive modeling, simplified methods development, failure modeling such as creep-fatigue interaction, and structural testing for validation.

\subsubsection{ASME Code Section III, Subsection NH and Associated Cases}

The design rules of Subsection $\mathrm{NH}$ for Class 1 elevated-temperature components consist of (1) load-controlled (primary) stress limits and (2) strain, deformation, and fatigue limits (Appendix $\mathrm{T}$ in $\mathrm{NH}$ ). The load-controlled stress limits are in the form of time-dependent allowable stresses based on both short-time tensile test results and long-term creep test results. Allowable stress reduction factors for weldments are given, as are reduction factors to account for the degrading effects of prior service. Only elastic analysis results are required to satisfy the primary stress limits. The second category of design rules-strain, deformation, and fatigue limits-are much more problematic. These rules deal with the complex loading and behavior resulting from primary plus cyclic secondary and peak stresses. They are aimed at preventing failures due to excessive deformation, creep-fatigue 
damage, and inelastic buckling, and they require inelastic design analysis results or, in some cases, simplified procedures for their satisfaction. The rules ${ }^{38}$ include strain accumulation limits, creep-fatigue criteria, buckling limits, and special limits for welds.

The materials that are currently covered, allowable lifetimes, and maximum allowable temperatures are limited in Subsection $\mathrm{NH}$ as shown in Table 4.1. Comparison of temperatures in Table 4.1 with the anticipated upper reactor system temperatures anticipated for some NGNP metallic components indicates that the current Code coverage is inadequate for the NGNP, as well as any higher temperature VHTRs. For example, when temperatures during abnormal events are considered, the temperature limits for Alloy $800 \mathrm{H}$ may or may not be adequate for those required for the NGNP control rods. Moreover, coverage is inadequate or nonexistent for use of the materials proposed for use in the very high temperature NGNP components, such as the IHX.

Table 4.1. Current subsection NH materials and maximum allowable times and temperatures

\begin{tabular}{lcc}
\hline \multirow{2}{*}{ Material } & \multicolumn{2}{c}{ Temperature $\left({ }^{\circ} \mathbf{C}\right)$} \\
\cline { 2 - 3 } & $\begin{array}{c}\text { Primary stress limits } \\
\text { and ratcheting rules }\end{array}$ & Fatigue curves \\
\hline 304 stainless steel & 816 & 704 \\
316 stainless steel & 816 & 704 \\
$21 / 4 \mathrm{Cr}$-1Mo steel & $593^{\mathrm{b}}$ & 593 \\
Alloy 800H & 760 & 760 \\
Modified 9Cr-1Mo steel & 649 & 538 \\
(Grade 91) & & 50 \\
\hline
\end{tabular}

${ }^{a}$ Allowable stresses extend to $300,000 \mathrm{~h}$ (34 years) unless otherwise noted.

${ }^{b}$ Temperatures up to $649^{\circ} \mathrm{C}$ are allowed for up to $1000 \mathrm{~h}$.

Aside from the fact that many preliminary candidate VHTR materials are not included in Subsection $\mathrm{NH}$, there are several generic shortcomings that will require resolution.

1. The maximum temperatures permitted will have to be significantly increased.

2. Allowable time-dependent stresses will have to be extended beyond the current $300,000 \mathrm{~h}$ maximum to $600,000 \mathrm{~h}$.

3. Environmental effects (e.g., impure helium in the case of NGNP) need to be incorporated into the failure criteria, particularly creep-fatigue.

4. Current simplified inelastic methods and stress classification techniques need to be assessed for very high temperature applications, and improved or alternate approaches developed.

5. The current linear damage accumulation rule for creep-fatigue has significant shortcomings, particularly at higher temperatures and longer times. These shortcomings must be remedied.

6. Design criteria for weldments and notches were identified in the Clinch River Breeder

Reactor Plant (CRBRP) to require remedies and must be addressed for Gen IV systems. ${ }^{41}$

Four current code cases and a draft code case are relevant. Case N-499 was developed for HTGRs. N-499 permits Class 1 components fabricated from SA-533, Grade B steel to exceed the normal $371^{\circ} \mathrm{C}$ low-temperature design limit for short periods for Levels $\mathrm{B}, \mathrm{C}$, and $D$ events. A similar case might be developed for the gas-cooled reactor vessel materials under off-normal conditions. Case N-201 provides rules for construction of core support structures made of ferritic steels, austenitic stainless steels, and high-nickel alloys, for which 
metal temperatures do not exceed those in Section II, Part D, of the ASME Code. This case, with modifications, might be useful for the metallic core internals of Gen IV systems. The basis for the case is the same high-temperature structural design methodology as that on which Subsection NH is based. Code case N-253 provides rules for Class 2 and 3 components for elevated temperature service. Unless exemption rules are met, the case essentially defaults to the criteria of Subsection NH. Code case N-290, which covers expansion joints in Class 1 liquid-metal piping and is based on design by test verification, might have application to bellows used in Gen IV systems. The Japanese have developed design-by-analysis procedures that would replace some of the more onerous aspects of $\mathrm{N}-290 .{ }^{42}$

A draft code case developed in the 1980s for design of nickel-base Alloy 617 components to $982^{\circ} \mathrm{C}$ is directly pertinent to NGNP and other Gen IV systems with veryhigh-temperature components. ${ }^{43}$ The case was approved by ASME Subsection $\mathrm{NH}$ and submitted to its parent group, the Subcommittee on Design, for approval. However, further action on the case was suspended when the DOE project was canceled. The case, of considerable value to Gen IV, can serve as a springboard for establishing very-hightemperature component code rules. The draft case, while having the same framework as Subsection $\mathrm{NH}$, has several unique features that are ramifications of the very-hightemperature material behavior. This behavior includes (a) the lack of clear distinction between time-independent and time-dependent behavior, (b) the high dependence of flow stress on strain rate, and (c) softening with time, temperature, and strain.

To summarize, the design rules of Subsection $\mathrm{NH}$ that are based on the separation of time- and rate-independent response, or on strain-hardening idealizations of material behavior, required careful reconsideration. In addition to inheriting the known shortcomings of Subsection $\mathrm{NH}$, the draft case has a number of gaps and shortcomings that would have to be overcome before it could be satisfactorily and reliably applied. These were identified as the case was being developed, and they are tabulated below because of their relevance to this plan.

- Actions Required to Complete Case

- Alloy 617 must be added to the low-temperature rules of Section III.

- Weldment stress rupture factors must be added.

- Thermal expansion coefficients must be added.

- Additional isochronous stress-strain curves, covering temperatures below $649^{\circ} \mathrm{C}$ and above $950^{\circ} \mathrm{C}$, must be added.

- Material Data Needs

- Weldment fatigue data are needed.

- A more complete creep-fatigue database must be developed.

- The synergistic effects of aging, environment, loading, and temperature should be better understood.

— The effects of aging on toughness must be characterized.

- Structural Design Technology Needs

- An experimentally validated constitutive model must be developed.

- Some very-high-temperature, time-dependent tests of simple Alloy 617 structural models are needed to (1) provide a better understanding of structural behavior and failure modes, (2) validate inelastic analysis methods, and (3) provide application feedback for the case.

- Simplified ratcheting evaluation procedures need to be developed for temperatures above $649^{\circ} \mathrm{C}$. 
- The use of linear damage fractions as the basis of creep-fatigue rules is probably the biggest shortcoming of the draft case. A basic effort is needed to identify and experimentally validate a more suitable damage theory.

- Recent Emergent Issues

- Justification for dropping onset of tertiary creep from the allowable stress criteria is needed.

- Determine if the effect of hold time on creep-fatigue saturates or if there is continuous degradation owing to environmental effects, for example, oxidation ahead of a creep crack tip.

- Assessment of the potential impact of diffusion creep on allowable stresses, constitutive equations, strain and deformation limits and simplified methods is required.

\subsubsection{Direct Support of ASME Section III Code for High-Temperature Design Methods}

To promote the accelerated development and implementation of needed improvements in the ASME Code, DOE is supporting activities in which key participants in HighTemperature Design Methodology, composed of both High-Temperature Structural Design and Materials Tasks and knowledgeable representatives from design organizations, are actively involved in ASME Subsection NH. A High-Temperature Design Methodology Coordinating Committee, chartered by DOE, was proposed in 2004, and a joint DOE-ASME collaboration agreement was reached in 2005, lead by technical experts at ORNL, INL, various stakeholders, and Subsection $\mathrm{NH}$. The initial 3-year agreement initiated the organization and task activities within ASME Section III in support of codification needs for Gen IV reactors, focused on VHTR requirements. Initially 12 main tasks were identified, with initial funding to support efforts on five of these tasks in beginning in 2006. Some tasks have since been added, others redefined, and they are continuing under available funding. A summary of the tasks is provided below. Additional details can be found in Ref. 44 .

Tasks 1 to 5 have now been completed and their results documented. The remaining tasks include those that have begun or are proposed.

\section{Task 1: Verification of allowable stresses in ASME Section III, Subsection NH with emphasis on Alloy $800 \mathrm{H}$ and Grade 91 Steel ( $9 \mathrm{Cr}-1 \mathrm{Mo}-\mathrm{V}$ or modified 9Cr-1Mo)}

Currently, five materials are approved for the construction of Class I nuclear components other than bolts under the rules of ASME Section III, Subsection NH (III-NH). Two of these materials, namely $800 \mathrm{H}$ and $9 \mathrm{Cr}-1 \mathrm{Mo}-\mathrm{V}$ steel, are candidates for the construction of components for the VHTR concept included in the Gen IV Nuclear Reactor Program. The major research that produced the database for these materials was undertaken in the 1970s and 1980s. Since then, considerable long-time experience has been gained for both materials, and data analysis methods for setting the allowables have been refined. These actions have produced changes in both the time-independent and time-dependent allowable stresses in ASME Section II for Sections I and VIII, D1.

Under this task, the sources for high-temperature creep-rupture data for $9 \mathrm{Cr}-1 \mathrm{Mo}-\mathrm{V}$ alloy base metal ( Gr 91) were reviewed and the development of $S_{t}$ values was traced for ASME Section III, Subsection-NH. A database for time to $1 \%$ strain, time to the initiation of tertiary creep, and rupture life was collected and characterized. Data were correlated over the temperature range from 450 to $780^{\circ} \mathrm{C}$ by means of the Larson Miller and other parameters. Applying the criteria set forth in ASME III-NH, it was found that the rupture strength 
controlled the $S_{t}$ values for all temperatures and times. The $S_{t}$ values estimated from the expanded database were found to be slightly greater than the values currently listed in ASME III-NH for some combinations of temperature and time.

Under this task, the sources for high-temperature creep-rupture data for $9 \mathrm{Cr}-1 \mathrm{Mo}-\mathrm{V}$ alloy weldments were also review. The database developed for III-NH was retrieved and evaluated. Based on this review, an activity is under way in the ASME Section II Subgroup on Strength of Weldments and other groups worldwide to develop stress reduction factors (SRFs) for $9 \mathrm{Cr}-1 \mathrm{Mo}-\mathrm{V}$. Additional testing of renormalized and tempered welded pipe may be recommended.

Results of the evaluation of Alloy $800 \mathrm{H}$ base metal data included (1) developing proposed values for $S_{y 1} \& S_{U}$ for $>550^{\circ} \mathrm{C}$ to $900^{\circ} \mathrm{C}$; (2) recommending additional tensile testing at $750^{\circ} \mathrm{C}$ and above to establish strain rate effects and low-stress, high-temperature creep testing to establish the dominant creep mechanism; (3) recommending proposed $S_{R \min }$ values extended to $600,000 \mathrm{~h}$ and $900^{\circ} \mathrm{C}$ be developed; (4) recommending that the average $S_{1 \%}$ control $S_{t}$ at long time above $750^{\circ} \mathrm{C}$, if III-NH NB-3221 is so revised; (5) recognizing that $80 \% \min S_{3}$ may control $S_{t}$ at long time above $750^{\circ} \mathrm{C}$, based on parametric fits; (6) recognizing that $80 \%$ min $S_{3}$ may not control $S_{t}$ at long time above $750^{\circ} \mathrm{C}$, if based on ratio to $S_{R}$; and (7) recommending that diffusional creep be explored.

Results of the evaluation of Alloy $800 \mathrm{H}$ weld metal data included (1) recognition that data for Inconel A and Inconel 82 filler metals were not sufficient to extend SRFs for weldments to $900^{\circ} \mathrm{C}$ for long times and (2) recommending further creep-rupture testing of Alloy $800 \mathrm{H}$ weldments at $750^{\circ} \mathrm{C}$ and testing of filler metals and weldments, including the matching filler metal $(21-33 \mathrm{Nb})$, to identify the optimum filler metal for Alloy $800 \mathrm{H}$.

This task, now completed ${ }^{45,46}$ has reviewed these changes and their impact on the allowable stresses in III-NH.

\section{Task 2: Regulatory safety issues in structural design criteria of ASME Section III Subsection NH and for very high temperatures for VHTR and Gen IV}

The NRC has not accepted (nor rejected) Subsection NH of Section III of the ASME Code "Class 1 Components in Elevated Temperature Service." Further, the Advisory Committee on Reactor Safeguards (ACRS) reviewed similar elevated temperature structural design criteria proposed for the Clinch River Breeder Reactor (CRBR) and generated a list of technical issues and safety concerns which they believed still needed to be resolved. ${ }^{39}$ DOE agreed to fund R\&D efforts to answer their concerns to the satisfaction of the NRC and the ACRS prior to requesting an operating license for the CRBR. The structural design criteria being used at that time were fundamentally similar to the current criteria in Subsection NH of Section III of the ASME Code. A paper on the NRC review summarized the situation as follows: "In a general sense, the NRC review of the CRBRP confirms the adequacy of the high-temperature structural design methodology that has been developed over the last 20 years..." and "The design criteria and basic approach to design evaluation have been accepted, and no major inadequacies were discovered. The review identified and resolved a number of issues relative to Code interpretation, and it identified areas where more detailed evaluation techniques would be useful. The required confirmatory programs would both improve design assurance of the CRBRP, and simplify design and evaluation of future plants." ${ }^{37}$ The four major areas of concern were (1) weldment safety evaluation, (2) notch weakening, (3) design analysis methods, codes, and standards, and (4) adequacy of tube sheet designs for the steam generator. The programs that were developed to address these concerns were not conducted when the program funding was terminated. It is clear that the confirmatory programs need to be completed. Assessment and identification of additional possible safety issues relative to Gen IV, and specifically VHTR, are needed. 
Ultimately, any safety issues need to be resolved from a regulatory perspective in order to ensure that the technology needed to support the licensing of VHTR and Gen IV will be in place to support Design Efforts in a timely manner.

In this task, prior regulatory reviews of elevated temperature reactors were acquired and reviewed, including those done for the CRBR in 1983 and the PRISM 1994. Creep crack growth in weldments and notches, inelastic analysis, and environmental effects were identified as primarily the issues of concern for VHTR applications.

A summary of the R\&D issues identified where more development work is needed includes (1) materials behavior characterization for cyclic loads at very high temperatures;

(2) the adequacy of structural analysis methods for cyclic loads at very high temperatures;

(3) fatigue, creep, and creep-fatigue interaction; (4) coolant impurities and crevice concentration impacts; (5) metal carburization, decarburization, and oxidation;

(6) sensitization of austenitic steels; and (7) alloy aging behavior at elevated temperatures.

This task, now completed, ${ }^{47}$ evaluates how the current version of $\mathrm{NH}$ addresses, or does not, the issues identified and indicates a path forward to resolve the issues relevant to the VHTR.

\section{Task 3: Improvement of ASME Subsection NH rules for Grade 91 Steel-(negligible creep and creep-fatigue)}

Mod9Cr-1Mo (Grade 91) is a candidate for the RPV of the NGNP and is also thought to be a potential candidate as a material for internals of other VHTRs. Two important issues related to the use of Mod9Cr-1Mo exist: negligible creep and creep-fatigue.

For the RPV, the issue to be addressed is related to the definition of negligible creep conditions. This need is linked to the choice to operate the RPV in the negligible creep domain so as to avoid the implementation of a surveillance program in the significant creep regime. This point is all the more important in that there is interest to increase the value of the core inlet temperature.

For internals, the major concern is creep-fatigue. Procedures are available in nuclear codes (ASME, RCC-MR, etc.) to cope with creep-fatigue, but most of those procedures have been established for austenitic stainless steels and do not necessarily take account of peculiarities of martensitic steels such as Mod9Cr-1Mo (e.g., softening and elastic-relaxation behavior). There is therefore a need to compare existing procedures and to confront numerical application with experimental results. A specific point to investigate is the definition of the creep-fatigue damage envelope for which significant differences are found from one procedure to another. This task is now completed, and the final report ${ }^{48}$ documents the recommendations of what is required to resolve these issues. For both major areas, negligible creep and creep-fatigue, extensive data collection, and evaluation were performed to assess existing and develop proposed criteria. Proposed test programs designed to provide the additional data needed to resolve these issues for the materials of interest were developed.

\section{Task 4: Updating of ASME Nuclear Code Case N-201 to accommodate the needs of core support structures in high-temperature gas-cooled reactors currently in development}

ASME Nuclear Code Case N-201 contains rules for construction of core support structures under Subsection NG for service at elevated temperatures. The rules of this code Case are similar to those contained in Subsection $\mathrm{NH}$, Class 1 Components in Elevated Temperature Service. Both Subsection NH and Code Case N-201-4 were developed before 
the requirements for Gen IV VHTRs were known and therefore require additions or amendment to be of value in the design and construction of the currently proposed VHTRs.

Part A of the current Code Case N-201-4 provides design rules for the construction of core support structures fabricated from five materials: ferritic steels $1 \mathrm{Cr}-0.5 \mathrm{Mo}-\mathrm{V}$ and 2.25Cr-IMo, Type 304 and 316 stainless steel (SS), and Alloy $800 \mathrm{H}$. Part A applies at times and temperatures where creep effects do not need to be considered. For Part B of the code case, "Rules for Construction of Subsection NG, altered for service at elevated temperature to suitably account for creep and stress-rupture effects," the permissible materials are limited to four, 2.25Cr-IMo, Type 304 and 316 stainless steel (SS), and Alloy $800 \mathrm{H}$, with varying maximum permitted temperature for use.

The maximum permitted temperature of $815^{\circ} \mathrm{C}\left(1500^{\circ} \mathrm{F}\right)$ is for SS 304 and 316 and $760^{\circ} \mathrm{C}\left(1400^{\circ} \mathrm{F}\right)$ for Alloy $800 \mathrm{H}$; these materials cannot be used when exposed to temperatures at or near the core gas outlet temperature for construction of VHTRs with core outlet temperatures of 900 to $1000^{\circ} \mathrm{C}$. Hence, the scope of the code case needs to be expanded to include the materials with higher allowable temperatures or extend the temperature limits of current materials and to confirm that the design methodology used is acceptable for design of core support structure components at the appropriate elevated temperatures.

The specific goals of this task were to determine what recommendation regarding the expansion of the code case to include additional materials and materials with higher allowable temperatures should be made, to extend the temperature limits of current materials covered in the code case, and confirm that the described design methodology is acceptable for core support structures operating in elevated temperature service or propose any needed modifications.

To assess the adequacy of the code case, a detailed review of the current version of $\mathrm{N}-201-4$ was completed and numerous errors and discrepancies were found. Additionally, a questionnaire on metallic core support structure design parameters was developed and sent to the major potential vendors and owners of VHTRs. A response was received from PBMR, AREVA, the Japan Atomic Energy Agency (JAEA), and General Atomics. The materials and proposed operating conditions contained in those responses are summarized in Table 4.2.

Table 4.2. Summary of materials and both operating and transient conditions of concern for VHTRs provided by the vendor and owner survey

\begin{tabular}{lcccc}
\hline & PBMR & AREVA & JAEA & $\begin{array}{c}\text { General } \\
\text { Atomics }\end{array}$ \\
\hline Materials & $316 \mathrm{H}$ & $800 \mathrm{H}$ Grade 91 & $3162.25 \mathrm{Cr}-1 \mathrm{Mo}$ & $800 \mathrm{H}$ \\
& $2.25 \mathrm{Cr}-1 \mathrm{Mo}$ & IN 718 (bolting) & & \\
Normal operating metal & $440^{\circ} \mathrm{C}\left(824^{\circ} \mathrm{F}\right)$ & $400^{\circ} \mathrm{C}\left(752^{\circ} \mathrm{F}\right)$ & $500^{\circ} \mathrm{C}\left(932^{\circ} \mathrm{F}\right)$ & $760^{\circ} \mathrm{C}\left(1400^{\circ} \mathrm{F}\right)$ \\
temperature and & $280,000 \mathrm{~h}$ & $470,000 \mathrm{~h}$ & $100,000 \mathrm{~h}$ & Duration NA \\
duration & $(32 \mathrm{EFPY})$ & $(53.6 \mathrm{EFPY})$ & $(11.4 \mathrm{EFPY})$ & \\
$\begin{array}{l}\text { Transient maximum } \\
\text { metal temperature and }\end{array}$ & $640^{\circ} \mathrm{C}\left(1184^{\circ} \mathrm{F}\right)$ & $670^{\circ} \mathrm{C}\left(1238^{\circ} \mathrm{F}\right)$ & $500^{\circ} \mathrm{C}\left(932^{\circ} \mathrm{F}\right)$ & $\mathrm{NA}$ \\
duration & $60 \mathrm{~h}$ & $100 \mathrm{~h}$ & $1000 \mathrm{~h}$ & \\
\hline
\end{tabular}

Results of the vendor and owner survey and evaluation of the existing Code Case $\mathrm{N}-201-4$ revealed (1) normal operating conditions (except for GT-MHR) do not exceed $900^{\circ} \mathrm{C}$, (2) expected creep and environmental effects are negligible or insignificant for normal operating conditions, (3) current design methods are largely adequate, (4) off-normal conditions are on the fringe of where creep may need to be considered. It was decided that the current code case required updating and corrections and a modified version of Code 
Case N-201 incorporating proposed changes was produced. Among the most pressing changes are to include additional materials (Types 321 and 347 SS, Grade 91, and Inconel 718) that are already in $\mathrm{NH}$ and the need to address life extension to 60 years. This task is now completed and documented. ${ }^{49}$

\section{Task 5: Collect available creep-fatigue data and study existing creep-fatigue evaluation procedures for Grade 91 steel and Hastelloy XR}

Creep-fatigue is a failure mode of great concern for reactors operated at elevated temperatures. ASME Section III Subsection NH incorporates procedures for creep-fatigue damage evaluation, which is one of the major features that distinguishes it from other parts of Section III. NH deals with such materials as conventional steels, Mod9Cr-1Mo, and Alloy $800 \mathrm{H}$. Temperature range and service duration covered in the code vary in range of temperature and time, up to $750^{\circ} \mathrm{C}$ and approximately 34 years, respectively.

There are noticeable deviations between what is required in the design of the NGNP and VHTR reactors and what the current NH covers. High-temperature structural alloys likely to be used in these reactors are Mod9Cr-1Mo, Alloy 617, and Haynes 230, as well as possibly Hastelloy XR. Gas temperature ranges expected in current design study are up to $600^{\circ} \mathrm{C}$ for Mod9Cr-1Mo and $950^{\circ} \mathrm{C}$ for Alloy 617 and Haynes 230; various design strategies will lower the actual metal temperature to varying degrees. However, components such as the IHX will experience the full gas temperature. Design life for the reactor is 60 years. Mod9Cr-1Mo has recently been incorporated in $\mathrm{NH}$, while Alloy 617, Haynes 230, and Hastelloy XR have not been incorporated yet (a draft code case for Alloy 617 exists). Temperature range and design life are well above the range covered by the current $\mathrm{NH}$. Many experts consider the current creep-fatigue criteria for Mod9Cr-1Mo in $\mathrm{NH}$ to be overly conservative because the limits are based on the interim results of Clinch River project. The project was interrupted many years ago when a good understanding of creep-fatigue in Mod9Cr-1Mo had not been achieved; consequently, the interaction diagram was intentionally constructed to err on the conservative side until the need (and associated funding required) to better understand the interaction arose. Nothing has been prepared for creep-fatigue evaluation of Haynes 230 and Hastelloy XR. The degree of conservatism and methods used in the creep-fatigue procedure for Alloy 617 in the draft code also requires a critical review.

Considering the gap between the basis for creep-fatigue procedures in $\mathrm{NH}$ and that needed in NGNP and VHTRs, creep-fatigue data acquisition and establishment of better creep-fatigue criteria for primary materials (Mod9Cr1Mo and Alloy 617, Haynes 230, and Hastelloy XR) are desired. However, because performing material tests from scratch requires extremely large resources, it is appropriate to start with analyzing existing data and creep-fatigue criteria. Therefore, collecting creep-fatigue data on Mod9Cr-1Mo and Hastelloy XR and studying existing creep-fatigue evaluation procedures, which will lead to identification of research and development items in the near future, was performed.

Data on Grade 91 steel was obtained from JAEA, ORNL, Electric Power Research Institute (EPRI), National Material Science in Japan (NIMS), and the Central Research Institute of Power Industry in Japan (CRIEPI). It included data on creep-fatigue life and cyclic inelastic behavior (when available) in air, vacuum, and sodium. Information on Hastelloy XR was obtained from JAEA and included data on cyclic inelastic behavior (when available) in air and helium.

An evaluation of creep-fatigue criteria contained in the ASME NH, RCC-MR, Japanese FBR Codes was performed for Grade 91 steel. This evaluation examined strain range, initial stress, relaxation behavior, formulation of creep damage, environmental effects (including creep-fatigue life under compressive strain hold conditions), metallurgical aspects, and the damage envelope used to model cyclic softening behavior. Comparisons between the time 
fraction rule and ductility exhaustion method were investigated, and suggestions to improve creep-fatigue rules in ASME NH made.

Assessments of Hastelloy XR were made according to criteria in the ASME NH, RCC-MR, and Japanese HTGR Codes. This evaluation examined strain range, initial stress, relaxation behavior, formulation of creep damage, and the damage envelope used to model cyclic softening behavior. The applicability of criteria in the various codes was discussed qualitatively.

Recommendations were made for test conditions under which more creep-fatigue data are necessary to capture the behavior of those materials under the conditions expected in VHTR Grade 91 and Hastelloy XR, as well as for items needed to be developed to improve creep-fatigue evaluation procedures in ASME NH. This task is now completed and has documented $^{50}$ the recommendations of what is required to resolve these issues.

\section{Task 6: Operating-condition allowable stress values}

A spot check of minimum stress to rupture values provided in $\mathrm{NH}$ revealed that there was disagreement between the minimum stress to rupture values, $S_{r}$, at $100,000 \mathrm{~h}$ and the values of Design Condition stress intensity, $S_{0}$. Based on the allowable stress criteria, the values of $S_{o}$ should be no greater than $80 \%$ of $S_{r}$ at $100,000 \mathrm{~h}$. However, for all the listed $\mathrm{NH}$ materials (304 and 316 stainless steels, Alloy $800 \mathrm{H}, 9 \mathrm{Cr}-1 \mathrm{Mo}-\mathrm{V}$ Grade 91 , and 21/4Cr-1Mo Gr 21 Class 1), at higher temperature there were values of $S_{o}$ which exceeded $80 \%$ of $S_{r}$. In most, if not all cases, the values of $S_{o}$ were significantly higher at some temperatures. Since the $\mathrm{NH}$ values of $S_{o}$ are in agreement with the allowable stress values listed in Section II, Part D, the expectation is that the values of $S_{r}$ are lower than would be expected if they were derived from the same data as the values for $S_{o}$. Further, the values of $S_{t}$, the allowable stresses for Operating Conditions, appear consistent with the values of $S_{r}$, thus throwing in doubt all the allowable Operating Condition stress values for both load-controlled stress limits and displacement-controlled limits in $\mathrm{NH}$. These issues are being addressed in three related activities.

Part I: Review Current-Operating-Condition Allowable Stresses and Assemble Original Data Base Used.

Review current values of $S_{r}$ and $S_{o}$ and identify discrepancies between ASME Section III $\mathrm{NH}$ and Section II. Do the same with $S_{t}$ and $S_{r}$. Identify and assemble the database(s) used to establish $S_{r}, S_{t}$, and $S_{0}$. A report will be prepared on the findings and the original database used to establish these allowable stresses

\section{Part II: Assessment of Data Base.}

Review the assembled databases for completeness and consistency. Identify areas of inconsistency and recommend a course of action to resolve them. This should include additional testing if required. Also identify those time and temperature regimes where the listed values of $S_{t}$ and $S_{r}$ are correct and no further action is required. A report will be prepared on assessing the database.

Part III: Correct-Operating-Condition Allowable Stress Values.

For those time/temperature regimes that require corrections, based on currently available data, prepare recommended corrections to the currently listed values of $S_{t}$ and $S_{r}$ for those regimes where the data is sufficient. Prepare a rough order-of-magnitude cost estimate for the testing required to complete the required corrections to $S_{t}$ and $S_{r}$. A report will be prepared on the recommended corrections for the current-operatingcondition allowables based on currently available data and report on the recommended 
testing, including an order-of-magnitude cost estimate, required to complete the corrections to $S_{t}$ and $S_{r}$.

These activities should be completed in 2009. To date, reviews of the data have indicated that only $800 \mathrm{H}$ has shown no inconsistency in stress allowables between Sections II and III NH. All other materials have inconsistencies and will need to have their allowables reconciled.

\section{Task 7: Development of ASME Code rules for the gas-cooled reactor intermediate heat exchanger (IHX)}

"Needs for Intermediate Heat Exchanger (IHX)" has been ranked as a priority item by AREVA to support the VHTR program and appears on the list of items generated by the ASME Board of Nuclear Codes and Standards (BNCS) New Reactors Task Group. From the standpoint of elevated temperature design, the critical section of the IHX is the internal heat transfer matrix. Generally, the outer shell is designed as the primary pressure-retaining member and is maintained at a temperature cool enough to minimize creep effects. The inner heat transfer matrix is, however, exposed to the full reactor outlet temperature. This matrix also serves as the boundary between primary and secondary coolant, so it does have a pressure boundary function even though it is not exposed to the full pressure differential between the gas and atmospheric pressure.

Since the heat transfer matrix is not part of the external pressure boundary, and designs may include an isolation valve to isolate any failure of the IHX to the nuclear plant, and not a hydrogen plant, one could question the need for ASME Code rules to cover this structure. When this issue was raised with potential reactor system suppliers, they reiterated the importance of code coverage from both the standpoint of achieving a reliable design and also protecting the secondary circuit from contamination from the gasses in the primary circuit. There is also a precedent with ASME Section VIII tube-and-shell heat exchangers where the tubes are designed as a pressure boundary in accordance with the code.

The intent of this task is to recommend how and where within ASME codes and standards the IHX, safety valve, etc., would be addressed and to provide guidance to equipment suppliers on potential critical code issues to be addressed. Part of this determination is the role of the IHX primary-to-secondary heat exchanger surface in plant licensing considerations. Although the main focus of this activity is on compact, microchannel heat exchangers due to their unique design features, consideration should also be given to plate-fin and shell-and-tube concepts in considering equivalent reliability and assessing critical "construction" issues at very high temperatures representative of VHTR operation. Note that in this context "construction" refers to the full scope of ASME Code rules, namely, materials, design, fabrication and installation, examination, and overpressure protection. In-service examination issues should also be considered. These issues are being addressed in two related activities.

\section{Part I: Review of Current Experience}

The objective is to identify, to the extent feasible, the current status of compact/ microchannel heat exchanger "construction" (including aging and coolant corrosion effects where available) of representative heat exchanger pressure boundary and internal designs. Heat exchangers with working fluid temperatures at the upper end of the creep regime for their materials of construction will be emphasized. Candidate designs should include shell-and-tube, plate-fin, and compact design. Additional concepts will be identified if possible. This is to be accomplished by soliciting input from component vendors, reactor heat transport system designers, and process heat end 
users. Particular attention will be paid to (a) service experience and problem resolution, (b) design criteria including methods, if any, for evaluation of cyclic life, (c) construction codes of record and designated pressure boundaries, and (d) qualification of materials and fabrication techniques for the intended service.

A report will be produced documenting current practice, lessons learned, and projected service environments.

So far, survey forms have already been sent to vendors, system designers, and process heat end users, including: JAEA, PBMR PTY., Westinghouse, General Atomic, Nordon, Alfa, Laval, Heatric, Velocys, and Ingersol Rand. Response are due back in late August 2008 and should provide their comments on high-temperature heat exchanger problems, service experience, and design criteria, as well as the construction codes to which they have been designed and where within them they have designated pressure boundaries.

\section{Part II: Recommended Code Approach}

Recommend key features of a construction code needed to address the unique issues associated with the VHTR IHX and associated equipment. Examples of what might be considered are as follows: (a) because the sharp corners associated with many if not all microchannel designs is a key feature, what test(s) should be required to establish cyclic life or to calibrate design methods, and (b) what sort of inspection or process control is required to achieve adequate joint reliability in components with on the order of a million joints and limited accessibility? Candidate codes to be considered include Subsection $\mathrm{NB}$ and $\mathrm{NH}$, Subsection NC and ND, and their respective elevated-temperature code cases and Section VIII, Div. 1 and 2. A rough order-of-magnitude estimate will be prepared for the cost and schedule of implementing the proposed code approach.

Further, it is desirable to review the adequacy of existing ASTM specifications for materials, testing, examination, etc., to determine if any new standards will need to be developed to support IHX design, fabrication, operation, or inspection. It is necessary to understand soon if the ASTM specification infrastructure will also have to be augmented in order to support the new test and inspection requirements for IHX.

A report on recommended ASME Code and ASTM considerations for the IHX and associated components will be developed, including a rough cost estimate and schedule for implementing the proposed approach.

To date, the draft code case on 617 and the high-temperature German codes, KTA 3221.1 and 3221.2, are under review with particular emphasis on safety classification and key design features for the heat exchangers. This task is scheduled for completion in early 2009.

\section{Task 8: Creep and creep-fatigue crack growth at structural discontinuities and welds}

The lack of a quantitative methodology for evaluating the potential for creep and creepfatigue crack growth at structural discontinuities and weldments has been identified in NRC reviews as an $\mathrm{NH}$ shortcoming. $\mathrm{NH}$ does provide a number of design factors and procedures to ensure elevated temperature weldments and stress risers will perform satisfactorily but does not provide for a quantitative assessment of creep crack growth. Although desirable for design, such a methodology is even more needed for evaluation of 
potential cracks and crack growth detected during in-service inspection. During the early years of the evolution of the current $\mathrm{NH}$, such methodologies for evaluation of creep crack growth were in their infancy. However, there have been numerous advances in the technology in recent years, for both nuclear and non-nuclear applications. A key issue for nuclear applications is whether these methodologies are sufficiently well established that they can be implemented to give the required assurances without undue conservatism, which would preclude designs and/or operating parameters that are actually not susceptible to premature failure. These issues are being addressed in two related activities:

Part I: Review and Assess Current Methodologies and Recommend NH Implementation Review currently used methods for creep and creep-fatigue crack growth at discontinuities and in weldments to assess their applicability for design and in-service inspection assessment of $\mathrm{NH}$ components. Methods used in other nuclear standards such as R5, RCC-MR, and KTA shall be considered as well as those employed in assessments of non-nuclear equipment. Currently approved materials for $\mathrm{NH}$ construction shall be considered as well as potential additions such as Alloy 617 and 230 , and a low- carbon/high-nitrogen version of 316 stainless steel. Identify promising technologies and the testing required to implement the specific methodology in $\mathrm{NH}$.

A report will be prepared on the review and assessment of current methodologies and recommended $\mathrm{NH}$ implementation.

\section{Part II: Draft Code Rules}

Prepare draft rules based on the above assessment for implementation in $\mathrm{NH}$. These rules should be based on existing data where feasible.

A report will be prepared containing the draft code rules.

Since there is no quantitative method for assessing creep cracking and creep-fatigue crack growth currently in ASME III NH but is needed for the NGNP, other codes containing such evaluation methods are already being reviewed. This review currently includes the European codes (i.e., UK R5 and British Standard 7910, French RCC-MR and A16, and Germans FBH and 2-criteria). Initial results suggest the R5 code contains the most promising assessment method. The remainder of the literature survey, assessment of NRC needs, recommendations for data needs and testing programs, and the development of a step-by-step procedure are expected to be completed by July 2009.

\section{Tasks 9 and 10: Update and improve Subsection NH}

Current design analysis rules in Subsection $\mathrm{NH}$ were developed during the decades ending in the late 1980's. Since then there have been notable advances in computing technology that permit evaluation methodologies not previously considered. There have also been advances in the understanding of elevated temperature material behavior and failure mechanisms. Also, as shown by the results from Tasks 3 and 5 of the first round DOEASME Gen IV Materials Project, the current methodologies for evaluating creep-fatigue interaction have a number of deficiencies. 


\section{Task 9: Update and improve Subsection $\mathrm{NH}-$ simplified elastic and inelastic design analysis methods}

This task will undertake to review and compare current design methods and assessment techniques in ASME NH, RCC-MR, BC5500, DIN, and JNC, R5, API 579, and other relevant sources. It will propose a range of design analysis methods consisting of (1) elastic analysis, (2) reference stress method, and (3) limit load, shakedown, and ratcheting analysis and recommend requisite requirements for codification, including data generation, data extrapolation strategies, round-robin structural analyses, and feature testing to validate methods. A final report with recommendation on design methods and requirements for supporting data will be prepared.

This task has already constructed a template for an idealized elevated-temperature design code that attempts to lay out a manner in which to resolve the working definition of high temperature for the specific situations to be evaluated, failure mechanisms, design criteria, required evaluations and analyses, the detailed types of materials properties needed, and the type of documentation such a code would need. The review of existing codes for adequacy of categories identified is expected to be done in mid 2009.

\section{Task 10: Update and improve Subsection NH-alternative simplified creep-fatigue design methods}

This task will review creep-fatigue methodologies, including damage based, strain based, and methods not involving separate accounting of creep and fatigue damage in various design codes, assessment procedures, and relevant literatures. It will assess the potential of deploying these methods in $\mathrm{NH}$ either to remove excessive conservatism or to resolve $\mathrm{NH}$ issues identified in the final report of Task 2 . Where applicable, rationale will be provided and implementation strategies proposed for these methods. Proposed methods will address the effects of aging, surface conditions, and geometric discontinuity.

Recommendations will include requisite requirements for codification, including data generation, data extrapolation strategies, and feature testing to validate methods. A report on alternative simplified creep-fatigue design methods will be prepared.

A review of the leading creep-fatigue methodologies has already begun. These will include the ductility exhaustion method, a new modified strain-range-partitioning method proposed by Hoffelner, and simplified model test approaches suggested by Jetter and Prager that do not require parsing of creep and fatigue damage. The methods will be primarily judged by their ability to predict experimental data, such as that which was developed in ASME Tasks 3 and 5. It is expected this task will be completed by March 2009.

\section{Task 11: New materials for NH}

Although current VHTR concepts are structured around the use of metallic materials currently approved for Subsection NH construction, it would be desirable to have additional materials available for consideration in accommodating the unique requirements of the VHTR. Unfortunately, obtaining complete approval of new materials for $\mathrm{NH}$ construction involves much more than establishing allowable stress values. It also involves establishing design rules for deformation controlled stresses, welding and weld rod materials, weld strength reduction factors, determination of creep law constants for inelastic analyses, isochronous stress strain curves, fatigue curves, yield and tensile strength reduction factors due to aging, and consideration of cold work effects and heat treating requirements to name some of the initial issues. Therefore, the goal of this task is to review the current information available for candidate new materials such as 617, 230, and Hastelloy XR and to scope out 
what would be required to gain approval for Subsection $\mathrm{NH}$ construction. Also to assist the VHTR design community, to the extent feasible, the long-term very high temperature strength properties relative to a to-be-determined reference material will be estimated.

Candidate materials will be selected for corresponding time and temperature operating conditions by consulting with VHTR stakeholders, consultants, and ASME Code members to identify candidate materials and design requirements. Available data will be reviewed to provide rough-order-of-magnitude (ROM) cost and schedule estimates for the candidate materials to identify gaps and provide data needed to obtain their approval for Subsection $\mathrm{NH}$ construction. This will include identifying any potential critical issues such as ASTM Standards requirements. Based on available information, provide a benchmark comparison of the creep rupture strength at $800^{\circ} \mathrm{C}$ and $100,000 \mathrm{~h}$ for the candidate materials. Data extrapolation should be done as consistently as possible to provide estimates of design strength characteristics. The results of this activity will be summarized in a final report.

This task has already begun to identify candidate materials and the operating conditions required by soliciting data from the high-temperature reactor community stakeholders. New alloys will be recommended for inclusion in section $\mathrm{NH}$ and an estimate of the costs and schedule prepared by September 2009 for the data generation and evaluation needed to support their inclusion.

\section{Proposed supplemental tasks}

Two supplemental tasks have been proposed by ASME, but no decision has yet been made on when or if they will be funded. Nonetheless, they are clearly germane the codification of high-temperature materials and are hence included here as potential areas for R\&D.

\section{Supplemental Task 1-High-temperature metallic materials}

The objective of the first supplemental task is to develop a roadmap clearly identifying the scope of the HTGR code, related research and development needs, and order of priorities with a timeline indicating by when ASME code rules can be developed and made available to all end users including regulators, government, and industry. The scope of work is extensive and requires coordination to align properly the needs with the appropriate resources, financial and labor hours, required to deliver ASME code rules in a timely manner to support NRC licensing of VHTRs. Specific activities would include the following:

- Evaluate existing information on the effects of HTGR environments on degradation of metallic components that are typical candidates for pressure vessel and other reactor internals. This will include compilation of results that have been obtained over the past 2 years from the ASME-DOE Gen IV Materials Project.

- Develop published project plan (roadmap) to identify the path forward for development of ASME code rules to fully support HTGR and VHTGR systems and applications, including the possible need for further activities for materials, design, examination and reliability integrity, and management, training, and manpower and suggested relative roles of $\mathrm{NRC}$, DOE, and industry.

\section{Supplemental Task 2-Non-destructive evaluation and in-service inspections technology}

Since VHTRs are designed to operate for much longer periods between in-service inspections (ISI) and scheduled short-duration shutdowns vs LWRs, it is important that the 
effectiveness of various ISI programs be assessed as a function of both the frequency of inspections and the number and types of components inspected. Therefore, the major objective of the second supplemental task is to evaluate nondestructive testing and continuous monitoring techniques for VHTR materials, environments, and degradation mechanisms. Specific activities would include the following:

- Conduct technology assessment for advanced monitoring, diagnostics, and prognostics. A key part of the review would involve an assessment of what technology and capabilities can be leveraged from past advanced and test reactor experience, laboratory studies, and migration from current nuclear LWR industry experience. The technology assessment will provide guidelines for designers and developers of codes and standards and assist in defining where and what upgrades are needed. It will assist in identifying technology that can be used to support regulatory needs, identifying technology gaps, and providing a technical foundation for defining a research agenda.

- Identify appropriate new construction and in-service non-destructive evaluation (NDE) methods for examination of metallic materials (e.g., acoustic emission, ultrasonic). Studies will be based upon NGNP-relevant considerations, such as conclusions of the Nuclear Energy Research Initiative (NERI) group that developed Load and Resistance Factor Design (LRFD)-based ASME Section III design equations. Subtasks would include (1) definition of maximum acceptable flaw types and sizes based on the LRFDapproach that is developed and the material properties of candidate materials have been obtained and (2) definition of NDE methods needed to detect sub-critical flaws of the size and type defined in (a) above in pressure equipment during initial construction and for periodic examination during the life of the equipment. It is anticipated that new methods will be needed to reliably detect smaller discontinuities than those of concern for the current generation of pressure equipment. The methods will include the characterization of uncertainties in a manner that is suitable for reliability-based LRFD development, including ultrasonic time-of-flight-diffraction and phased arrays.

\subsection{NUCLEAR ENGINEERING RESEARCH INITIATIVE}

Under sponsorship from DOE's Office of Nuclear Energy, NERI programs are being conducted across a wide range of technical areas supporting their numerous major programs, including the Generation IV Reactor Initiative. Currently, NERI research programs relevant to the development of structural materials for VHTR systems are being performed at four universities. These NERI R\&D activities are described in this section.

VHTR-materials-related NERI research at participating universities provides the opportunity for technical developments that supplement the mainstream NGNP program activities and, at the same time, offers the potential for educating and training the next generation of materials researchers who will be needed as Gen IV VHTRs and other advanced nuclear power systems require them.

\subsubsection{Multi-scale Modeling of the Deformation of Advanced Ferritic Steels for Generation IV Nuclear Energy}

This activity is in progress at the University of California, Los Angeles (UCLA), under the direction of Prof. Nasr M. Ghoniem. 


\subsubsection{Research objectives}

The objective of this project is to develop a multi-scale modeling framework to assist in the development of radiation-resistant steels with improved mechanical properties for hightemperature applications in GEN-IV reactors. In this project, a hybrid ab initio/continuum model was developed to describe the core of dislocations in iron, since empirical interatomic potentials are not accurate and do not allow studies of the effects of local chemical changes in alloys. The developed model facilitates studies of dislocation core structures in steels, without ad hoc assumptions of interatomic forces. The model is applied to determine the core structure of screw dislocations in iron, and the interaction between dislocations and oxide and carbide precipitates, because dislocations control the ductility and hightemperature strength of steels. Dislocation dynamics models are developed to simulate the mechanical properties of radiation-damaged steels as a function of the neutron dose. Single dislocation interactions with nano-voids, precipitates, and self-interstitial atom (SIA) clusters during irradiation are developed. This information is used in a comprehensive rate theory model of radiation damage and in-reactor deformation. Predictions will be made for in-reactor deformation, with full microstructure information linked with the deformation field.

\subsubsection{Research highlights}

Ab Initio modeling of dislocation-precipitate interaction. One of the primary reasons for hardening of iron-based alloys is the presence of precipitates in the iron matrix induced by neutron irradiation. Copper precipitates interact with dislocations in a-Fe, changing the mobility and/or dislocation core structure, thus inducing embitterment of a-Fe. Ab initio simulations are necessary to reveal the underlying mechanism for the interaction between the copper precipitates and the screw dislocation in a-Fe. Results indicate that the dislocation core cannot be localized at the precipitate-matrix interface; namely, the dislocation core spontaneously returns to the center of the precipitate. In addition, for the first time the precipitate size was found to have a large effect on the dislocation core polarization, which may affect the mobility. Spherical copper precipitates larger than $2.0 \mathrm{~nm}$ have a polarized dislocation core, whereas the core is unpolarized for precipitates smaller than $1.3 \mathrm{~nm}$, similar to the unpolarized core in a-Fe.

Research under this task includes continued development of formalism and codes for a Peierls-Nabarro model for bcc materials, and the effect of impurities on the core structure, continued development of a hybrid ab initio approach for the copper-iron interface and copper precipitates, continued development of the concurrent multiscale approach, and examination of the formation of kinks on screw dislocations in iron.

Core structure of self-interstitial clusters in copper and iron. A new computational method was developed to analyze the core structure of dislocations and self-interstitial loops in bcc iron and fcc copper, combining quantum mechanical determination of crystal lattice slip resistance with continuum mechanics for the elastic field. The method was originally developed by Banerjee, Ghoniem and Kioussis based on the Pierels-Nabarro (PN) model and input of atomistic information prepared by separate ab initio calculations. The core structure of dislocations can also be simulated by the classical Molecular Dynamics (MD) method. However, the reliability of the classical MD simulation result strongly depends on the accuracy of the interatomic potential, which is either empirically or semi-empirically developed by fitting an equation to available experimental and ab initio calculation results.

Research under this task includes development of a new method that enables the calculation of displacements of atoms based on the elasticity of the infinitesimal dislocations and the construction of atomic arrangements of the dislocation core to determine the atomic arrangements in the dislocation cores using the hybrid method. 
Dislocation interaction with SIA clusters and radiation hardening. Self-interstitial Atom (SIA) clusters have a significant influence on damage evolution and the mechanical properties of irradiated materials. Kinetic Monte Carlo (KMC) computer simulations are performed to determine the kinetics of SIA cluster "clouds" in the vicinity of edge dislocations. The simulations include the elastic interactions between SIA clusters and between clusters and dislocations. Results of KMC simulations that describe the formation of clouds of SIA clusters in the presence of internal elastic fields during neutron irradiation of bcc iron and the corresponding evolution kinetics are presented, and the size and spatial distribution of SIA clusters in the cloud region are studied for a variety of neutron displacement damage dose levels. The main features of the investigations are (1) determination of the kinetics and spatial extent of defect clouds near static dislocations; (2) assessment of the influence of localized patches of SIA clouds on the pinning-depinning motion of dislocations in irradiated materials; (3) demonstration of the conditions for the formation of self-organized SIA raft patterns as a result of the interaction between mobile dislocations and glissile SIA clusters; and (4) estimation of the radiation-hardening effects of SIA clusters. A study of the collective dynamics of thousands of SIA clusters, driven in their motion by their own interactions and by their interactions with moving dislocations, is conducted to demonstrate some of the conditions for the emergence of a self-organized pattern of SIA cluster rafts. It is also shown that the critical stress to unlock trapped dislocations from SIA cluster clouds is in reasonable agreement with experimental observations.

Research under this task includes continued dislocation dynamics simulations of the collective motion of large numbers (over several thousand) of SIA clusters and moving dislocations to investigate SIA cluster patterns in irradiated iron.

Crystal plasticity modeling of localized deformation. The objective of this research is to develop an understanding of the mechanical behavior and dislocation microstructure evolution of single and polycrystals and to delineate the physical and mechanical origins of spatially localized plastic deformation in irradiated materials. A rate-independent crystal plasticity model was developed to incorporate micromechanics, crystallinity, and microstructure into a continuum description of finite strain plasticity. A comprehensive dislocation density model based on rate theory is employed to determine the strain hardening behavior within each plastic slip system for the fcc crystal structure. Finite strain effects and the kinematics of crystal plasticity are coupled with the dislocation-density-based model via the hardening matrix in crystal plasticity. The developed material models are applied to study single and polycrystal deformation behavior of copper. Interfaces between the ABAQUS user's subroutine Umat and the ABAQUS main code are developed to allow further extension of the current method. Simulations carried out for polycrystals clearly illustrate the heterogeneous nature of plastic strain, and the corresponding spatial heterogeneity of the mobile dislocation density. The origins of the spatial heterogeneities are essentially geometric, as a result of constraints on grain rotation (finite strain effects), geometric softening due to plastic unloading of neighboring crystals.

Research under this task includes continued development of a rate theory model for dislocation populations in irradiated iron, including spatial gradient effects in the rate theory model of dislocation populations, continued development of a crystal plasticity framework that includes dislocation populations in the finite element model (FEM) solutions, and applications of the crystal plasticity model to polycrystalline material deformation.

\subsubsection{Cladding and Structural Materials for Advanced Nuclear Energy Systems}

This activity is being initiated this year at the University of Michigan under the direction of Prof. Gary S. Was. 


\subsubsection{Research objectives}

The goal of this consortium is to address key materials issues in the most promising advanced reactor concepts that are yet to be resolved, or that are beyond the existing experience (dose/burnup) base, in order to (1) provide for a sound fundamental and engineering basis for operation in the intended application, (2) bring together key university, national laboratory, and industry capability and support in order to provide the most comprehensive approach possible, and (3) create a long-term, evolutionary program that seeks to address these and future nuclear materials issues in a progressive manner. This consortium will serve as a nucleation site, about which materials research activities will be catalyzed and grown among the leading individuals and institutions from academia, the national laboratories and industry. It represents an unprecedented opportunity to combine expertise and facilities in an effort to attack the challenge of materials behavior under irradiation on a scale that is not feasible for a single individual or institution.

The objectives of this research are as follows:

- Develop an understanding of the high-dose radiation stability of candidate sodiumcooled fast reactor (SFR) cladding and duct alloys under the expected range of temperatures and dose, using a closely integrated program that combines targeted charged particle and neutron irradiation, in situ irradiation, and computer simulation of defect microstructure

- Determine the stability of oxide-dispersion-strengthened (ODS) steel and hightemperature ultrafine precipitate-strengthened (HT-UPS) austenitic steel

- Characterize and understand the mechanisms for irradiation creep in silicon carbide (SiC) in TRISO fuel, ferritic-martensitic (F-M) alloys, and ODS and HT-UPS steels

- Develop barrier layers for protection of F-M alloys from fuel-clad chemical interaction and of Alloy 617 from attack by coolant impurities in the intermediate heat exchanger of the VHTR

- Develop modeling tools to explain the behavior of F-M steels under irradiation and predictive tools to extend the reach of understanding beyond the experimental database

The objectives will be accomplished in a research program consisting of three major thrusts: (1) high-dose-radiation stability of advanced-fast-reactor fuel cladding alloys, (2) irradiation creep at high temperature, and (3) innovative cladding concepts embodying functionally graded barrier materials. While the initial 3-year program will emphasize ion irradiation and irradiated microstructures, we expect that, if successful, the second 3-year program will increasingly emphasize reactor irradiations and will include mechanical property determination through national user facilities.

Industry partners (EPRI and GE) will utilize the core program as leverage to guide or support additional activities that are of special interest to them and that fall within the scope of the core program. National laboratory partners (ANL, INL, LANL, ORNL, and PNNL) will provide additional capability and direction to various aspects of the core program that are of interest to them. The technical society partner, ASME, will introduce the data generated by the consortium into the ASME Codes \& Standards (C\&S) process.

\subsubsection{Research highlights}

The major tasks comprising this program are as follows:

- High-dose-radiation stability of advanced-fast-reactor fuel cladding and structural materials

— Formation and characterization of irradiated microstructures 
— In situ ion irradiation

- Simulation and microstructure evolution

- Characterization of neutron irradiation effects

- Irradiation creep at high temperatures

- Irradiation creep of candidate materials for high-temperature application

- Transmission electron microscopy study of the creep and strengthening mechanisms

- Innovative cladding concepts embodying functionally graded barrier materials

- Barrier layer process development

- Barrier layer durability

Beyond scientific achievements, this consortium will provide substantial additional outcomes that are expected to provide long-term benefits to the advanced rector program, including the education of numerous graduate students and several post-docs, inclusion of minority students into the radiation effects and reactor materials fields through the participation of Alabama A\&M University (an HBCU institution), creation of new working relationships between universities, laboratories, and industry in an unprecedented manner and to an unprecedented degree, and establishment of a pathway to begin to incorporate data generated by the research thrusts into the ASME codes and standards that will be crucial for success of the advanced reactor programs.

\subsubsection{Alloys for $1000^{\circ} \mathrm{C}$ Service in the Next Generation Nuclear Plant}

This activity is being completed this year at the University of Michigan under the direction of Prof. Gary S. Was.

\subsubsection{Research objectives}

The objective of this project is to define strategies for improving alloys used for structural components in high-temperature helium reactors, such as the intermediate heat exchangers and primary-to-secondary piping. Specifically, the project will investigate oxidation/ carburization from helium impurities, microstructural stability, and impact on creep behavior at temperatures between 900 and $1000^{\circ} \mathrm{C}$. The aim is to better understand the synergisms among these critical processes and to provide data for long-term prediction of properties.

The design of the VHTR proposed for the NGNP project calls for outlet gas temperatures of up to $950^{\circ} \mathrm{C}$. These are extremely challenging conditions for operating the metallic components in the IHX and primary-to-secondary piping. Inconel 617, an advanced nickelbased alloy, has been identified as a leading candidate for such applications. However, its material properties in a high-temperature, impure-helium environment are not sufficiently understood to qualify this alloy for service. Therefore, this study will also investigate alloy and microstructure modifications needed to enhance Inconel 617 properties.

\subsubsection{Research progress}

Experiments on the behavior of Alloy 617 in $\mathrm{He}-\mathrm{CO}-\mathrm{CO}_{2}$ gas have been conducted for six gas mixtures in which the $\mathrm{CO} / \mathrm{CO}_{2}$ ratio varies between 7.2 and 1320 and between temperatures of $850^{\circ} \mathrm{C}$ and $1000^{\circ} \mathrm{C}$. The mixture with a $\mathrm{CO} / \mathrm{CO}_{2}$ ratio of 7.2 and temperatures of $950^{\circ} \mathrm{C}$ and $1000^{\circ} \mathrm{C}$ results in a net production of $\mathrm{CO}$, while at temperatures of 900 and $850^{\circ} \mathrm{C}$ and at all $\mathrm{CO} / \mathrm{CO}_{2}$ ratios above $7.2, \mathrm{CO}$ is consumed at all temperatures 
(Fig. 4.1). Exposure of 617 to a $\mathrm{CO} / \mathrm{CO}_{2}$ ratio of 7.2 at 950 and $1000^{\circ} \mathrm{C}$ causes oxidation and decarburization of the sample, indicated by an initial weight loss (Fig. 4.2a). The lower temperatures at a ratio of 7.2 and all other temperatures at all other $\mathrm{CO} / \mathrm{CO}_{2}$ ratios resulted in oxidation and carburization, as typified by the plot for a $\mathrm{CO} / \mathrm{CO}_{2}$ ratio of 455 (Fig. 4.2b). For $\mathrm{CO} / \mathrm{CO}_{2}$ ratios above 7.2 , oxidation is characterized by formation of a chromium-rich external scale, internal oxidation of aluminum to form alumina, and formation of a thin discontinuous layer of alumina just below the external oxide scale at all temperatures (Fig. 4.3). For all $\mathrm{CO} / \mathrm{CO}_{2}$ ratios above 7.2, the partial pressure of $\mathrm{CO}$ in helium is high enough for the $\mathrm{CO}$ to react with chromium to form chromium carbide and chromium oxide according to

$$
(27 / 6) \mathrm{Cr}+\mathrm{CO} \Leftrightarrow(1 / 6) \mathrm{Cr}_{23} \mathrm{C}_{6}+(1 / 3) \mathrm{Cr}_{2} \mathrm{O}_{3}
$$
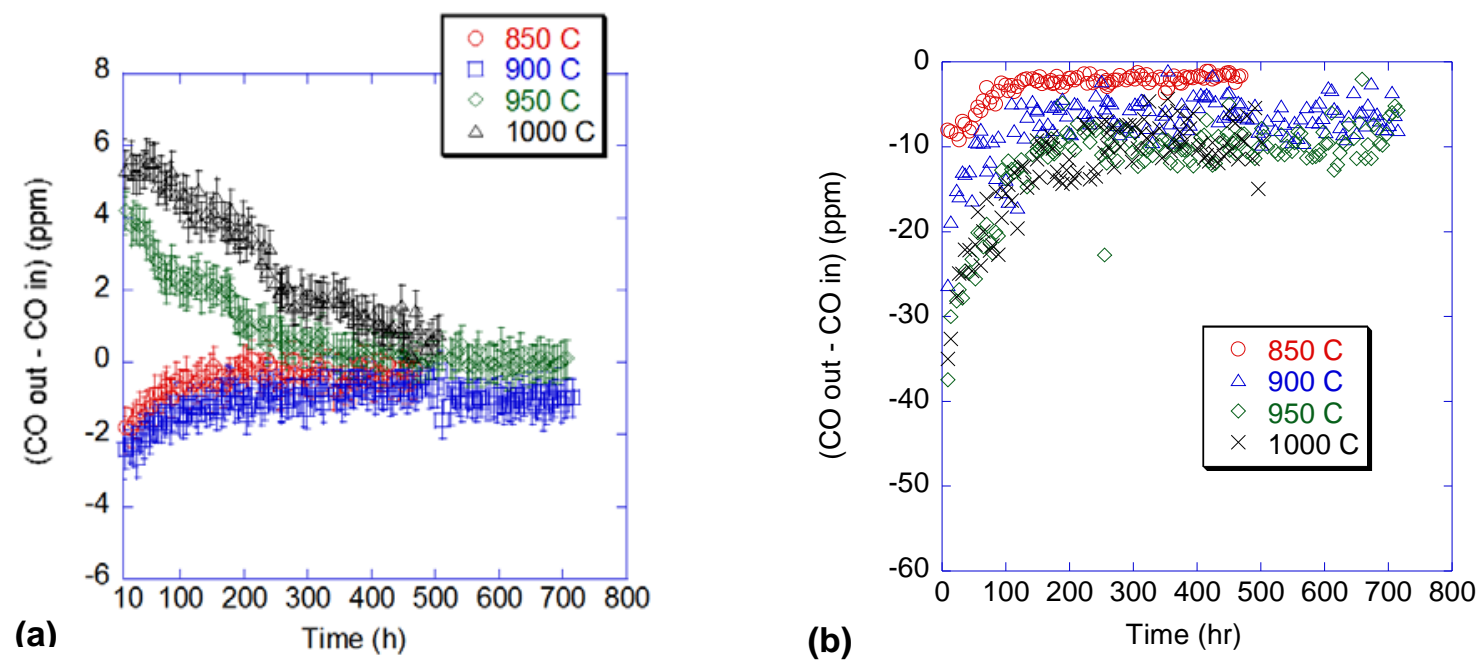

Fig. 4.1. Plot of the difference between the $\mathrm{CO}$ concentrations at the outlet and inlet for (a) a $\mathrm{CO} / \mathrm{CO}_{2}$ ratio of 7.2 and (b) a $\mathrm{CO} / \mathrm{CO}_{2}$ ratio of 455 at $850,900,950$, and $1000^{\circ} \mathrm{C}$.
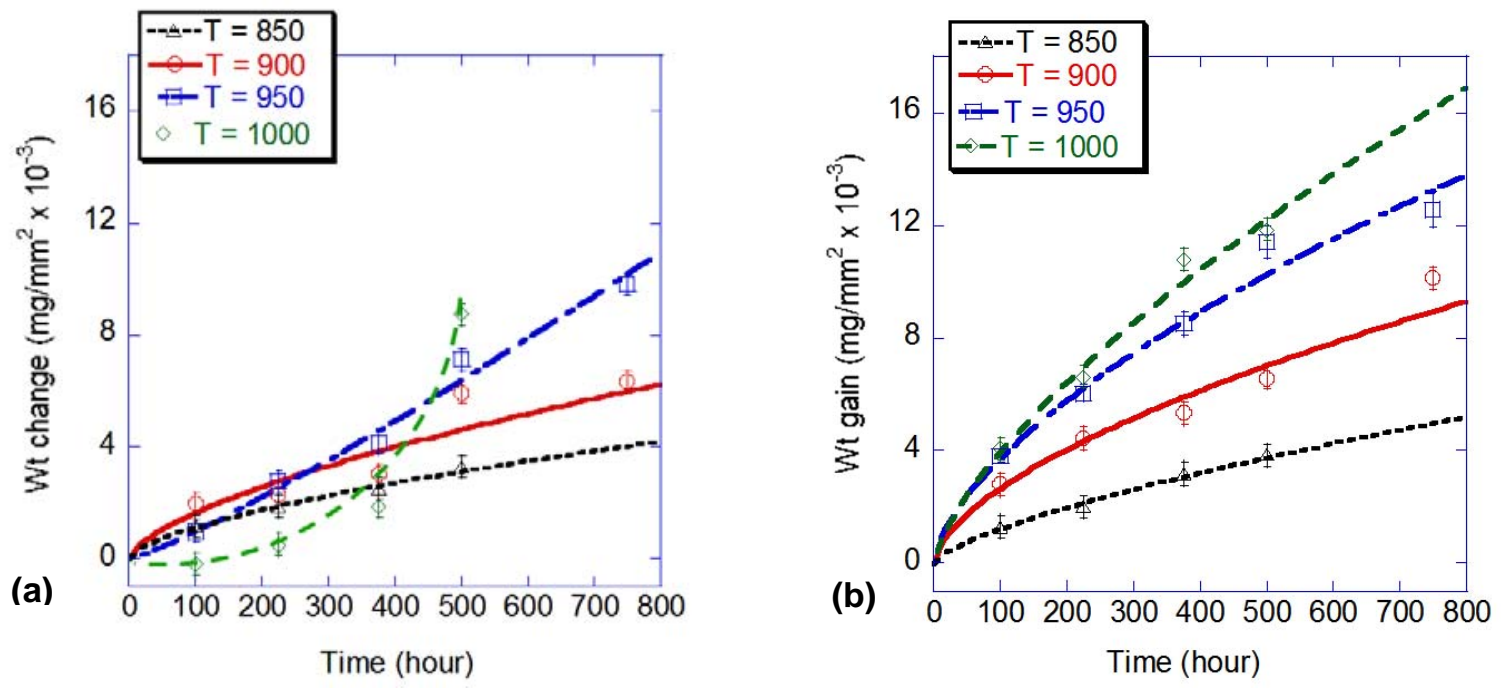

Fig. 4.2. Weight change for alloy 617 over the temperature range $850-1000^{\circ} \mathrm{C}$ in (a) a $\mathrm{CO} / \mathrm{CO}_{2}$ ratio of 7.2 and $(\mathrm{b})$ a $\mathrm{CO} / \mathrm{CO}_{2}$ ratio of 455 . 

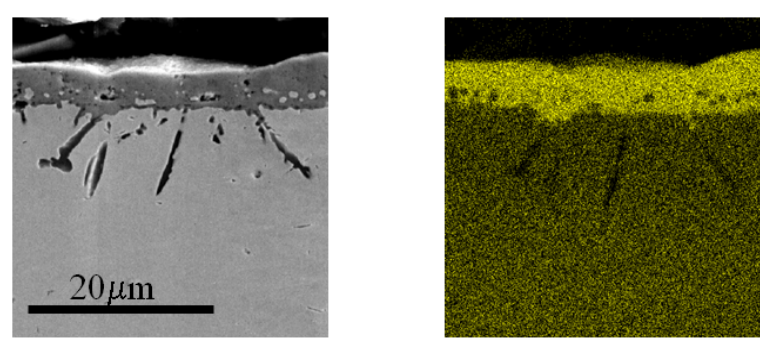

Chromium

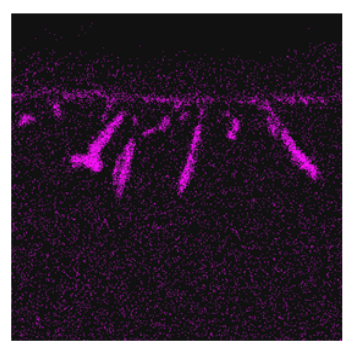

Aluminum

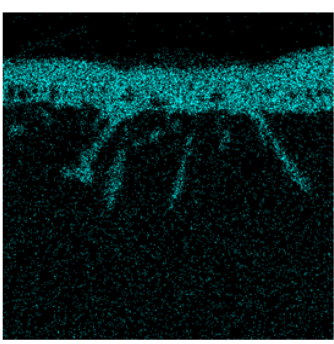

Oxygen

Fig. 4.3. SEM image and corresponding $x$-ray maps for chromium, aluminum, and oxygen for a sample of 617 exposed to a $\mathrm{CO} / \mathrm{CO}_{2}$ ratio of 455 for $750 \mathrm{~h}$ at $950^{\circ} \mathrm{C}$.

over the temperature range $850-1000^{\circ} \mathrm{C}$. However, the partial pressure of $\mathrm{CO}$ in a gas mixture with $\mathrm{CO} / \mathrm{CO}_{2}=7.2$ and above 950 and $1000^{\circ} \mathrm{C}$ is low enough to cause the reaction above to proceed in the reverse direction, resulting in decarburization and the release of CO, as observed.

The first set of experimental alloys (J-series) that exhibited potential in terms of oxidation resistance (weight loss/gain) and creep strength (in compression) at $1000^{\circ} \mathrm{C}$ consisted of the compositions listed in Table 4.3.

Table 4.3. Composition of potential high-temperature nickel alloys from the J-series

\begin{tabular}{cccccccccc}
\hline Alloy & Cr & Co & Mo & W & Re & Al & C & $\begin{array}{c}\text { Wt. gain } \\
\left(\mathbf{m g} / \mathbf{c m}^{2} \text { ) }\right.\end{array}$ & $\begin{array}{c}\text { Compressive } \\
\text { strength } \\
\text { (MPa) }\end{array}$ \\
\hline J2 & 12 & - & - & 12 & - & 3 & 0.05 & 1.2 & 123 \\
J6 & 15 & 12 & 2.7 & 5.3 & 7.6 & 2.3 & 0.05 & 0.175 & 133 \\
J7 & 15 & 12 & -3 & 8 & 6 & 2.3 & 0.05 & 0.92 & 113 \\
J8 & 15 & 12 & 3 & 12 & 3 & 2.3 & 0.05 & 0.42 & 123 \\
J9 & 12 & 12 & 3 & 8 & 6 & 2.3 & 0.05 & 0.08 & 123 \\
\hline
\end{tabular}

Based on the oxidation results, the order or increasing oxidation resistance for the $\mathrm{J}$-alloys listed in Table 4.3 is $\mathrm{J} 2<\mathrm{J} 7<\mathrm{J} 8<\mathrm{J} 6<\mathrm{J} 9$. The preliminary impure-helium exposure results for $\mathrm{J}$-alloys in atmosphere $\# 1\left(\mathrm{CO} / \mathrm{CO}_{2}=7.2\right)$ at $1000^{\circ} \mathrm{C}$ is shown in Fig. 4.4. The alloys with Re addition exhibited decreased weight gain at $25 \mathrm{~h}$ and $50 \mathrm{~h}$ of exposure compared to the Re-free J2 alloys. Additionally, the weight gain is seen to decrease with increasing Re between J8 (3 wt \% Re), J9 (6 wt \% Re) and J6 (7.6 wt \% Re) alloys, in that order. Evidently, the Re additions are affecting reactions at $1000^{\circ} \mathrm{C}$ in this decarburizing atmosphere and exhibit potential for corrosion resistance in these atmospheres. The order or increasing corrosion resistance for the J-alloys under impure helium exposure is $\mathrm{J} 2<\mathrm{J} 8<\mathrm{J} 6<\mathrm{J} 9$; this is similar to the oxidation behavior. Preliminary $\mathrm{X}$-ray diffraction analysis has shown that the presence of Re may discourage the formation of $\mathrm{Cr}_{2} \mathrm{O}_{3}$ compared with $\mathrm{Al}_{2} \mathrm{O}_{3}$. This is important because $\mathrm{Cr}_{2} \mathrm{O}_{3}$ becomes unstable at temperatures near or above $1000^{\circ} \mathrm{C}$ compared to the stable $\mathrm{Al}_{2} \mathrm{O}_{3}$. Further analysis is currently under way. 


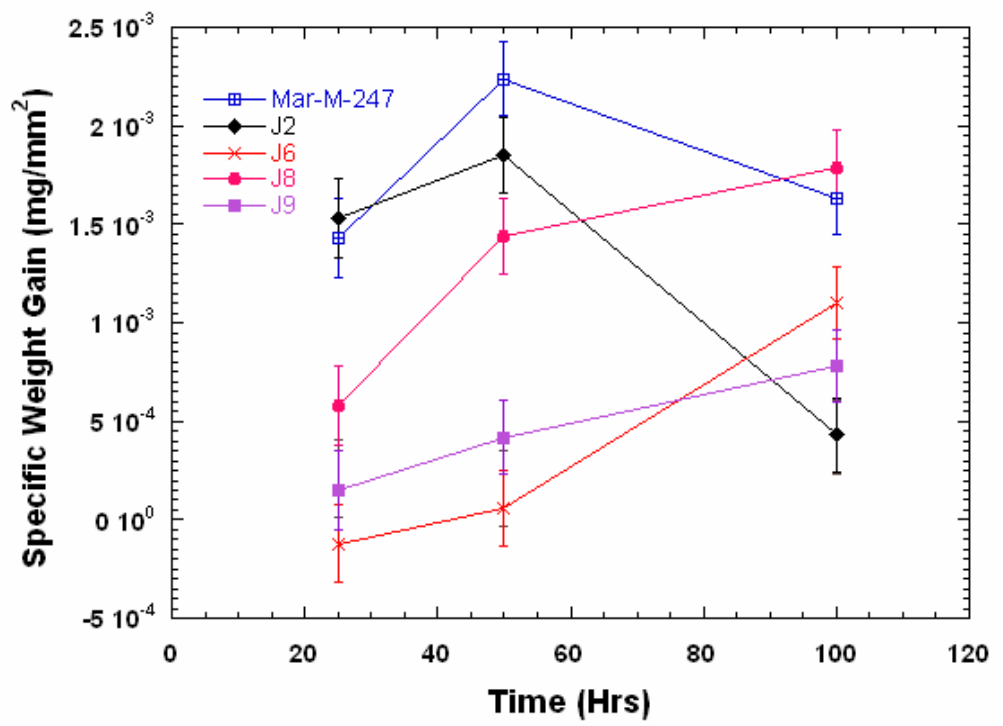

Fig. 4.4. Specific weight gain of J-alloys containing Re during impure-helium exposure at $1000^{\circ} \mathrm{C}$. Except the $\mathrm{J} 2$ alloy, J6, J8, and $\mathrm{J} 9$ alloys contain $7.6 \mathrm{wt} \%, 3 \mathrm{wt} \%$, and $6 \mathrm{wt} \% \mathrm{Re}$, respectively.

\subsubsection{Ab Initio-Based Modeling of Radiation Effects in Multi-Component Alloys}

This activity is being conducted at the University of Wisconsin under the direction of Prof. Dane Morgan.

\subsubsection{Research objectives}

Due their structural stability and creep and corrosion resistance at high temperatures, nickel-based alloys are under consideration for pressure vessel internals (piping, core barrel), ducts, and IHXs. These alloys will be exposed to low-level stress, temperatures from $450-1000^{\circ} \mathrm{C}$, limited radiation dose, and corrosive environments for extended periods. A quantitative understanding of materials changes in these conditions is important for materials qualification and optimization. Direct experimental exploration of the relevant space of compositions, temperatures, and timescales is not practical, so physics-based models, or simple correlations, must be established to predict properties in these environments. Diffusion constants are a fundamental materials property essential for physics-based models of phase transformations, corrosion, and microstructural evolution. However, the diffusion constants in complex nickel alloys have proven difficult to establish over a wide range of temperatures and compositions. The goal of this work is to use modern quantum mechanical ab initio methods and recent developments in alloy theory to predict diffusion constants for nickel-based alloys. The modeling approach makes it possible to derive the full diffusion constant matrix, describing the coupled motion of all the species, as a function of composition, chemical ordering, and temperature.

\subsubsection{Research highlights}

Recent work. Work over the last 2 years has focused on establishing the point defect properties governing diffusion in nickel-rich model alloys of fcc Ni-Fe-Cr. Results have already yielded a significant changes in our picture of diffusion in this system. ${ }^{51}$ Table 4.4 
Table 4.4. Hopping barriers in nickel-rich Ni-Fe-Cra

\begin{tabular}{ccc}
\hline $\begin{array}{c}\text { Migrating } \\
\text { species }\end{array}$ & $\begin{array}{c}\text { Vacancy } \\
\text { barrier } \\
(\mathbf{e V})\end{array}$ & $\begin{array}{c}\text { Interstitial barrier } \\
(\mathbf{e V})\end{array}$ \\
\hline $\mathrm{Cr}$ & 0.82 & 0.08 \\
$\mathrm{Fe}$ & 0.95 & 0.11 \\
$\mathrm{Ni}$ & 1.08 & 0.14 \\
\hline
\end{tabular}

${ }^{a}$ The wide range of values for vacancies is unexpected, and the species dependence of the interstitial hops had not been previously measured.

shows the hopping barriers for nickel, iron, and chromium through both vacancy and interstitial mechanisms. For vacancy hops, values can be used to predict tracer diffusion constants that are consistent with experiments within the measurement errors bars (Fig. 4.5). Nonetheless, the barriers predicted are quite different from those proposed in the literature, ${ }^{52,53}$ which were nearly identical for the three species. The new values strongly suggest different diffusion of the different species, particularly at lower temperatures.

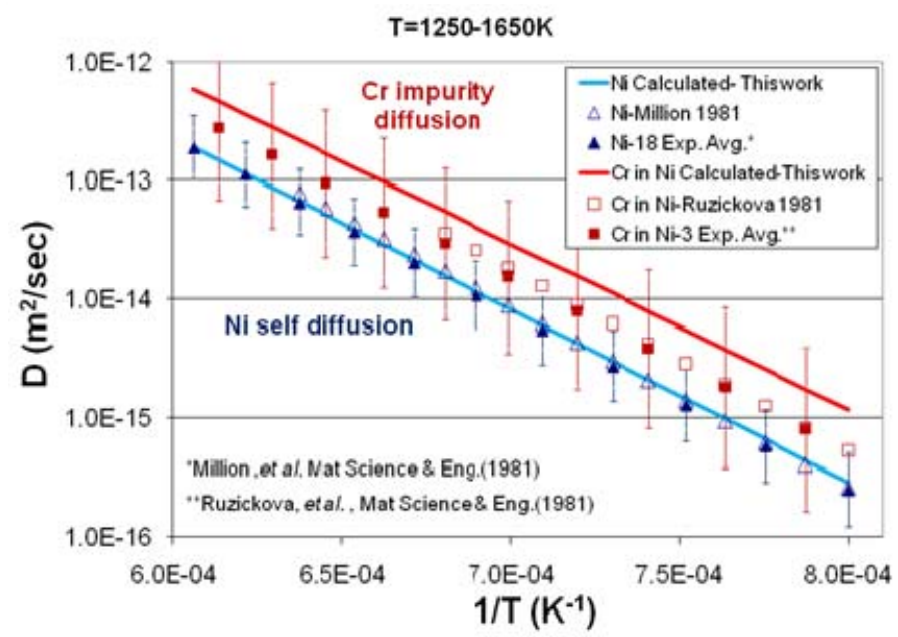

Fig. 4.5. Predicted and measured diffusion constants for nickel and dilute chromium in nickel

Future work. Work to date has proven we can predict dilute diffusion over a range of temperatures accurately in terms of atomic-scale ab initio-derived parameters (Fig. 4.6). The next step is to model concentrated alloys, where the atomic interactions will impact diffusion. We adopt a framework recently developed for binary alloys to our ternary problem. ${ }^{54,55}$ This multi-scale approach fits the atomic energies to a simplified cluster model and then uses Monte Carlo techniques and statistical mechanics theory to derive the diffusion constants.

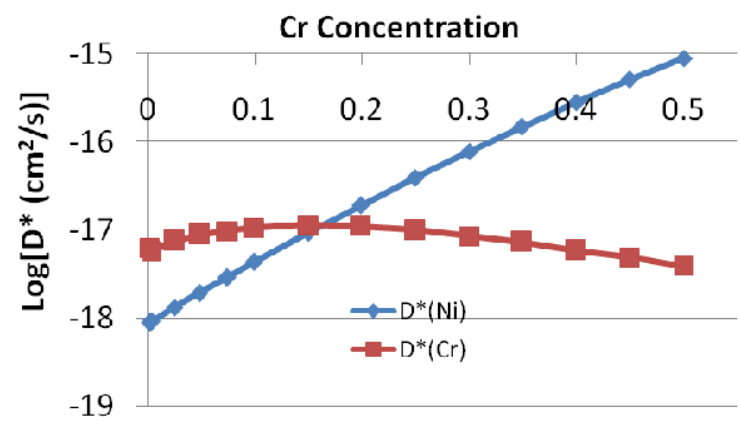

Fig. 4.6. Predicted concentration dependence of tracer diffusion constants under simple interaction model. 
The approach is somewhat complex to implement but, once developed, will enable modeling of transport in concentrated alloys for many applications beyond just Ni-Fe-Cr fcc steels. As an example of the model for a binary suballoy, we show results for a $\mathrm{Ni}$-Cr solid solution at $1000 \mathrm{~K}$ based on the same parameters used for the dilute case above. While this extrapolation of the dilute energetic is very approximate, we see that the effects of concentration can be dramatic, in this case due to couplings between the concentrated atoms causing changes in the activation barriers. Based on hundereds of ab initio calculations now under way, we hope to predict the full diffusion constant matrix for the $\mathrm{Ni}-\mathrm{Fe}-\mathrm{Cr}$ model alloy system. For the first time this will provide complete diffusion properties as a function of temperaute, composition, and ordering and connect these values to the atomic-scale interactions in the alloy. In the future, this model can be extended to include minor elements used in real industrial steels.

\subsubsection{Emissivity of Candidate Materials for VHTR Applications: Role of Oxidation and Surface Modification Treatments}

This activity is being conducted at the University of Wisconsin under the direction of Research Prof. Kumar Sridharan.

\subsubsection{Research objectives}

The Reactor Pressure Vessel (RPV), which represents the outermost metallic structural boundary of a nuclear reactor, and the internal components (power conversion system components such as turbomachinery, heat exchangers, connecting pipelines) rely partially on radiation from their outer surface for cooling. This is particularly the case in VHTRs, where higher temperatures are targeted. Furthermore, in the event of an unexpected hightemperature excursion, the dependence on radiation for the expulsion of heat from the system becomes critically important because of the fourth-power temperature dependence of radiated heat. The key material parameter that dictates the extent of heat radiated from the surface is emissivity, which is defined as the ratio of emissive power (power radiated per unit area) of the material's surface to that of an ideal black body.

Emissivity is a surface phenomenon and is dictated by the material's surface chemical composition as well as the physical nature of the surface such as roughness, porosity, and texture. Since oxidation (and carburization) of the surface will inevitably occur at high temperatures, it is important that studies on evaluation of emissivity for candidate materials be closely integrated with the evaluation of emissivities of the oxide layers that form on these materials at various elevated temperatures and at various stages of growth. Emissivity of the oxide layers will depend on the composition and physical characteristics of the oxide as well as its mechanical stability, which in turn are dictated by the composition of the alloy and exposure temperature. Given that thermal radiation is a surface phenomenon, opportunities also exist to apply an array of emerging and commercial surface treatments to change the physical and compositional nature of the surface in order to achieve higher thermal radiation capabilities, independently, without affecting the critical bulk material property requirements such as strength, toughness, weldability, and fabricability. The NGNP Materials Research and Development Program Plan ${ }^{39}$ has identified emissivity and its relationship to the properties of oxide layers and surface treatments as a potential area for research for future nuclear reactors. The objectives in this research program are as follows: 
1. Evaluate emissivities of candidate materials (code-certified alloys of both ferritic and austenitic categories) for RPV and internal components for the VHTR in the temperature range of $300^{\circ} \mathrm{C}$ to $900^{\circ} \mathrm{C}$ in air and helium (with expected contaminants) environments. Procedures for evaluation of emissivities to specifically address the needs of NGNP materials will accrue from this work.

2. Apply emerging and commercial surface treatments to induce physical and compositional changes of the alloy's surface and evaluate emissivities of surface-treated alloys after exposure to elevated temperatures in the range of $300^{\circ} \mathrm{C}$ to $900^{\circ} \mathrm{C}$ (also in air and impure helium environments). The effects of surface treatments on oxidation resistance of alloys will also accrue from this study.

3. Perform detailed characterization of surface oxides that form on the surface of the untreated and surface-modified alloys after elevated-temperature exposure in order to develop a comprehensive understanding of the relationships between emissivity, oxide characteristics, and surface treatments.

4. Develop an integral separate-effects emissivity database for potential candidate materials and surface modification treatments that is applicable to VHTR RPV and internal component materials and designs.

\subsubsection{Research highlights}

Materials to be investigated. The alloys selected for this study are of direct relevance to the NGNP-VHTR program and include T91, SA508, and T22 ferritic steels and austenitic alloys Inconel 617, Incoloy $800 \mathrm{H}$, Haynes 230, and 304 stainless steel. Additionally, the effects of commercial and emerging surface treatment technologies on high-temperature spectral emissivity will also be investigated. These surface treatments include shot peening, xenon ion bombardment (for nanoscale surface topographical modification), and coatings of silicon carbide, chromium oxide, hafnium oxide, and diamond-like carbon.

Design of the system for real-time measurements of high-temperature spectral emissivity of VHTR material. An experimental system for in situ high-temperature measurements of spectral emissivity of VHTR materials has been designed and constructed. The design consists of a cylindrical block of silicon carbide 8 in. in diameter and $8 \mathrm{in}$. in height with seven machined cavities for placement of test samples, as well as a black body cavity. Additionally, thermocouple inlet holes are provided in the block for the direct measurements temperatures in the vicinity of samples and black body. The block is

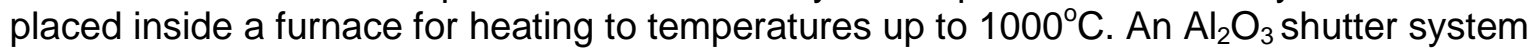
allows for selective exposure of a given sample while insulating the optical system from the radiant heat emitting from the furnace. An optical periscope guides the thermal radiation from the sample to a Fourier Transform Infra Red (FTIR) spectrometer which is used for real-time measurements of spectral emissivities over a wavelength range of $0.8 \mu \mathrm{m}$ to $10 \mu \mathrm{m}$, at high temperatures. To specifically address the needs of VHTR applications, the system has been designed for studies in VHTR-grade helium environments and air transients. Inlet and outlet gas compositions are measured using a gas chromatograph, which in conjunction with ex situ analysis of the samples by electron microscopy and $\mathrm{x}$-ray diffraction will allow for the correlation of surface corrosion of the materials and their spectral emissivities under different operating and off-normal conditions. Figure 4.7 shows a schematic illustration of the test facility. 


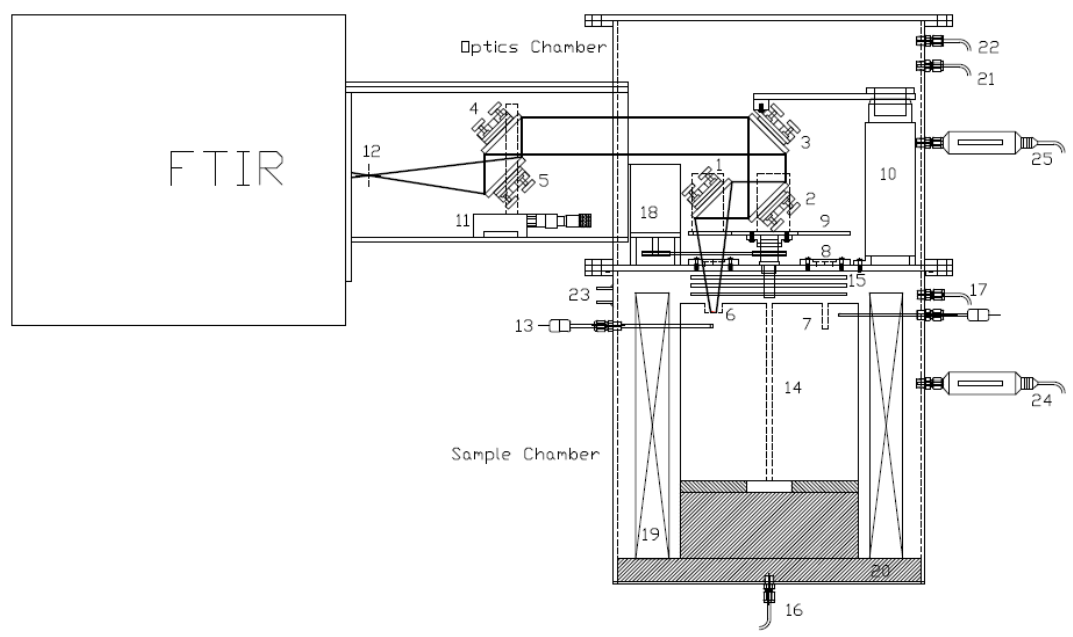

Fig. 4.7. Schematic illustration of the high-temperature spectral emissivity measurement system. (1, 5) Collimating mirrors; (2, 3, 4) Flat mirrors; (6) Test samples; (7) Black body; (8) Aperture and calcium fluoride window; (9) Optical plate and rod assembly; (10) Vertical optical adjustment; (11) Optical stage and post assembly; (12) FTIR focus point; (13) thermocouples; (14) Silicon carbide block; (15) Ceramic radiation shields; (16) Test gas inlet; (17) Test gas outlet; (18) Stepper motor; (19) Radiation heaters; (20) Alumina insulation; (21) Cover gas inlet; (22) Cover gas outlet; (23) 240 V power in; (24) Sample chamber pressure transducer; (25) Optical chamber pressure transducer.

\subsection{INTERNATIONAL PROGRAMS}

DOE's Office of Nuclear Energy supports both bilateral and multilateral international research agreements that include major activities related to the development of materials for VHTR systems. International Nuclear Energy Research Initiatives (I-NERIs) are the bilateral arrangements with individual foreign partners. The multilateral agreement for VHTR materials development is part of DOE's involvement with the Generation IV International Forum (GIF). Both sets of interactions are described in this section.

\subsubsection{I-NERI Programs}

DOE's I-NERI mission is to sponsor innovative scientific and engineering R\&D in cooperation with international partner countries. This mission includes the DOE directive to address key issues affecting the future use of nuclear energy and its global deployment by improving cost performance, increasing proliferation resistance, enhancing safety, and improving the waste management of future nuclear energy systems.

Through its mission, the I-NERI program is designed to foster closer collaboration among international and U.S. researchers, improve communications, and expand the sharing of nuclear research information. In order to accomplish its assigned mission, the I-NERI program has established the following overall objectives:

- To develop advanced concepts and scientific breakthroughs in nuclear energy and reactor technology in order to address and overcome the principal technical and scientific obstacles to expanding the global use of nuclear energy

- To promote bilateral and multilateral collaboration with international agencies and research organizations to improve the development of nuclear energy

- To promote and maintain a nuclear science and engineering infrastructure to meet future technical challenges 
There are currently two I-NERIs active that are related to structural materials for VHTRs, one with France on mechanical and corrosion testing of high-temperature nickel-based alloys for VHTR applications and one on VHTR environmental and irradiation effects on high-temperature materials with the Republic of Korea (ROK).

\subsubsection{U.S.-French I-NERI high-temperature nickel-based alloys for VHTR applications: mechanical and corrosion testing}

Research objectives. The VHTR is a helium-cooled reactor operating with outlet temperatures exceeding $950^{\circ} \mathrm{C}$. There are two main advantages of this concept-high yields for energy generation and the ability to supply high-temperature process heat for hydrogen production. However, the high temperatures impose challenging design requirements on structural materials, particularly for the IHXs.

Nickel-based alloys are the most suitable materials for high temperatures, particularly Inconel Alloy 617 and Haynes 230. However, these alloys are not fully ASME code-qualified for nuclear applications. Basic data are needed to achieve a complete understanding of their behavior at high temperatures. Researchers must investigate the mechanical properties of these alloys and study surface/subsurface corrosion effects caused by helium impurities. As component integrity must be demonstrated over the entire operational lifetime (on the order of $100,000 \mathrm{~h}$ ), the evolution of properties over time must be taken into account, specifically the effects of thermal aging.

In this work, researchers will conduct experimental thermal aging studies of Alloy 617 and Haynes 230 through short-duration $(500 \mathrm{~h})$ and medium-duration (5,000 h) exposure tests of material coupons and specimens. Through these experiments, they will evaluate the microstructural evolution under thermal aging conditions and determine the effect of thermal aging on Charpy and tensile test data. They will use the results of these studies to develop a model capable of extrapolating the effects of thermal aging on materials properties over a very long duration in order to predict component lifetimes. Finally, they will validate the model by conducting long-exposure testing on material specimens to $15,000 \mathrm{~h}$.

Research highlights. Both the United States and France have exposed specimens of Alloys 617 and 230 in various helium environments that may represent coolant environments for VHTRs. Critical temperatures have been determined for the stability of the chromium oxide as a function of material and coolant chemistry. Alloy 230 has been shown to be much more sensitive to carburization than 617 , though both alloys exhibit increasing carburization with increasing coolant content of $\mathrm{CH}_{4}$. Moreover, tensile ductility of both alloys decreased as they became oxidized and carburized, with large reductions in the ductility of 230 , the carburized condition. Aging of the alloys in air also significantly reduced the impact toughness and tensile ductility of both alloys, with aging at $800^{\circ} \mathrm{C}$ having much greater reductions for Alloy 617 than aging at $1000^{\circ} \mathrm{C}$. There did not appear to be a saturation of the toughness reductions out to aging times of $10,000 \mathrm{~h}$ for 617 , raising concerns about these properties at very long lives. A lack of saturation in effects of hold times for the conditions examined on the creep-fatigue behavior raised similar flags. These interim conclusions have demonstrated the need for longer aging times in air and carburizing environments to assess the degradation of tensile and impact properties.

\subsubsection{U.S.-ROK I-NERI VHTR environmental and irradiation effects on high- temperature materials}

Research objectives. This project seeks to select and qualify high-temperature materials for the next generation of reactors. The collaboration will include work to analyze 
irradiation and environmental effects and to develop a materials handbook containing the properties of high-temperature metallic materials.

Specifically, researchers will study the effects of helium environments on the mechanical properties of high-temperature metallic alloys proposed for use in the VHTR. The helium primary coolant in an operating VHTR is expected to be contaminated by small amounts of gaseous impurities from a variety of sources. Corrosion of structural alloys by these impurities at elevated temperatures can be significant. Researchers will also evaluate the effects of irradiation on these alloys using ROK's High-Flux Advanced Neutron Application Reactor (HANARO) and the Irradiated Materials Evaluation Facility (IMEF). Reactor operating conditions are very challenging for these materials, and they require qualification against the effects of irradiation. Materials testing of key components, such as the reactor pressure vessel, will provide the necessary design data and develop and confirm available margins. Lastly, researchers will develop the Generation IV Materials Handbook containing a database of high-temperature materials.

Research highlights. In the first year of this I-NERI, significant progress was made on three tasks. On the U.S. side, environmental studies in Alloys 617 and 230 were initiated and the development of the Gen IV Handbook to the point of allowing international access was completed. The Koreans completed the design of pool-side irradiation facilities for exposure of $9 \mathrm{Cr}-1 \mathrm{Mo}$ steel fracture specimens and began irradiations.

Specimens of Alloys 617 and 230 were exposed in various helium environments that may represent coolant environments for VHTRs. Alloy 230 has been shown to be much more sensitive to carburization than 617 , though both alloys exhibit increasing carburization with increasing coolant content of $\mathrm{CH}_{4}$. Moreover, tensile ductility of both alloys decreased as they became oxidized and carburized, with large reductions in the ductility of 230, the carburized condition. Aging of the alloys in air also significantly reduced the impact toughness and tensile ductility of both alloys, with aging at $800^{\circ} \mathrm{C}$ having much greater reductions for Alloy 617 than aging at $1000^{\circ} \mathrm{C}$. There did not appear to be a saturation of the toughness reductions out to aging times of $10,000 \mathrm{~h}$ for 617 , raising concerns about these properties at very long lives.

Details on the overall Generation IV Materials Handbook status and activities are contained Sect. 4.5.2 of this report, but interactions with Korea as part of this I-NERI are focused on bilateral access to the information developed by each partner using the Handbook as a vehicle. The demonstration version of the Handbook loaded with publically exportable data and information has been shared with the Koreans, and access procedures to ensure only bilateral access to the actual I-NERI information are being developed. It is envisioned that this information will likely be made available on a multilateral basis with the other GIF partners once the appropriate multi-lateral agreements have been executed.

I-NERI irradiations of $9 \mathrm{Cr}-1 \mathrm{MoV}$ steel are being conducted in the HANARO reactor at the Korean Atomic Energy Research Institute (KAERI). The irradiations are focused on the fracture behavior of both base- and weld-metal and include tensile, Charpy V-notch and both full and subsized precracked Charpy fracture toughness specimens that are being irradiated at $400^{\circ} \mathrm{C}$. Irradiations are being performed at a moderately low flux of about $1 \times 10^{13} \mathrm{n} / \mathrm{cm}^{2}$ (e > $1 \mathrm{MeV}$ ) to fluences up to about $2 \times 10^{19} \mathrm{n} / \mathrm{cm}^{2}-\mathrm{s}(\mathrm{e}>1 \mathrm{MeV})$. Work to date has included design and fabrication of the irradiation facility, unirradiated characterization of the material, and fabrication of the specimens to be irradiated. It is anticipated that irradiations and post-irradiation examination (PIE) will be completed during the course of the I-NERI. 


\subsubsection{Generation IV International Forum}

The primary mechanism for international collaboration for materials $R \& D$ activities in support of VHTR systems is through the Generation IV International Forum (GIF). The GIF is an international body working to advance nuclear energy to meet future energy needs. It includes nine partners that have now signed the treaty-level GIF International Framework Agreement: Canada, China, France, Japan, the Republic of Korea, the Republic of South Africa, Switzerland, the United States and the European Union. These partners have agreed on a framework for international cooperation in research necessary to build a future generation of nuclear energy systems.

The GIF objective is to have VHTR systems available for international deployment by about 2030, when many of the world's currently operating nuclear plants will be at or near the end of their operating lifetimes. Collaboration plans for materials $R \& D$ area have been developed, and once in place, execution and sharing of materials data to be jointly produced will begin immediately.

\subsubsection{VHTR materials project arrangement}

The specific international vehicle that will govern the production and exchange of GIF information on structural materials relevant to the VHTR is the Project Arrangement on Materials for the International Research and Development of the Very-High-Temperature Reactor Nuclear Energy System. This Project Arrangement (PA) is being established by the VHTR Materials Project Management Board (PMB), as part of the VHTR System Steering Committee, and covers both individual and cooperative contributions by the international partners. The initial PA will cover the exchange of materials information generated during the time frame from 2007 to 2012, as well historical information that has heretofore not been publicly available. Information will be generated and exchanged on three major classes of materials: graphite for core components; metals for pressure boundaries, reactor internals, piping, heat exchangers, and balance of plant; and ceramics and ceramic composites for special needs, such as control rods, insulation, reactor internals, etc. All materials data identified within the PA that is produced by any partner shall be shared with all other partners for use in their national programs.

Currently, the final details of the VHTR Materials Project Plan (PP), the mandatory annex of the PA containing the specific details on contributions from each signatory, as well as individual and collective deliverables, are in the process of final review. The PP includes activities largely focused on near-term deployment of VHTRs, such as the PBMR in South Africa and the NGNP in the United States, but also includes longer-term R\&D designed to enable the advancement of VHTRs to higher temperatures. Moreover, it is expected to support both of the Gen IV advanced gas-cooled reactor systems, thus allowing a sequenced development phasing for the VHTR and the GFR. The key design parameters that will affect the choice of materials, and therefore the needed R\&D, include the reactor core geometry concept, the reactor coolant system pressure, the reactor coolant inlet and outlet temperatures, and, in the case of the indirect cycle plants, the choice of the secondary-side coolant and the associated temperatures and pressures of the secondary coolant. The anticipated specifications of the VHTR system for the establishment of the PP include an outlet core temperature greater than $900^{\circ} \mathrm{C}$ with an objective of $1000^{\circ} \mathrm{C}$. Depending on the VHTR concepts (pebble-bed- or prismatic-block-type core reactor), the inlet core temperature could range from about $400^{\circ} \mathrm{C}$ to $600^{\circ} \mathrm{C}$ and the reactor primary coolant system pressure could range from $5 \mathrm{MPa}$ to $9 \mathrm{MPa}$.

The thermal, environmental, and irradiation exposure conditions of the VHTR considered in the PP, in conjunction with a desired 60-year design life, will make selection and 
qualification of some high-temperature materials a significant challenge, thus new materials and approaches will be included. Some materials will be exposed to temperatures beyond what is currently allowed in the ASME Boiler and Pressure Vessel (B\&PV) Code for nuclear construction. Numerous areas of models and the associated computer codes will have to be modified or expanded to address these new design conditions. Particularly the question of extrapolation of material data to the required long service period (up to 60 years) must be resolved. It is clear that significant materials $R \& D$ work is required to support the design of components of these VHTR concepts, at these temperatures. This PP reflects the international, collaborative contributions to fulfill these R\&D needs.

The major activities in the VHTR materials PP will address the following topics.

\section{Assessment and evaluation of selected materials for the following reactor subsystems and components:}

- reactor pressure vessel

- high-temperature metallic core internals

- hot ducts and other pressure boundary components for the primary coolant system

- graphite used for the reflectors and support structures in the core region (resistance to irradiation and oxidation damage)

- high-temperature control rod cladding and/or guide tube components (carbon/carbon or $\mathrm{SiC} / \mathrm{SiC}$ composite materials)

- Ceramic materials for thermal insulation and corrosion resistant coating

Assessment and evaluation of selected designs, structural materials, and joining processes for the reactor/process IHX:

- Characterization of materials and welds in relevant service conditions (mechanical behavior, corrosion resistance, etc.)

\section{Specification and development of test loops and other experimental facilities, such as the following:}

- Dedicated test benches (tribology, tightness, thermal barriers, purification, etc.)

- Helium test loops for medium-size components

- Irradiation test facilities

\section{Codification of very-high-temperature mechanical design rules:}

High-temperature design methodology improvements in structural design methods, materials testing and databases, and nuclear design codes and standards will be needed. Numerous areas of the code will have to be modified or expanded to address these new design conditions. Some of the important materials issues that need to be addressed include the following:

- High-temperature mechanical properties in air and impure helium environments

- Environmental degradation processes from exposure to high-temperature helium with contaminants

- Long-term irradiation effects on mechanical properties

- High-temperature metallurgical stability (thermal aging effects)

- Development and ASME Code approval for graphite, composite, and ceramic materials

- Development of component fabrication technologies for critical components, such as the RPV and control rods 
- Emissivity of the components responsible for passive heat removal (i.e., RPV, core barrel, etc.)

- Modeling and description of materials behavior and damage development will provide the basis for codification improvements

The PP is composed of three work packages that are material specific, that is, structured to comprise detailed activities grouped on a material-specific basis (graphite, metallic materials and composites and ceramics). These materials have been designated for the following reactor sub-systems and nuclear energy system components.

- Graphite

Graphite will be used for the reflectors and support structures in the core region, and for fuel elements:

- Qualification of developmental and existing grades of graphite

- Specification and acquisition accounting for dimensional and property stability under irradiation, irradiation creep, oxidation resistance

- Behavior model development, particularly for the effects of irradiation

- Development of disposal options for graphite core structures

- Metals and design methods

Metallic materials are needed for the following:

- The reactor sub-systems: RPV, high-temperature metallic core internals, hot ducts, and other pressure boundary components for the primary coolant system

- The reactor-to-process heat-and/or primary-to-secondary-circuit IHX

The $R \& D$ program will be defined according to the service temperature conditions which are also VHTR concept dependent

- Low-temperature materials $\mathrm{T}<650^{\circ} \mathrm{C}$, notably for the reactor pressure vessel and other structural parts

- High-temperature materials will be characterized for $650^{\circ} \mathrm{C}<\mathrm{T}<950^{\circ} \mathrm{C}$ (mainly super-alloys), notably for metallic reactor internals and IHXs

- Long-term materials will be developed for $\mathrm{T}>950^{\circ} \mathrm{C}$ (such as ODS alloys, refractorybased and advanced superalloys)

- Composites and ceramics

Ceramics and composites are envisaged for the following:

- IHXs

— insulating structures

- control rods

- other internal structures, such as core restraints, belts, barrel and tie-rods

The R\&D program concerns monolithic ceramics and composite materials, meeting specific service temperature and irradiation conditions, which are also VHTR concept dependent, such as the following:

- monolithic ceramics: $\mathrm{SiC}, \mathrm{ZrC}, \mathrm{TiC}$

- fiber-reinforced $\mathrm{C} / \mathrm{C}$ - and $\mathrm{SiCf} / \mathrm{SiC}$-type materials, including coatings

— insulator materials and composites

- nanostructured and toughness-improved ceramics 
Well over $\$ 100 \mathrm{M}$ in VHTR materials data is being committed as contributions by the GIF signatories, plus significant amounts of proprietary historical data. Once the PA is signed and in effect, now anticipated to occur in the fall of 2009, detailed assessments will be made of the portion of the GIF VHTR materials data that will be available to meet the specific data needs of the NGNP and reduce the resources required by that project.

\subsection{OTHER DOE-NE VHTR MATERIALS RESEARCH PROGRAMS}

In 2008, DOE-NE narrowed the focus of their broader Gen IV research of multiple advanced reactor systems to address only the VHTR. The majority of the VHTR materials R\&D will support the NGNP project, but some activities are included that cover the broader requirements of VHTR systems, including higher output temperatures and materials databases to support VHTR development.

\subsubsection{Nanostructured Materials for High-Temperature Service}

Currently available commercial alloys have well recognized and codified temperature limits for applications, particularly within nuclear systems. To provide a potential path for VHTR systems to increase output temperatures, studies of very advanced alloy systems and strengthening mechanisms are being performed. Two current studies are focusing on significantly improving the properties of ferritic alloys using different approaches. One is evaluating advanced power metallurgy processes to produce nanostructures for improved high-temperature strength and irradiation resistance in developmental alloys. The second one is developing improved thermo-mechanical treatments of wrought materials to significantly improve high-temperature strength in current alloy systems.

Dispersing oxide particles by mechanical alloying (MA) of alloys produced using metallurgical powders is a well-known method for improving the high-temperature strength and creep properties of many technologically important alloys. In recent years, advances in understanding the MA process have resulted in the development of the advanced ODS ferritic alloy, known as 14YWT nanostructured ferritic alloy (NFA), that contains a high number density of $\sim 2-5 \mathrm{~nm}$ size O-, Ti-, and Y-enriched clusters, or nanoclusters. These nanoclusters (NC) possess an unusually high degree of thermal stability and are primarily responsible for the excellent combination of mechanical properties of the NFA at room and elevated temperatures. Furthermore, the combination of a high number density of NC and nano-size grains typical of the 14YWT NFA may improve its tolerance to neutron irradiation damage by providing potent sinks for trapping point defects and transmutation products such as helium. This represents a promising direction for developing materials for applications in advanced nuclear energy systems.

The creep properties of the 14YWT NFA and the deformation mechanisms that influence the creep behavior are being examined at elevated temperatures and different strain rates. The research approach includes both life-to-rupture creep tests and tensile tests using two types of specimens that were prepared from the $1.2 \mathrm{~kg} 14 \mathrm{YWT}$ plate produced at the beginning of this project in 2007 . In addition, detailed microstructural characterization is to be utilized to study the stability of the nanoclusters and their interaction with dislocations during plastic deformation using deformed tensile specimens of 14YWT and two MA957 creep specimens from tests that were initiated during an previous I-NERI project. ${ }^{56} \mathrm{An}$ improved understanding of the role of alloy additions, the conditions of the processing used for producing the alloy, and the resulting properties has already enabled the production of improved microstructures and properties. The data from the creep tests and deformation study will be used for developing the deformation map for 14YWT. 
Planned future work in this task includes additional creep test of 14YWT, the initiation of the two types of deformation tests using SS-3 tensile specimens to study the deformation mechanisms that influence the creep behavior of 14YWT, detailed microstructural analysis of deformed and creep-tested specimens to study the stability of the nanoclusters and their interaction with dislocations during plastic deformation at elevated temperatures, and the further development of the predicted deformation map of 14YWT using data from the experimental deformation and creep studies.

An alternative approach to producing alloys with improved high-temperature strength is developing an advanced thermo-mechanical treatment (TMT) to produce nano-particlestrengthened martensitic steels using conventional processing techniques. While the potential improvements in properties using this approach may be somewhat more limited than those obtainable with mechanical alloying, this has the distinct advantage of being able to produce large quantities of high-temperature materials in the much nearer term.

Preliminary work has demonstrated the potential for significant increases in elevatedtemperature strength. Present commercial ferritic/martensitic steels are limited to maximum temperature applications in the $550-600^{\circ} \mathrm{C}$ range. Initial work has demonstrated possibilities of extending the practical temperature range for commercial steels with TMT to $650-700^{\circ} \mathrm{C}$ with only limited additional processing and associated cost. The microstructures produced contain a very high number density of small precipitate particles, with the result that the TMT steels show large increases in strength relative to steels produced by conventional heat treatments. The strengths in these materials are comparable to strong mechanically alloyed ODS steels at $650-700^{\circ} \mathrm{C}$.

Additional work is required to develop such steels for widespread service. The TMT process needs to be modified for optimized strength. Understanding of the effects of the TMT processing on the microstructure and properties of the steels needs to be refined. Steels with optimized compositions for TMT need to be developed and tested. Once the process is refined and optimized compositions are determined, the process must then be established at a commercial scale, using larger heats and TMT on appropriate geometries, such as plates, tubes, etc.

\subsubsection{Gen IV Materials Handbook}

The development of Gen IV Nuclear Reactor Systems requires significant materials data management. Many material types such as metals, ceramics, graphites, and composites are involved in the development; various activities such as material selection, component design, and stress analysis will also be conducted. To efficiently manage all the materials data and facilitate coordinating the activities, it was recognized at an early stage of the Gen IV Program that a materials property database that provides an authoritative single source and is internally consistent, validated, and highly qualified is crucial to the success of the program. A task supported by the DOE-NE was then established to develop a database named the Gen IV Materials Handbook. Because constant updates are expected in the Handbook as the Gen IV Program develops and, further, that Handbook users will be scattered across the states and around the globe among the GIF countries, it was decided that the database will be constructed electronically using specialized computer software and will be remotely accessible through the Internet.

To prepare for the Handbook development, a Gen IV Materials Handbook Workshop was held in La Jolla, California, in July 2004, to discuss goals and priorities with potential Handbook stakeholders and users. In March 2005, the Gen IV Materials Handbook Implementation Plan was completed at ORNL to provide guidelines and strategies for the development. ${ }^{57}$ Efforts were then pursued in three major areas: (1) to establish the framework including software and hardware for the Handbook; (2) to collect and evaluate 
applicable existing data for initial Handbook population; and (3) to organize supporting expertise for Handbook development and operation.

The early activities to establish the Handbook database framework included efforts on two fronts: developing software functionality specifications and investigating the marketplace for customizable software products. As a result of the efforts, the Granta Materials Intelligence (MI) System software developed under the guidance of the Material Data Management Consortium (MDMC) was selected to provide the basic functionalities required for the Handbook with desired flexibility for customization and future enhancement at a significant savings as compared with other options such as developing such software.

Evaluation, configuration, and customization of the base software for Handbook applications has been under way since November 2005 and is being aggressively continued. At this point, designs of the Handbook architecture, system, and data management schema, including the fine structures of the Handbook materials data tree, have been completed. Detailed design and construction of several major components of Handbook parts/chapters for metallic materials have also been completed with limited demonstration data loaded ${ }^{58}$. Massive uploading of historic data and preparations to upload significant amounts of data to be produced in the NGNP materials program have been initiated.

The Gen IV Materials Handbook successfully passed its beta version evaluation in early 2007 and was subsequently unanimously accepted as the vehicle that will be used by the VHTR Materials Project Management Board (PMB) for exchange of all data to be shared under its PA. In compliance with the DOE's requirements for cyber security at the ORNL, a new access control system has been developed to facilitate international user access initiation yet maintain very high levels of information protection.

Because the Handbook is now on the verge of being used for international data collaboration after its acceptance by the VHTR PMB, it has become necessary and important to help international users familiarize themselves with its structure and features and provide feedback for structural modification and functionality enhancement to satisfy their needs. For this purpose, a demonstration version of the Handbook for the Gen IV GIF, dubbed the Gen IV Materials Handbook GIF Demo, was developed. The GIF Demo was loaded with exportable data and information and released to the participating GIF member countries for their evaluation. Along with the release, a comprehensive Handbook user guide was developed and provided. ${ }^{58}$ A step-by-step procedure for international user access was also developed and tested in preparation for the upcoming release. In addition to the GIF members, collaboration opportunities have been extended to Korean participants of the joint U.S.-Korean I-NERI. Preparation activities for potential direct data exchange with international materials databases were also conducted. Meanwhile, Handbook improvements regarding detailed component structural design and construction, as well as content expansion, also continued. It is anticipated that uploading of data from the VHTR PA signatories will begin in the fall of 2009 , once the PA is signed. 



\section{SUMMARY}

An extensive R\&D program is being supported by the DOE Gen IV Reactor Program to study, quantify, and in some cases, develop materials with required properties for the VHTR reactor systems. The goal is to provide materials information needed to support near- and long-term deployment of VHTR systems.

The materials R\&D for VHTR systems is currently focused on those activities required for the relatively near-term deployment of a VHTR demonstration system, the NGNP. In addition, there are several additional materials research areas being performed as part of DOE's overall program to support materials technology needed for both near- and long-term VHTR systems with higher output temperatures. These activities include subcontracts with the ASME Code for high-temperature design and materials codification issues, various NERI and I-NERI projects, multilateral international materials research coordinated under the GIF Project Arrangement for VHTR Materials, and other materials research supporting advanced, higher temperature VHTR systems.

High-priority materials research on graphite, ceramics, ceramic composites, pressure vessel steels, and high-temperature alloys that is needed to deploy the NGNP and provide a basis for subsequent VHTRs is also described. 



\section{REFERENCES}

1. U.S. Department of Energy, A Technology Roadmap for Generation IV Nuclear Energy Systems, Generation IV International Forum, GIF-002-00, December 2002.

2. W. R. Corwin, Initial Generation IV Reactors Integrated Materials Plan, ORNL/TM-2003/244, September 30, 2003.

3. W. R. Corwin, Updated Generation IV Reactors Integrated Materials Plan, Revision 1, ORNL/TM-2003/244/R1, August 31, 2004.

4. W. R. Corwin et al., Updated Generation IV Reactors Integrated Materials Plan, Revision 2, ORNL/TM-2005/556, December 31, 2005.

5. G .O. Hayner et al., Next Generation Nuclear Plant Materials Research and Development Program Plan, INEEL/EXT-05-00758, September, 2005.

6. J. Buongiorno, P. MacDonald, W. R. Corwin, L. K. Mansur, R. K. Nanstad, R. W. Swindeman, A. F. Rowcliff, D. F. Wilson, I. G. Wright, and G. Was, Supercritical Water Reactor (SCWR) Survey of Materials Experience and R\&D Needs to Assess Viability, INEEL/EXT-03-00693 (Rev. 1), September 2003.

7. W. R. Corwin et al., The Gas Fast Reactor (GFR) Survey of Materials Experience and $R \& D$ Needs to Assess Viability, ORNL/TM-2004/99, April 30, 2004.

8. Office of Advanced Nuclear Research, DOE Office of Nuclear Energy, Science and Technology, Generation IV Nuclear Energy Systems Ten-Year Program Plan, Fiscal Year 2005 - Appendix 4: Lead-cooled Fast Reactor, March 2005.

9. The Gas-Cooled Fast Reactor (GFR) Material Requirements for the Material Selection and Qualification Program, INEEL/EXT-04-01606 (Rev 0), August 2004.

10. W. R. Corwin et al., Materials Requirements for Nuclear Hydrogen Generation Systems (Draft), September 21, 2004.

11. W. G. Halsey, N. W. Brown, C. F. Smith, J. J. Sienicki, A. V. Moisseytsev, S. J. Kim, M. A. Smith, W. S. Yang, M. Williamson, and N. Li, Interim Status Report On PreConceptual LFR Design Studies and Evaluations, UCRL-TR-209718, Lawrence Livermore National Laboratory, Livermore, California, January 2005.

12. J. J. Sienicki et al., Interim Status Report on the Small Secure Transportable Autonomous Reactor (SSTAR)/Lead-Cooled Fast Reactor (LFR) and Related Research and Development, ANL-GenIV-068, Argonne National Laboratory, Argonne, Illinois, September 2005.

13. INL, Next Generation Nuclear Plant Pre-Conceptual Design Report; Revision 1, INL/EXT-07-12967, November 2007.

14. AREVA NP Inc., NGNP with Hydrogen Production Preconceptual Design Studies Report Executive Summary, 12-9052076-000, June 2007.

15. S. A. Caspersson, Westinghouse Electric Company LLC, Nuclear Power Plants, NGNP and Hydrogen Production Preconceptual Design Report Executive Summary Report; NGNP-ESR-RPT-001 Revision 1, June 2007.

16. General Atomics, Preconceptual Engineering Services for the Next Generation Nuclear Plant (NGNP) with Hydrogen Production, PC-000544, July 10, 2007.

17. K. D. Weaver, NGNP Engineering White Paper: Reactor Type Trade Study, INL/EXT-07-12729, Idaho National Laboratory.

18. S. R. Sherman, NGNP Engineering White Paper: NGNP Project Pre-Conceptual Heat Transfer and Transport Studies, INL/EXT-07-12730, Idaho National Laboratory, April 2007.

19. D. S. Vandel, NGNP Engineering White Paper: Primary and Secondary Cycle Trade Study, INL/EXT-07-12732, Idaho National Laboratory, April 2007.

20. R. R. Schultz, NGNP Engineering White Paper: Power Conversion System Trade Study, INL/EXT-07-12727, Idaho National Laboratory, April 2007. 
21. B. Copsey, M. Lecomte, G. Brinkmann et al., "The Framatome Anp Indirect-Cycle Very High-Temperature Reactor," ICAPP 2004, Pittsburg, Pennsylvania, June 13-17, 2004.

22. S. Fazluddin, K. Smit, and J. Slabber, "The Use of Advanced Materials in VHTR's," Proceedings of the 2nd International Topical Meeting on High Temperature Reactor Technology, Beijing, China, September 22-24, 2004, International Atomic Energy Agency.

23. S. Ion, D. Nicholls, R. Matzie, et al., "Pebble Bed Modular Reactor the First Generation IV Reactor to Be Constructed," http://www.world-nuclear.org/sym/ 2003/matzie.htm.

24. D. Matzner, "PBMR Project Status and the Way Ahead," pp. 1-13 in Proceedings of the 2nd International Topical Meeting on High Temperature Reactor Technology, Beijing China, September 22-24, 2004, International Atomic Energy Agency.

25. A. Koster, R. Matzie, and D. Matzner, "PBMR: A Generation IV High Temperature Gas Cooled Reactor," Proc. Instn. Mech. Engrs, J. Power and Energy, Vol. 218, Part A.

26. N. Broom and K. Smit, "PBMR Design Methodology," slides from Generation IV International Forum, Oak Ridge, Tennessee, April 12, 2005.

27. J. K. Wright and W. L. Lloyd, Analysis of Potential Materials for the Control Rod Sleeves of the Next Generation Nuclear Plant, INL/EXT-06-11614, Idaho National Laboratory, October 2006.

28. R. N. Wright, J. K. Wright, T. L. Sham, R. Nanstad, and W. Ren, Next Generation Nuclear Plant Reactor Pressure Vessel Materials Research and Development Plan, PLN-2803, Idaho National Laboratory, Revision 0, April 2008.

29. R. N. Wright, J. K. Wright, and T. L. Sham, Next Generation Nuclear Plant Intermediate Heat Exchanger Materials Research and Development Plan, PLN-2804, Idaho National Laboratory, Revision 0, April 2008.

30. E. Wallace, R. Matzie, R. Heiderd, and J. Maddalena, "From field to factory-Taking advantage of shop manufacturing for the pebble bed modular reactor," Nuc. Eng. and Design 236, 445-453 (2006).

31. A. Koster, H. Matzner, and D. Nichols, "PBMR design for the future," Nuc. Eng. and Design 222, 231-245 (2003).

32. W. Windes, T. Burchell, and R. Bratton, Graphite Technology Development Plan, INL/EXT-07-13165, Idaho National Laboratory, September 2007.

33. T. Burchell, R. Bratton, and W. Windes, NGNP Graphite Selection and Acquisition Strategy, ORNL/TM-2007/153, September 2007.

34. T. R. Allen et al., "Materials Challenges for Generation IV Nuclear Energy Systems," Nuclear Technology 162, 342-357 (2008).

35. J. C. H. Henager and R. G. Hoagland, Acta Mat. 49, 3739 (2001).

36. J. C. H. Henager, C. A. Lewinsohn, and R. H. Jones, Acta Mat. 49, 3727 (2001).

37. V. N. Shah, S. Majumdar, and K. Natesan, Review and Assessment of Codes and

Procedures for HTGR Components, NUREG/CR-6816 (ANL-02/36), Argonne National Laboratory, June 2003.

38. 2001 ASME Boiler and Pressure Vessel Code, Sect. III, Subsect. NH, Rules for Construction of Nuclear Facility Components, Class I Components in Elevated Temperature Service, Am. Soc. of Mechanical Engineers.

39. G. O. Hayner et al., Next Generation Nuclear Plant Materials Research and Development Program Plan, INEEL/EXT-05-00758, September 2005.

40. J. M. Corum and T. E. McGreevy, R\&D Plan for Development of High-Temperature Structural Design Technology for Generation IV Reactor Systems, ORNL/TM-2004/309, Oak Ridge National Laboratory, December 2004.

41. D. S. Griffin, "Elevated-Temperature Structural Design Evaluation Issues in LMFBR Licensing," Proceedings of Eighth International Conference on Structural Mechanics in Reactor Technology, Vol. L, Paper L9/1, Brussels, August 1985. 
42. K. Tsukimori et al., "Development of FBR Piping Bellows Joints in Japan," Nuclear Engineering and Design 155, 571-589, May 1995.

43. J. M. Corum and J. J. Blass, "Rules for Design of Alloy 617 Nuclear Components to Very High Temperatures," Fatigue, Fracture, and Risk, Am. Soc. of Mechanical Engineers, PVP-Vol. 215, 147-153, 1991.

44. T. E. McGreevy, D. M. Marriott, and P. Carter, High-Temperature Design Methods Development Advances for 617: Status \& Plans, ORNL/TM-2005/515, July 28, 2005.

45. R. W. Swindeman et al., Verification of Allowable Stresses in ASME Section III, Subsection NH for Grade 91 Steel, ASME ST-LLC, STP-NU-019, 2008.

46. R. W. Swindeman et al., Creep-Rupture Data Sources, Data Analysis Procedures, and the Estimation of Strength for Alloy $800 \mathrm{H}$ at $750^{\circ} \mathrm{C}$ and above, ASME ST-LLC, STP-NU-020, 2008.

47. W. J. O'Donnell and D. S. Griffin, Regulatory Safety Issues in the Structural Design Criteria of ASME Section III Subsection NH for Very High Temperatures for VHTR and Gen IV, ASME ST-LLC, STP-NU-010, 2007.

48. B. Riou, Improvement of ASME NH for Grade 91 Negligible Creep and CreepFatigue, ASME Report, STP-NU-013, 2008.

49. M. Basol et al., DOE Gen IV Materials Project-Task 4, Updating of ASME Nuclear Code Case N-201 to Accommodate the Needs of Metallic Core Support Structures for High Temperature Gas Cooled Reactors, WCAP-16691-NP Revision 0, Westinghouse, May 2007.

50. T. Asayama and Y. Tachibana, Creep-Fatigue Data and Creep-Fatigue Evaluation Procedures for Grade 91 and Hastelloy XR, STP-NU-018, 2008.

51. J. D. Tucker et al.,, in Proceedings of the 13th International Symposium on Environmental Degradation of Materials in Nuclear Power Systems, edited by T. R. Allen, J. T. Busby, and P. J. King, Canadian Nuclear Society, Whistler, BC Canada, 2007.

52. B. Million, J. Ruzickova, and J. Vrestal, "Diffusion in Fe-Ni-Cr Alloys with an Fcc Lattice," Materials Science and Engineering 72, 85 (1981).

53. J. Ruzickova and B. Million, "Self-Diffusion of the Components in the Fcc Phase of Binary Solid-Solutions of the Fe-Ni-Cr System," Materials Science and Engineering 50, 59 (1981).

54. A. Van der Ven and G. Ceder, "First principles calculation of the interdiffusion coefficient in binary alloys," Phys. Rev. Lett. 94, 045901 (2005).

55. A. Van der Ven, G. Ceder, M. Asta, and P. D. Tepesch, "First-principles theory of ionic diffusion with nondilute carriers," Phys. Rev. B 64, 184307 (2001).

56. D. T. Hoelzer, Initial Creep Testing of 14YWT Nanostructured Ferritic Alloy, ORNL/GEN4/LTR-08-004, June 30, 2008.

57. P. Rittenhouse and W. Ren, Gen IV Materials Handbook Implementation Plan, ORNL/TM-2005/77, March 2005.

58. W. Ren, GEN IV Materials Handbook GIF Release for Architecture and Functionality Demonstration-Introduction and Navigation Guide, ORNL/GEN4/LTR-08-002-R2, July 25, 2008. 